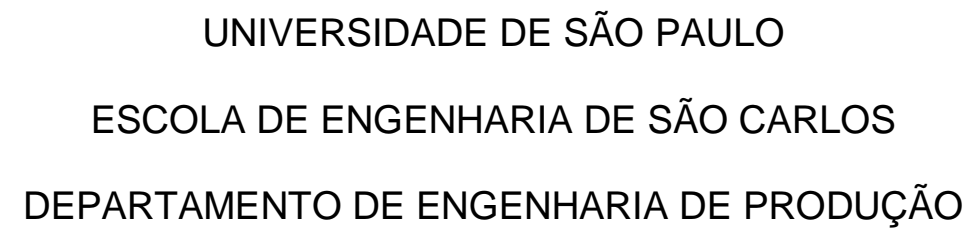

Paula Gabriela Lhama

\title{
ANÁLISE DAS DISFUNÇÕES E BENEFÍCIOS QUE OCORREM NA IMPLANTAÇÃO E USO DO MODELO DE REFERÊNCIA NO PROCESSO DE DESENVOLVIMENTO DE PRODUTO
}





\section{ANÁLISE DAS DISFUNÇÕES E BENEFÍCIOS QUE OCORREM NA IMPLANTAÇÃO E USO DO MODELO DE REFERÊNCIA NO PROCESSO DE DESENVOLVIMENTO DE PRODUTO}

Dissertação apresentada à Escola de Engenharia de São Carlos da Universidade de São Paulo para obtenção do título de mestre em Engenharia de Produção

Área de Concentração: Processos e Gestão de Operações

Orientador: Prof. Tit. Henrique Rozenfeld

SÃO CARLOS-SP

2013 
AUTORIZO A REPRODUÇÃO TOTAL OU PARCIAL DESTE TRABALHO, POR QUALQUER MEIO CONVENCIONAL OU ELETRÔNICO, PARA FINS DE ESTUDO E PESQUISA, DESDE QUE CITADA A FONTE.

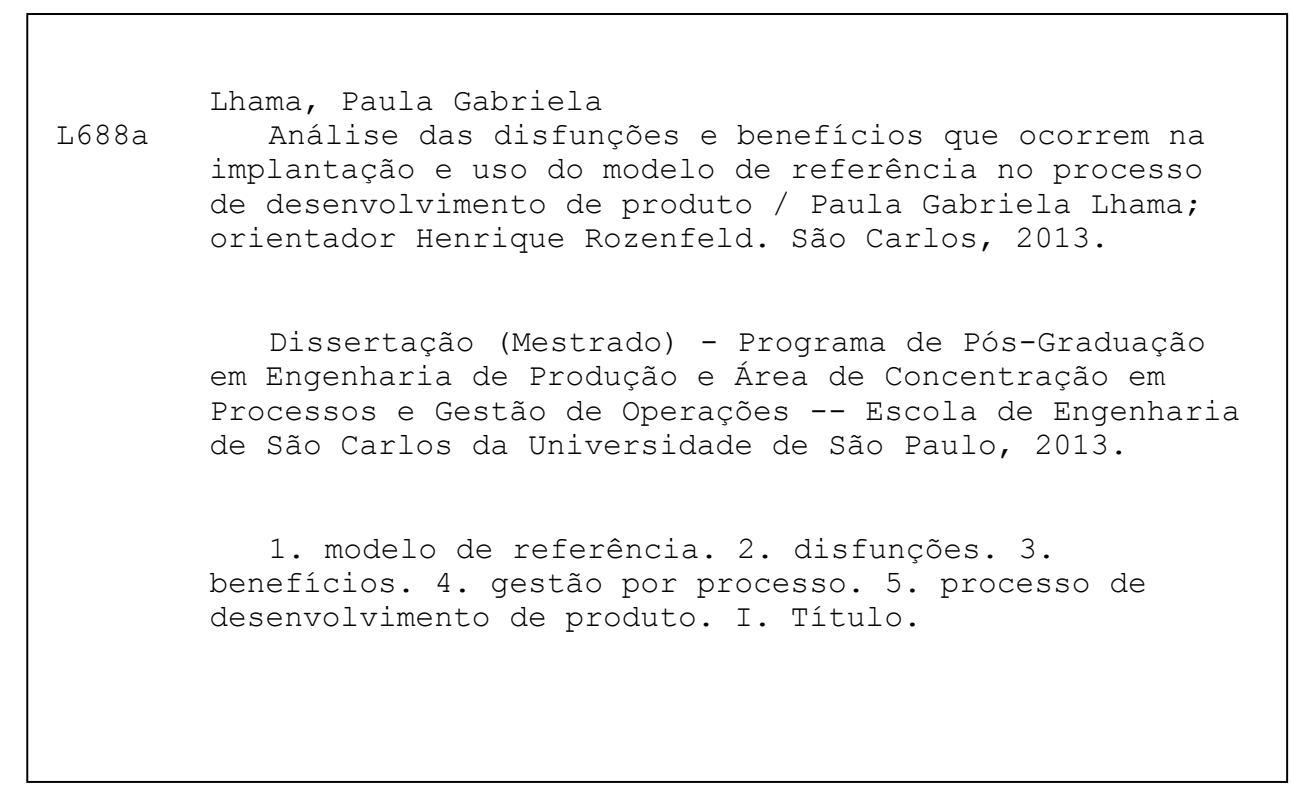




\section{FOLHA DE JULGAMENTO}

Candidata: Bacharel PAULA GABRIELA LHAMA.

Título da dissertação: "Análise das disfunções e benefícios que ocorrem na implantação e uso do modelo de referência no processo de desenvolvimento de produto".

Data da defesa: 23/08/2013

\section{Comissão Julgadora:}

Prof. Titular Henrique Rozenfeld (Orientador)

(Escola de Engenharia de São Carlos/EESC)

Prof. Associado Fábio Müller Guerrini

(Escola de Engenharia de São Carlos/EESC)

Dra. Creusa Sayuri Tahara Amaral

(Pesquisadora do Grupo OPF/NUMA) $\underline{\text { Resultado: }}$
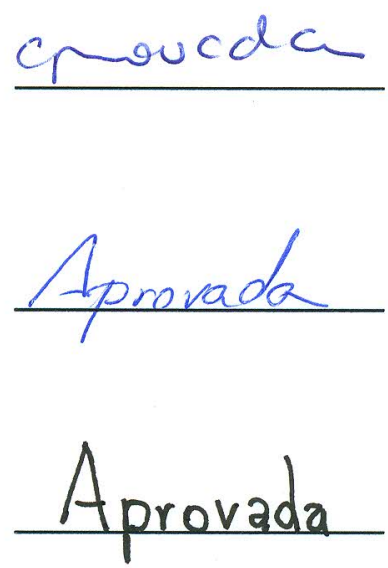

Coordenador do Programa de Pós-Graduação em Engenharia de Produção:

Prof. Titular Luiz César Ribeiro Carpinetti

Presidente da Comissão de Pós-Graduação:

Prof. Titular Denis Vinicius Coury 
Aos meus pais Paulo Cesar Llama e Margaret Benedita Siviero Llama, e minhas avós Maria da Glória Siviero e Luiza do Carmo Lhama. 


\section{AGRADECIMENTOS}

Em primeiro lugar, agradeço a Deus pela Sua presença constante em minha vida, por me conceder a bênção diária da existência, persistência e a capacidade necessária para a realização desse trabalho.

Aos meus pais Paulo Cesar Llama e Margaret Benedita Siviero Llama pela dedicação, amor incondicional, carinho e orações que incutiram os valores eternos que hoje me orientam, essenciais para minha formação.

A minha irmã Isabela Llama por estar sempre ao meu lado, ser minha companheira de músicas, filmes e conversas engraçadas.

A Nina, Paulo e Gabriel por estarem comigo em todas as fases da minha vida e torcerem por mim, além de me ajudarem nas minhas mudanças de uma cidade para outra (risos!).

Ao meu orientador, Prof. Henrique Rozenfeld, pela orientação e paciência em acompanhar cada etapa desta pesquisa.

Aos colegas do grupo de Engenharia Integrada e Engenharia de Integração da EESC/USP, pelo convívio e amizade. Um agradecimento especial a Sayuri, Jana, Luke e Vanessa por me ajudarem no momento em que eu mais precisei e por compartilharem o tempo deles bem como seus conhecimentos para a realização deste trabalho. $\mathrm{E}$ aos demais e igualmente importantes amigos integrantes do Departamento de Engenharia de Produção da Escola de Engenharia de São Carlos.

Às empresas e aos profissionais que gentilmente cederam seu tempo e colaboraram imensamente com o estudo de caso, sou inteiramente grata.

A meu amigo Guilherme Serpa por me ajudar na época do processo seletivo do mestrado e pela companhia em Sanca.

A Alessandra, Juliana, Natália, Patrícia e Francine pelos conselhos no momento mais difícil do mestrado e pelas boas risadas em nossos encontros.

A Alinne por me ajudar na leitura e discussão de ideias para o trabalho e por me apresentar um pouquinho da culinária de Belém do Pará, nos divertidos almoços de domingo. 
A minha amiga Mathilde, a francesa mais brasileira que eu conheci. Obrigada pela companhia e por deixar Sanca mais engraçada.

As minhas amigas Peolla Stein e Michelle Rodrigues Batista por serem amigas fieis e companheiras e me apoiarem nos momentos mais difíceis.

As minhas amigas da época de graduação Laísa, Thaís e Érika por estarem presentes na minha vida e pelos nossos encontros que sempre são repletos de risadas e muitas histórias.

À Comissão de Aperfeiçoamento de Pessoal de Nível Superior (CAPES) pelo suporte financeiro que viabilizou minha dedicação exclusiva a este mestrado.

Aos funcionários do Departamento de Engenharia de Produção da EESC pelo apoio e à Universidade de São Paulo, pelo ensino gratuito e de excelência.

A todos, que de alguma forma contribuíram com este trabalho, o meu MUITO OBRIGADO! 
Jesus,

Rei admirável

E nobre triunfador,

Doçura inefável,

Todo desejável:

Ficai conosco, Senhor,

E clarificai-nos com a Luz,

Expulsai da mente as trevas,

Enchei o mundo de doçura!

Jesu Rex Admirábilis 


\section{RESUMO}

LHAMA, P. G. Análise das disfunções e benefícios que ocorrem na implantação e uso de modelos de referência no PDP. 2013. 156 p. Dissertação (Mestrado em Engenharia de Produção) - Escola de Engenharia de São Carlos, Universidade de São Paulo, São Carlos, 2013.

O desempenho do Processo de Desenvolvimento de Produto (PDP) depende de como a empresa gerencia seu processo. A adoção de um modelo de referência para o PDP tem se mostrado uma boa prática, pois aumenta a capacidade de a empresa em controlar as mudanças no processo, avaliar seu desempenho, propor melhorias além de permitir uma maior compreensão do processo como um todo, padronizando e controlando todas as fases do PDP. Isso proporciona um melhor aproveitamento de recursos e, consequentemente, menor tempo de desenvolvimento e maior satisfação do cliente. Entretanto, muitas empresas não obtêm os resultados esperados durante e/ou após a implantação do modelo de referência específico, uma vez que nem todas estão preparadas culturalmente para adotar um processo estruturado. Na literatura, há poucas pesquisas que relatam, por meio de estudos de casos, quais os problemas e impactos que as organizações enfrentam ao aplicar um modelo de referência específico. $O$ presente estudo tem por objetivo analisar as disfunções e benefícios que ocorrem no modelo de referência específico no PDP. Para isso, foram pesquisadas inicialmente as disfunções e benefícios na literatura e realizado estudo de caso em duas empresas. Os resultados mostram que as disfunções encontradas na literatura em sua maioria não foram confirmadas nas empresas, devido às particularidades de cada uma. E foi constatado por meio de entrevistas que algumas disfunções estiveram presentes apenas durante a implantação do modelo de referência específico. Diferentemente do panorama das disfunções, os benefícios apresentados, em sua maioria, foram confirmados em ambas as empresas.

Palavras chaves: modelo de referência, disfunções, benefícios, gestão por processo, processo de desenvolvimento de produto (PDP). 


\begin{abstract}
LHAMA, P. G. Dysfunctions and benefits analysis that occur at the implementation and use of the reference model in the new product development. 2013. $156 \mathrm{p}$. Dissertação (Mestrado em Engenharia de Produção) - Escola de Engenharia de São Carlos, Universidade de São Paulo, São Carlos, 2013.
\end{abstract}

New Product development (NPD) performance depends on how the company manages its process. The adoption of a reference model for NDP has been shown to be a good practice, because increases a company's capacity in controlling the alterations in the process, evaluate its performance, propose improvements besides allowing a greater comprehension of the process as a whole, creating a pattern and controlling all NPD's phases, which gives a better utilization of the resources, and consequently less time to market and better client satisfaction. However, many companies do not get the expected results during and/or after implementation of the specific reference model, once not all are culturally prepared to adopt a structurally process. In the literature there are few researchers that report by means of case studies which are the problems and impacts that companies face when applying a specific reference model. The objective of this study is to analyze the dysfunctions and benefits that occur in the NPD specific reference model. To do this end, it was initially searched the dysfunctions and the benefits in the literature and performed a case study in two companies. Results show that most of the dysfunctions found in the literature were not confirmed in the companies, because of the specificities of each one. In addition, it was observed by means of a focused interview that some of the dysfunctions were present only during the specific reference model's implementation. Differently of the dysfunctions scenery, most of the shown benefits were confirmed in both companies.

Keywords: reference model, dysfunctions, benefits, business process management, new product development. 


\section{LISTA DE FIGURAS}

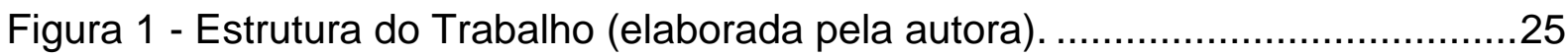

Figura 2 - Temas da Revisão da Literatura (elaborada pela autora). ......................27

Figura 3 - Processos de Negócios (ROZENFELD, 1996). ..................................32

Figura 4 - Ciclo hype do BPM (JESTON; NELIS, 2006)................................ 34

Figura 5 - Relação entre modelos de referência genéricos e específicos (elaborada pela autora). 40

Figura 6 - Cenários de aplicação do modelo de referência (elaborada pela autora). 42 Figura 7 - Elaboração do Modelo de Referência (adaptado de FETTKE; LOOS, 2007)

Figura 8 - Estrutura de classificação e caracterização do modelo de referência (adaptado de FETTKE, LOOS; ZWICKER, 2006b). 46

Figura 9 - Time Multifuncional do PDP (ROZENFELD et al., 2006). .50

Figura 10 - Modelo de PDP (adaptado de COOPER, 2001). .55

Figura 11 - Modelo de Referência Unificado do PDP (ROZENFELD et al., 2006)...57

Figura 12 - Etapas de Pesquisa (elaborada pela autora). 64

Figura 13 - Classe para valores das médias (elaborada pela autora). .90

Figura 14 - Gráfico das médias e índice de concordância das empresas A e B (elaborado pela autora).

Figura 15 - Gráfico da média e índice de concordância dos benefícios das empresas A e B (elaborado pela autora). 108 


\section{LISTA DE TABELAS}

Tabela 1 - As três categorias de processo (GONÇALVES, 2000)..........................30

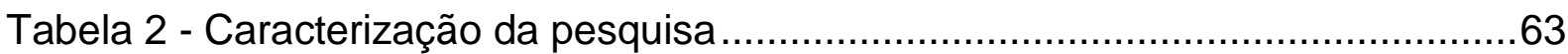

Tabela 3 - Palavras-chave para a busca nas bases de dados ............................65

Tabela 4 - Strings para a busca nas bases de dados .....................................66

Tabela 5 - Preparação para a Coleta de Dados (YIN, 2005) ..............................67

Tabela 6 - Protocolo do Estudo de Caso- visão geral do projeto (YIN, 2005).........67

Tabela 7 Protocolo do Estudo de Caso - procedimento de campo (YIN, 2005)......68

Tabela 8 - Descrição dos entrevistados da empresa "A" ......................................69

Tabela 9 - Descrição dos entrevistados da empresa "B" ..................................... 70

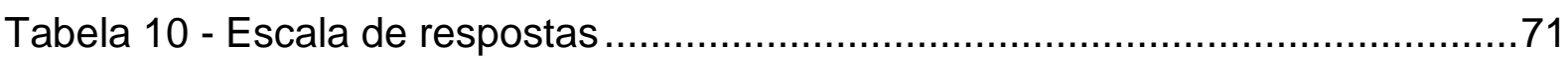

Tabela 11 - Classe para os valores da média ............................................ 72

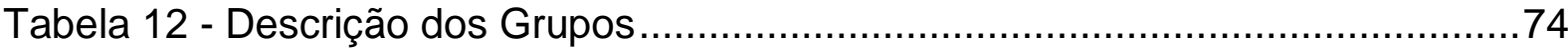

Tabela 13- Resultado do cálculo da média, índice de concordância e coeficiente de variação das respostas dos entrevistados referentes às disfunções. .85

Tabela 14 - Resultado do cálculo da média , índice de concordância e coeficiente de variação das respostas dos entrevistados referentes aos benefícios .88

Tabela 15 - Descrição dos Grupos (Disfunções) ............................................. 91

Tabela 16 - Grupo 1 - Disfunções (Empresa A) ............................................93

Tabela 17 - Grupo 2 - Disfunções (Empresa A) ..............................................96

Tabela 18 - Grupo 4 - Disfunções (Empresa A) ...............................................97

Tabela 19 - Grupo 1 - Disfunções (Empresa B) ............................................100

Tabela 20 - Grupo 3 - Disfunções (Empresa B) ..............................................102

Tabela 21 - Grupo 4 - Disfunções (Empresa B) ............................................103

Tabela 22 - Descrição dos Grupos (Benefícios) ..............................................106

Tabela 23 - Grupo 2 - Benefícios (Empresa A) ...........................................109

Tabela 24 - Grupo 3 - Benefícios (Empresa A) ................................................110

Tabela 25 - Grupo 4 - Benefícios (Empresa A) .............................................111

Tabela 26 - Grupo 3 - Benefícios (Empresa B) ..........................................113

Tabela 27 - Total da Categoria das Disfunções com concordância acima de 0,7 ...117

Tabela 28 - Total da Categoria dos Benefícios com concordância acima de 0,7 ...119

Tabela 29 - Total das disfunções e benefícios nas empresas A e B. 


\section{SUMÁRIO}

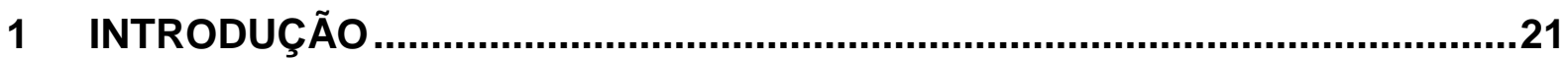

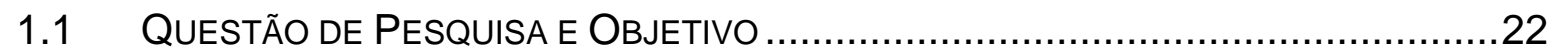

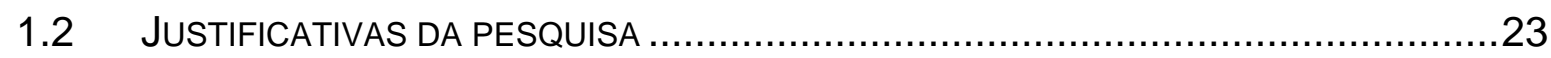

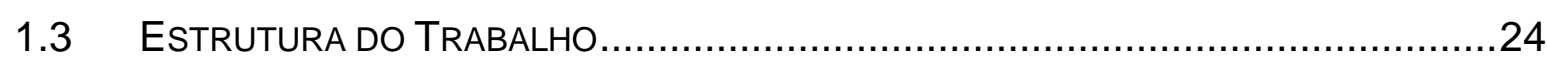

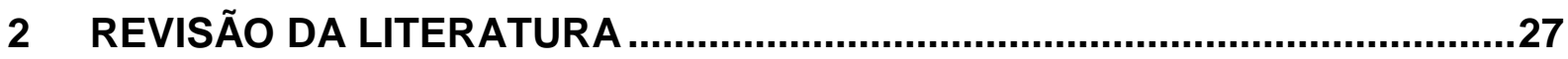

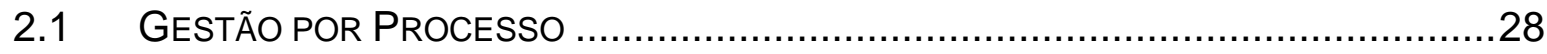

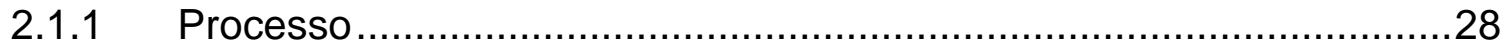

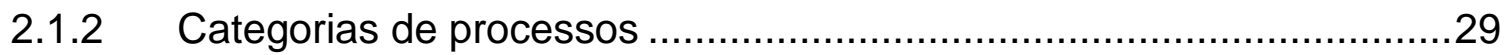

2.1.3 Processo de Negócio ............................................................. 31

2.1.4 Abordagem da Gestão por Processos ...........................................33

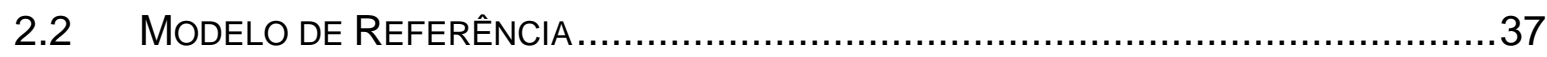

2.2.1 Conceitos e Definições ....................................................... 38

2.2.2 Benefícios do Modelo de Referência Específico.............................42

2.2.3 Elaboração do Modelo de Referência ............................................44

2.2.4 Classificação do Modelo de Referência........................................46

2.3 Processo de Desenvolvimento de Produto (PDP) .............................49

2.3.1 Conceitos e definições .......................................................... 49

2.3.2 Características específicas do PDP ....................................... 52

2.3.3 Modelo de Referência para o PDP ............................................ 53

3 MÉTODO DE PESQUISA .......................................................................61

3.1 CARACTERIZAÇÃO DA PESQUISA .................................................. 61

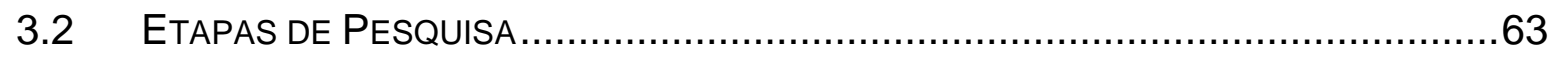

3.2.1 $1^{\circ}$ Etapa de Pesquisa - Revisão Bibliográfica....................................65

3.2.2 $2{ }^{\circ}$ Etapa de Pesquisa - Planejamento e Condução do Estudo de Caso 66

3.2.3 $3^{\circ}$ Etapa de Pesquisa - Descrição e Análise dos Resultados ..............70

4 RESULTADOS E ANÁLISES ............................................................ 77

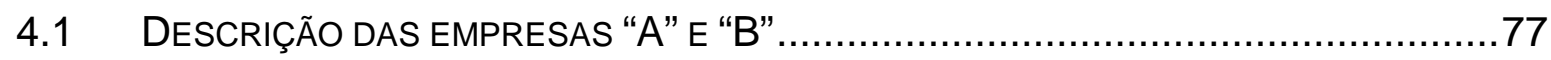

4.1.1 Descrição do estudo de caso - Empresa A ..................................77

4.1.2 Descrição do estudo de caso - Empresa B ................................ 81 


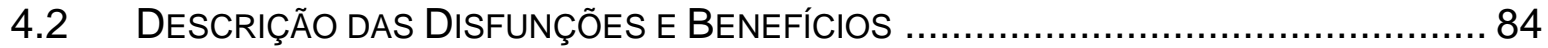

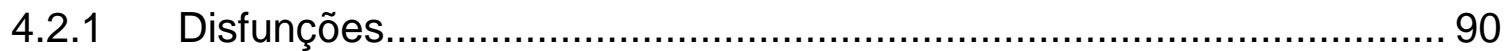

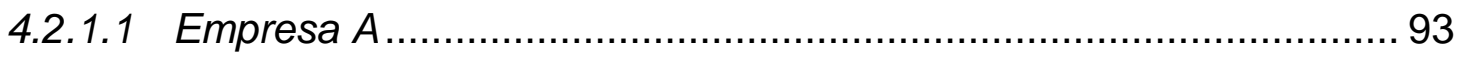

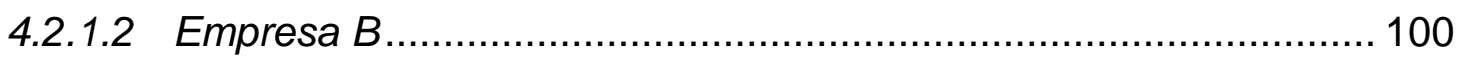

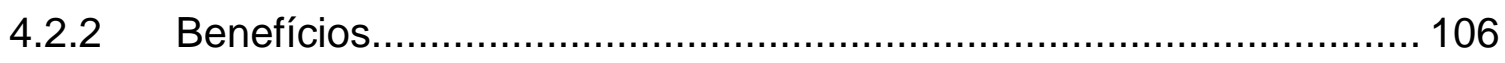

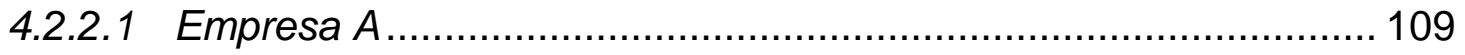

4.2.2.2 Empresa $B$.................................................................. 113

4.3 ANÁLISE dOS RESULTADOS ....................................................... 116

4.3.1 Disfunções..................................................................... 116

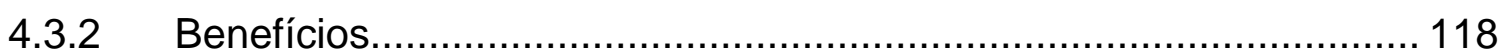

4.3.3 Inconsistência entre as Disfunções e Benefícios ............................ 119

4.3.4 Disfunções e Benefícios com Î́ndice de Concordância Negativo....... 121

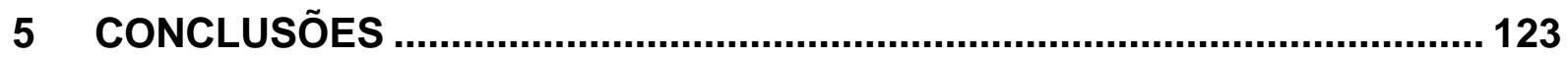

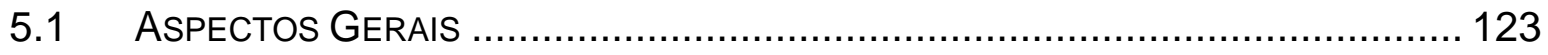

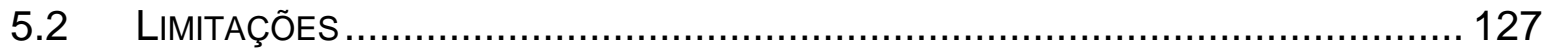

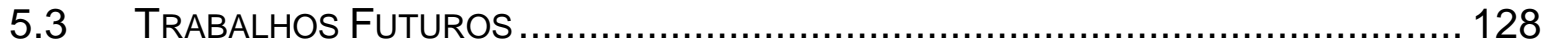




\section{INTRODUÇÃO}

Atualmente, a competitividade está fortemente associada à rápida introdução de bens e serviços de alto valor agregado ao mercado, e o processo de desenvolvimento de produtos (PDP) emerge como uma atividade essencial nas organizações como elemento de sustentação no longo prazo. O sucesso de um novo produto está relacionado como as atividades que compõem o PDP são executadas (MORETTI et al. 2012a, p.02). Para atingir um processo efetivo do PDP, é necessário então que os processos estejam devidamente coordenados e sincronizados. A sincronização dos fluxos de informação é um fator-chave para 0 êxito do PDP (HAMMERS; SCHMITT, 2009, p.207).

Assim, as empresas investem cada dia mais na melhoria contínua do processo de desenvolvimento de produto e no fornecimento de apoio adequado para sua execução, pois a qualidade da gestão do PDP está intimamente ligada à padronização do processo (KALPIC; BERNUS, 2002, p.302).

Neste contexto, a adoção de um modelo de referência pode vir contribuir para que as empresas comecem a executar o processo de desenvolvimento de produto de maneira formalizada e sistemática (FASS et al., 2009, p.05). O modelo de referência determina a capacidade das empresas controlar o processo de desenvolvimento de aperfeiçoar os produtos e de interagir com o mercado e com as fontes de inovação tecnológica (ROZENFELD et al., 2006, p.32).

Há modelos de referência genéricos e específicos. Modelos de referência genéricos são representações de processos de negócio que possuem um conjunto de diretrizes de caráter genérico, de forma que eles possam refletir a realidade encontrada em várias empresas e em diversas situações de negócio. Isso possibilita que os modelos de referência genéricos possam ser adaptados para aplicação em diversos contextos. Quando adaptado para um determinado contexto, isso resulta em um modelo de referência específico (VERNADAT, 1996).

A adoção de um modelo de referência específico nas empresas possibilitam um conjunto de benefícios e melhores práticas. Segundo Rozenfeld et al., (2006, p.32), os modelos de referência possibilitam que todos os envolvidos tenham uma visão comum desse processo: o que se espera dos resultados do PDP, quais e 
como as atividades devem ser realizadas, quais condições devem ser atendidas, fonte de informações, e os critérios de decisões a serem adotados. Engwall (2005, p.433) afirma que os modelos de referência ajudam os gestores a se concentrarem nas tarefas mais importantes e assim evitar trabalho desnecessário. Além de outros possíveis benefícios apresentados por Amaral (2008b) como: redução no lead time de desenvolvimento, repetibilidade dos projetos de desenvolvimento, maior racionalização no uso das informações, maior facilidade em treinar pessoas novas no processo e reutilização de conhecimentos gerados em outros projetos.

A implantação do modelo de referência específico envolve as áreas da empresa como um todo e tem impacto direto na rotina das pessoas que fazem parte do PDP. Todos esses fatores fazem com que a implantação seja um processo longo e isso resulta em algumas disfunções. Neste trabalho, o termo "disfunção" é compreendido como problemas relacionados à implantação e ao uso do modelo de referência específico nas empresas.

No estado da arte, há poucos estudos, principalmente na literatura recente, que analisam as disfunções que ocorrem durante a implantação do modelo de referência específico nas empresas e quais são as disfunções que ocorrem no uso do modelo pós-implantado. Assim, este trabalho tem como finalidade de sanar essa lacuna de pesquisa existente na literatura.

Com base nessas constatações foram definidos o objetivo do trabalho e a questão de pesquisa apresentada a seguir.

\subsection{Questão de Pesquisa e Objetivo}

Diante da contextualização apresentada, foram definidas as seguintes questões de pesquisa:

- Quais são as disfunções que ocorrem na implantação e uso de modelos de referência específicos no processo de desenvolvimento de produtos?

- $\quad$ Quais são os benefícios que resultam do uso de modelos de referência específicos no processo de desenvolvimento de produtos?

- $\quad$ Por que as disfunções e os benefícios ocorrem durante a implantação e o uso de modelos de referência específicos no processo de desenvolvimento de produtos? 
Para responder a essas questões, o objetivo deste trabalho é identificar e analisar as disfunções e os benefícios que ocorrem na implantação e uso de modelos de referência específicos no processo de desenvolvimento de produto.

\subsection{Justificativas da pesquisa}

Por meio do estado da arte, foi possível constatar que a maior parte dos estudos sobre modelos de referência tem duas vertentes. A primeira vertente são pesquisas que têm como finalidade propor novos modelos de referência genéricos, como por exemplo, pesquisas elaboradas por autores consagrados como Pahl e Beitz (1996), Crawford (1983), Clark e Fujimoto (1991), Clark e Wheelwright (1993), e Urilch e Eppinger (2000). A segunda vertente é constituída por pesquisas que têm como propósito desenvolver modelos de referência específicos para um determinado segmento de mercado e/ou adaptar os modelos de referência genéricos para uma empresa.

Moretti et al.(2012, p.6) apresenta em seu artigo, um levantamento das dissertações e teses sobre modelos de referência nos programas de pós-graduação em engenharia de produção no Brasil, entre os anos de 2001 e 2011. Ambos afirmam que existe uma tendência em se desenvolver modelos de referência específicos para um mercado particular.

Desta maneira, este trabalho pretende analisar uma lacuna de pesquisa na literatura, que são as disfunções que ocorrem na implantação e uso do modelo de referência específico no processo de desenvolvimento de produto das empresas.

Segundo Cooper (2008), muitas empresas falham durante a fase de implantação do modelo de referência específico e, muitas vezes, não chegam ao resultado desejado quando colocam o processo em prática. O mesmo autor revela que isto se deve ao fato de que as empresas esquecem pontos chaves, princípios e métodos quando realizam a implantação do modelo de referência específico.

Outro problema a destacar, de acordo com Zanatta (2010), são as empresas multinacionais, que normalmente adotam o modelo de referência específico em todas suas filiais para que haja padronização e maior comunicação entre elas. Porém, nota-se uma recorrência do fato de que a implantação não resulta em sucesso, pois não foram consideradas as diferenças entre a matriz e a filial bem 
como não foram realizadas as análises e a criação de condições para adaptar o modelo de referência específico nas empresas filiais.

Diante das duas vertentes apresentadas e da lacuna de pesquisa, é comum encontrar na literatura apropriada a este domínio, estudos com a finalidade de desenvolver modelos de referência para segmentos específicos que apresentam os benefícios e/ou as melhores práticas decorrentes da implantação (SUAREZ, 2009; BARBALHO, 2012; MORETTI, 2012b). Assim, é importante que os benefícios também sejam tratados no presente trabalho em conjunto com as disfunções.

Assim, investigar e analisar as disfunções e benefícios é de fundamental importância, pois quando forem identificados haverá conhecimento e informações que poderão ser utilizados pelas empresas que pretendem implantar o modelo de referência específico no seu processo de desenvolvimento de produtos e com isso contribuir para a melhoria do desempenho na empresa.

\subsection{Estrutura do Trabalho}

Esta dissertação está estruturada em 5 capítulos, cada um organizado de acordo com a sequência ilustrada na Figura 1.

No capítulo 1 (Introdução) constam o contexto de pesquisa e o objetivo geral do trabalho. O contexto compreende a importância dos modelos de referência no processo de desenvolvimento de produto e como a implantação do modelo de referência nas empresas pode resultar em disfunções, que, por sua vez, não são muito pesquisadas na literatura. O entendimento da situação atual permite a identificação de uma lacuna de pesquisa - há poucos estudos na literatura que abordam as disfunções que ocorrem na implantação e uso do modelo de referência específico no PDP. A fim de preencher essa lacuna, são definidos a pergunta de pesquisa e o objetivo do trabalho e suas justificativas. 


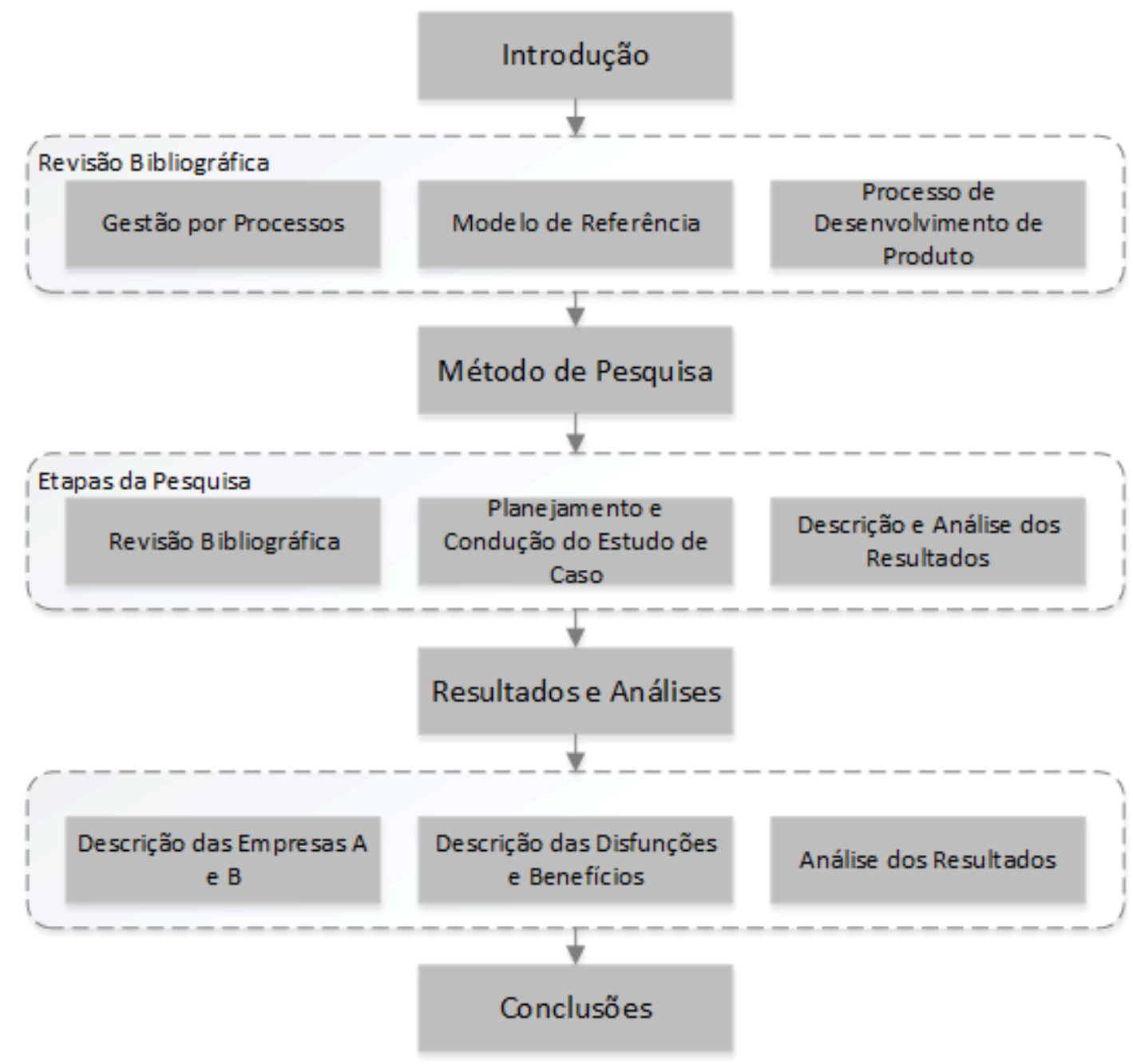

Figura 1 - Estrutura do Trabalho (elaborada pela autora).

O capítulo 2 (Revisão Bibliográfica) está dividido em três grandes temas: gestão por processos, processo de desenvolvimento de produto (PDP) e modelo de referência. Na gestão por processos, são definidos os processos, categorias de processos e processo de negócio. São apresentadas a definição, as características e as fases do PDP e o Modelo de Referência do processo de desenvolvimento de produto. Este capítulo então finaliza com o conceito de modelo de referência, sua diferenciação, elaboração, classificação e benefícios.

Em seguida, o capítulo 3 (Método de Pesquisa) apresenta a caracterização e o procedimento para a realização do trabalho. São definidas as três etapas de pesquisa: Revisão Bibliográfica, Planejamento e Condução do Estudo de Caso e Descrição e Análise dos Resultados. 
Já no capítulo 4 (Resultados e Análises), mostra-se os resultados do estudo de caso. Primeiramente é realizada a descrição das empresas "A" e "B" com base nos dados obtidos das questões abertas do questionário de pesquisa. Em seguida, são realizadas a descrição das disfunções e dos benefícios, com base nos dados das questões fechadas do questionário. Por fim, apresenta-se a análise dos resultados com base nas questões fechadas do questionário de pesquisa. São apresentadas as disfunções e benefícios comuns nas empresas "A" e "B" e as inconsistências entre as respostas assinaladas pelos entrevistados e os relatos da entrevista focada.

Finalmente no capítulo 5 (Conclusões) são apresentados os aspectos gerais, com as conclusões do trabalho, em seguida são expostas as limitações da dissertação e alguns apontamentos para trabalhos futuros. 


\section{REVISÃO DA LITERATURA}

Neste capítulo, apresentam-se os principais conceitos e os trabalhos desenvolvidos sobre os temas que norteiam a proposta desta pesquisa (Figura 2).

A revisão da literatura está dividida em três temas principais: Gestão por Processos, Processo de Desenvolvimento de Produto (PDP) e Modelo de Referência que são descritos a seguir.

Compreender todos estes conceitos, neste trabalho, é importante, visto que atualmente a perspectiva das organizações é melhorar os seus processos de negócios por meio da gestão por processos. Os modelos de referência nesse contexto são fundamentais, pois auxiliam as empresas no controle do desempenho das atividades e processos, além de definir melhorias no processo de negócio como um todo. Entretanto, a implantação do modelo de referência específico tem um impacto grande nas empresas e, a depender da sua maturidade, pode ocasionar disfunções, que é o tema central do trabalho e que será discutido nos próximos capítulos.

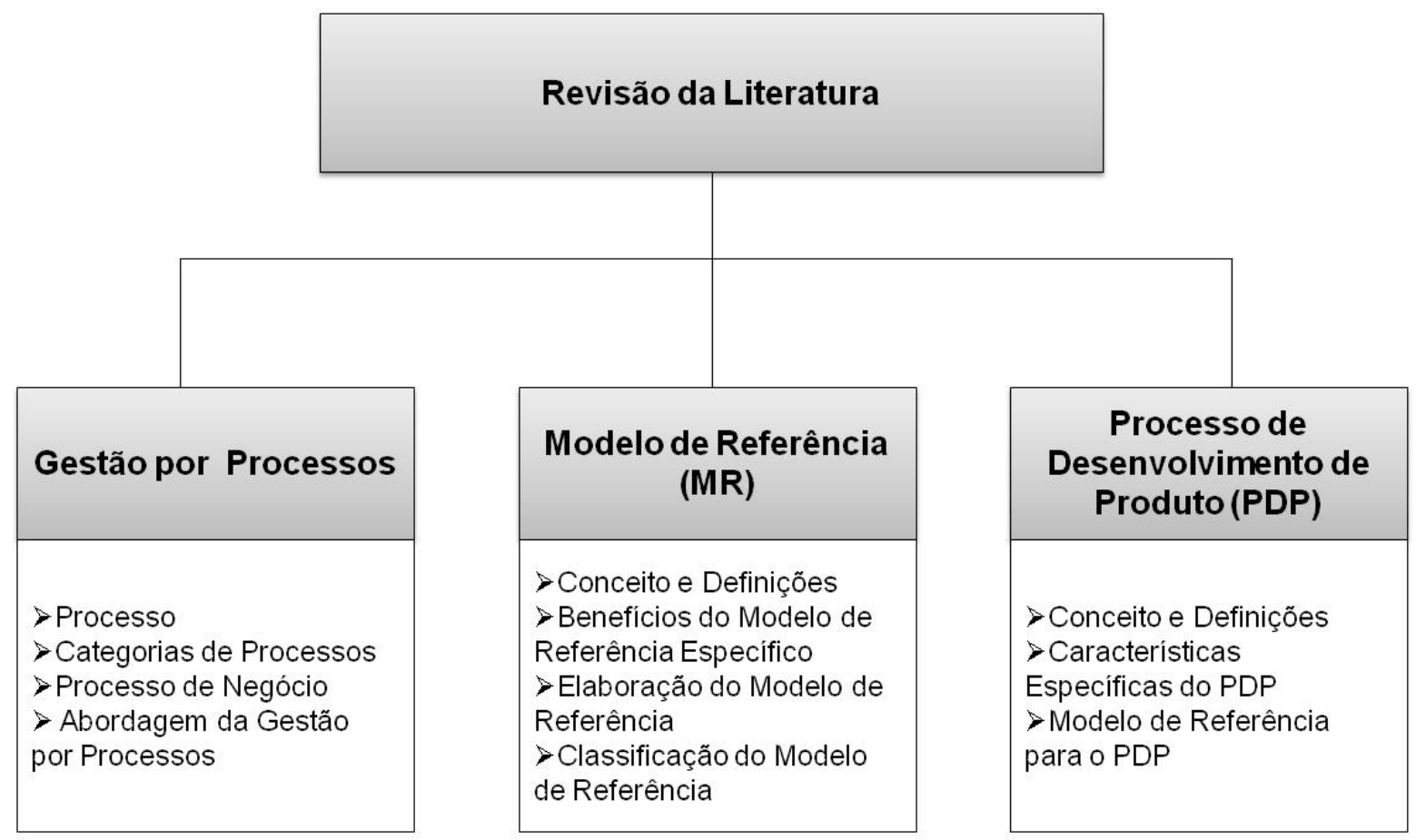

Figura 2 - Temas da Revisão da Literatura (elaborada pela autora). 


\subsection{Gestão por Processo}

Gerenciar processos, como o processo de desenvolvimento de produtos, é fundamental para atingir a satisfação dos clientes e a competitividade das empresas. A gestão por processos realiza os objetivos de uma organização por meio da melhoria, gestão e controle de processos de negócio (JESTON E NELIS, 2006).

A seguir são definidos os conceitos de processo, categorias de processo e processo de negócio que estão incorporados no grande tema que é a gestão por processo ou BPM.

\subsubsection{Processo}

Harrington (1993), Hammer e Champy (1994) definem processo como sendo um conjunto de atividades que recebem uma entrada (input), que agrega um valor e gera uma saída (output) para um cliente interno ou externo.

Neste trabalho será utilizada a definição da Norma ISO (ABNT, 2000, p.02), que define processo como sendo

[...] um conjunto de atividades inter-relacionadas, definidas, repetitivas e mensuráveis que agregam valor ao transformar entradas em saídas, em outras palavras, é um conjunto de atividades que transforma insumos em produtos, satisfazendo as necessidades dos clientes e atendendo a política da organização.

A cadeia de valor é uma relação integrada aos processos, que podem levar a organização a uma posição competitiva superior. A fonte de vantagem competitiva é a competência para gerir as interfaces entre os processos na cadeia de valor e tem sido utilizada como um recurso de representação gráfica dos processos de ação organizacional. A macrovisão da ação organizacional traduzida pela cadeia de valor é uma importante referência para as decisões e orientações gerenciais (VALLE; COSTA, 2009, p.4-6).

Segundo Valle e Costa (2009, p.6), gerenciar a cadeia de valor pressupõe cumprir um ciclo de alinhamento contínuo, que tem por objetivo o ajuste de 
percepções para produzir sincronismo na decisão e na ação dos grupos de trabalho. O alinhamento é um ajuste mútuo entre as múltiplas dimensões da cadeia de valor, que podem ocorrer nas seguintes direções: estratégica, dos clientes e intervenientes, do modelo de produção, do desenvolvimento organizacional, da cultura organizacional e local e/ ou da estrutura organizacional.

De acordo com Smith e Fingar (2003), os processos são a principal propriedade intelectual e manifesto diferencial competitivo em todas as atividades empresariais. E as empresas devem tratá-los com um grande grau de habilidade e cuidado para garantir sua eficácia. Nesse sentido, o futuro vai pertencer às empresas que conseguirem explorar o potencial da centralização das prioridades, as ações e recursos nos seus processos. (GONÇALVES, 2000a, p.10).

Assim, os processos são de grande importância nas organizações, pois permitem enxergar uma linha de atividades que começa com o entendimento exato do que o cliente deseja e que termina com o cliente adquirindo o produto/serviço (GONÇALVES, 2000b, p.10).

\subsubsection{Categorias de processos}

É interessante separar os processos de produção dos bens e serviços oferecidos dos demais processos que podem ocorrer na empresa: os processos relacionados com a gestão da empresa e os de apoio aos processos produtivos (HARRINGTON, 1993).

Existem três categorias básicas de processos. Com base em uma pesquisa bibliográfica, Gonçalves (2000a, p.13) identifica os diferentes tipos de processos nas empresas:

- $\quad$ processos de negócio (ou de cliente): são os que caracterizam a atuação da empresa e que são apoiados por outros processos internos resultando no produto ou serviço que é recebido pelo cliente externo;

- processos organizacionais (ou de integração): apoiam os processos de negócio pela viabilização do funcionamento coordenado da organização; e 
- $\quad$ processos gerenciais: focalizam os gerentes e suas relações incluindo ações de medição e ajuste de desempenho da empresa.

A Tabela 1 apresenta exemplos de processos empresariais genéricos, organizados nas três categorias fundamentais aqui definidas.

Tabela 1 - As três categorias de processo (GONÇALVES, 2000)

\begin{tabular}{|c|c|c|c|}
\hline & Processos de Negócio & Processos Organizacionais & Processos Gerenciais \\
\hline 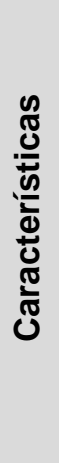 & $\begin{array}{l}\text { São ligados à essência do } \\
\text { funcionamento da organização } \\
\text { São apoiados por processos } \\
\text { internos } \\
\text { Resultam no produto ou } \\
\text { serviço que é recebido pelo } \\
\text { cliente }\end{array}$ & $\begin{array}{l}\text { São centrados na organização } \\
\text { Viabilizam o funcionamento } \\
\text { coordenado dos vários } \\
\text { subsistemas da organização } \\
\text { Garantem suporte adequado aos } \\
\text { processos de negócio }\end{array}$ & $\begin{array}{l}\text { São centrados nos gerentes } \\
\text { e nas suas relações } \\
\text { Incluem ações de medição e } \\
\text { ajuste do desenvolvimento } \\
\text { da organização } \\
\text { Incluem as ações de suporte } \\
\text { que os gerentes devem } \\
\text { realizar }\end{array}$ \\
\hline $\begin{array}{l}\text { 오 } \\
\text { 을 } \\
\text { हों } \\
\text { யे }\end{array}$ & $\begin{array}{l}\text { Vendas } \\
\text { Desenvolvimento de produtos } \\
\text { Distribuição } \\
\text { Cobrança } \\
\text { Atendimento de pedidos } \\
\text { Atendimento de garantia }\end{array}$ & $\begin{array}{l}\text { Planejamento estratégico } \\
\text { Orçamento empresarial } \\
\text { Recrutamento e seleção } \\
\text { Compras } \\
\text { Treinamento operacional }\end{array}$ & $\begin{array}{l}\text { Fixação de metas } \\
\text { Avaliação do resultado da } \\
\text { empresa } \\
\text { Gestão das interfaces } \\
\text { Alocação de recursos }\end{array}$ \\
\hline & Processos Primários & \multicolumn{2}{|c|}{ Processos de suporte } \\
\hline
\end{tabular}

Com relação à capacidade de geração de valor para o cliente, os processos podem ser caracterizados de duas maneiras: a) primários, quando incluem as atividades que geram valor para o cliente ou b) de suporte, constituído por conjuntos de atividades que garantem o apoio necessário ao funcionamento adequado dos processos primários (MARTIN, 1996).

Os processos de negócio são considerados processos primários e os organizacionais e gerenciais, de acordo com essa definição, são processos de suporte (GONÇALVES, 2000a, p.13). 
Segundo De Oliveira (2009, p. 23-25), os processos primários são os mais importantes, pois afetam diretamente os clientes externos. Podem ser subdivididos em duas maneiras: chaves e críticos. Os autores definem os processos-chaves como aqueles que geram alto custo para a organização e alto impacto para os clientes externos.

Dentre a classificação descrita por Gonçalves (2000a), o processo de desenvolvimento de produtos (PDP) é considerado um processo de negócio, um fenômeno que ocorre dentro das empresas e que são ligados à essência do funcionamento da organização (ROZENFELD et al., 2006).

\subsubsection{Processo de Negócio}

O conceito de processo de negócio está no centro da abordagem sistêmica utilizada para descrever e interpretar as organizações de modo integrado, observando-a como um todo coeso e não como uma junção de partes isoladas (GEORGES, 2010).

Davenport (1993) emerge como um dos principais autores que tratam dessa questão. Ele desenvolve a seguinte definição de Processo de Negócio:

\footnotetext{
Um conjunto de atividades estruturadas e mensuráveis que foram projetadas para produzir um resultado específico para um mercado ou consumidor em particular. Um processo é uma ordem de trabalho específica ao longo do tempo e espaço, com começo e fim e entradas e saídas claramente definidas.
}

Rummler e Brache (1995) definem o processo de negócio como uma série de etapas criadas para produzir um produto ou serviço, incluindo várias funções e preenchendo as lacunas existentes entre as diversas áreas organizacionais, objetivando com isso estruturar uma cadeia de agregação de valor ao cliente. 
Smith e Fingar (2003), por sua vez, definem processo de negócio como o conjunto completo de atividades transacionais colaborativas e dinamicamente coordenadas que entregam valor para os clientes.

Já para Rozenfeld (1996) um processo de negócio compreende um conjunto de atividades realizadas na empresa, associadas às informações que manipulam, utilizando os recursos e a organização da empresa. Os recursos podem ser entendidos como técnicas, métodos, ferramentas, sistemas de informação, recursos financeiros e todo o conhecimento envolvido na sua utilização. A organização engloba não somente os aspectos organizacionais e estruturais das empresas, como também os seus agentes, ou seja, as pessoas com sua qualificação, motivação etc. A capacidade de aprendizado da empresa também é um dos elementos da organização de um processo de negócio.

Logo, o autor enfatiza que o processo de negócio forma uma unidade coesa e deve ser focalizado em um tipo de negócio, que normalmente está direcionado a um determinado mercado/cliente com fornecedores bem definidos (Figura 3).

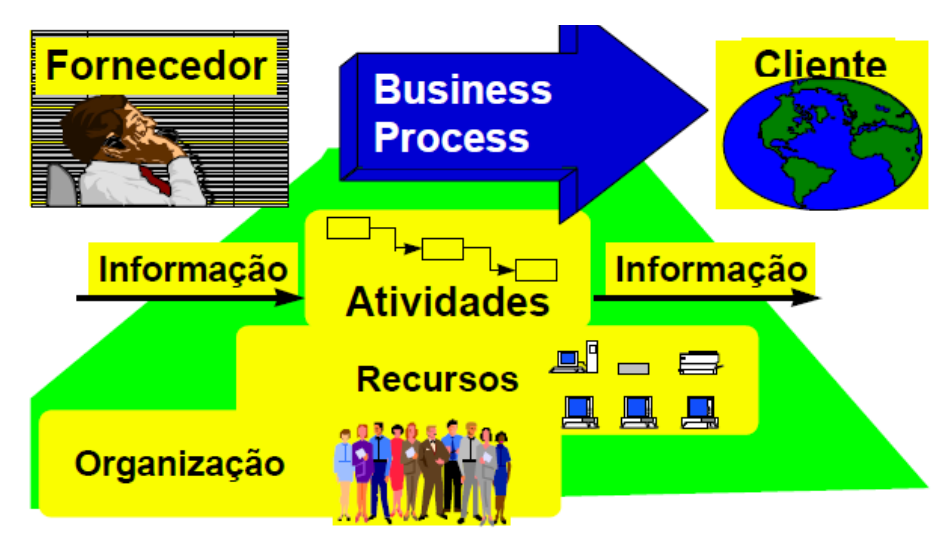

Figura 3 - Processos de Negócios (ROZENFELD, 1996).

Segundo Rozenfeld (1996, p.04), visualizar a empresa por meio de seus processos de negócios permite um melhor gerenciamento de recursos, das informações e mesmo das atividades inerentes a cada processo, visto que possibilita a formalização de uma visão sistemática desses elementos, permitindo identificar compartilhamentos por mais de um processo. 
Para garantir a compreensão e a visualização por meio dos processos de negócios por toda organização, esses processos precisam ser mapeados. Dessa forma, desenvolver modelos de referência que capturem as diversas características do negócio é fundamental, pois pode identificar problemas e oportunidades de melhorias.

Neste contexto, o modelo de referência torna-se relevante, uma vez que é possível construir uma visão dos aspectos organizacionais a partir dele, podendo essa visão ser compartilhada por toda a empresa (BREMER; LENZA, 2000).

\subsubsection{Abordagem da Gestão por Processos}

A introdução de processos de negócios nas organizações trouxe um novo desafio: como administrar organizações orientadas por processos de negócios? A resposta da academia a esse questionamento proporcionou o desenvolvimento da gestão por processos denominado Business Process Management ou BPM (DE SORDI, 2008, p.21).

As raízes da gestão por processos podem ser encontradas na década de 1980 com a filosofia da Total Quality Management (gestão da qualidade total), e na década de 1990 com o Business Process Reengineering (reengenharia de processos) promovidos pelo Hammer e Champy (CHANG, 2006).

Contudo, segundo Jeston e Nelis (2006, p.05), a abordagem da gestão por processos sempre esteve presente no dia a dia da gestão das empresas e nas pesquisas acadêmicas de gestão, analisando o ciclo hype ${ }^{1}$ da BPM (Figura 4).

\footnotetext{
${ }^{1}$ De acordo com o dicionário Oxford (OXFORD, 2010) hype significa "afirmações exageradas ou extravagantes realizadas para promover um produto".
} 


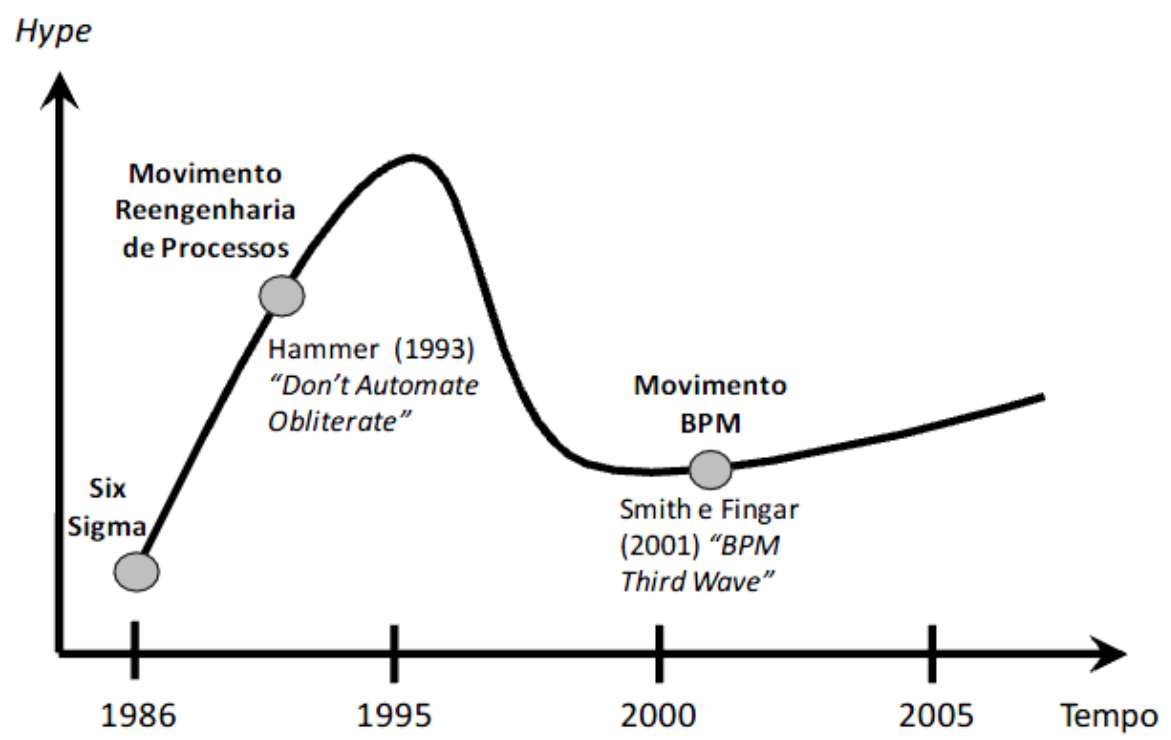

Figura 4 - Ciclo hype do BPM (JESTON; NELIS, 2006).

Para os autores Chang (2006), Jeston e Nelis (2006) e Zairi (1997), a gestão por processos é uma abordagem sistêmica e estruturada para análise, melhoria, e controle. Ela tem o objetivo de melhorar a qualidade de suas saídas, produtos e serviços.

Cruz (2008) apresenta a seguinte definição para a gestão por processos:

[...] é um conjunto formado por metodologias e tecnologias cujo objetivo é possibilitar que processos de negócio integrem, lógica e cronologicamente, clientes, fornecedores, parceiros, influenciadores, funcionários e todo e qualquer elemento com que eles possam, queiram ou tenham que interagir possibilitando à organização visão completa e essencialmente integrada do ambiente interno e externo das suas operações e das atuações de cada participante em todos os processos de negócio.

A finalidade da gestão por processos é fazer com que as atividades sejam vistas não em termos de funções, departamentos ou produtos, mas de processoschave dentro da empresa (CARVALHO, 2006).

Neste sentido Alvarenga-Netto (2006) lista alguns objetivos da gestão por processos. São eles:

- $\quad$ Aumentar valor do produto ou do serviço na percepção do cliente; 
- Melhorar a competitividade;

- $\quad$ Atuar segundo a estratégia competitiva mais relevante para a organização;

- Aumentar a produtividade com eficiência e eficácia; e

- $\quad$ Simplificar processos, removendo tarefas que não agregam valor ao cliente.

Jeston e Nelis (2006) enfatizam que a gestão por processos não é um objetivo em si, mas é um meio para atingir um objetivo das estratégias da organização, até o processo individual.

Os motivos que levam uma organização a buscar a gestão por processos são particulares a cada organização. Entretanto, é possível identificar os motivos mais comuns (MÜCKENBERGER, E. et al., 2011).

- A organização apresenta crescimento acentuado, chegando a dificuldades em atingir seus objetivos e perda de controle e agilidade para aproveitar oportunidades;

- Há dificuldades no gerenciamento, com informações imprecisas e/ou conflitantes e necessidade de cortar custos e aumentar produtividade;

- $\quad$ Ocorre alta rotatividade, falta de preparo e insatisfação dos colaboradores;

- Há um aumento no número de clientes, fornecedores ou parceiros e uma exigência maior em atendê-los através de um relacionamento de proximidade;

- $\quad$ Os produtos e serviços oferecidos são complexos e há duplicação de tarefas;

- Não há visão dos processos ponta a ponta, gerando lacunas e falta de padronização e clareza quanto às responsabilidades; e

- $\quad$ Ocorre a introdução ou eliminação de sistemas de informação.

Com o BPM, a transformação das organizações deixa de ser uma arte imprecisa e de resultados imprevisíveis, tornando-se uma disciplina administrativa e de engenharia, com indicadores predefinidos, mas alteráveis. Na leitura de Baldam et al. (2006) o BPM possibilita:

- Meios de colocar os processos concebidos em prática;

- Um método sistemático e confiável de análise do impacto do processo de negócio e de introdução de inovações; 
- Modelos de execução de processos que sejam alinhados à estratégia da organização, que reflitam a complexidade de suas atividades diárias e que facilitem a análise, a transformação e a mobilização das equipes;

- $\quad$ O gerenciamento de um portfólio de processos de negócios voltado não apenas para as necessidades atuais dos clientes, mas para a alteração constante destas necessidades;

- Habilidade para responder a alterações no mercado e para combinar e customizar processos;

- Uma melhor compreensão da trajetória estratégica da organização: expansão de mercado e incremento dos lucros, ou diminuição de influências externas, obstáculos e falhas internas para responder mais rapidamente às mudanças de mercado;

- Um meio consistente, resiliente e previsível de "processar processos", transformando a empresa em um permanente laboratório de processos, habilitando continuamente inovações, transformações e agilidade de execução.

A partir da adoção da gestão por processos, deve-se considerar o atendimento a alguns princípios importantes (ALVARENGA-NETTO, 2006) como:

- $\quad$ Organizar processos em função das saídas e não das tarefas;

- Permitir que o usuário das saídas executem o processo;

- Processar a informação juntamente com sua produção;

- Recursos dispersos geograficamente devem ser tratados como centralizados;

- Atividades paralelas devem ser interligadas, ao invés de apenas integrar os seus resultados;

- $\quad$ Obter informação uma única vez;

- $\quad$ Dar o enfoque sistêmico aos processos;

- Criar responsáveis pelos processos.

Considerando abordagens anteriores da reengenharia de processos e melhoria contínua Burlton (2001) também listou uma série de princípios 
fundamentais a fim de entregar resultados de negócios para os clientes e outras partes interessadas na organização, que são:

- Mudanças nos processos devem ser direcionadas por desempenho;

- Decisões de mudança nos processos devem ser traçadas com base nos critérios estabelecidos pelos stakeholders;

- O negócio deve ser segmentado de acordo com os processos de negócios para sincronizar as mudanças;

- $\quad$ Processos de negócio devem ser gerenciados holisticamente;

- Iniciativas de renovação do processo devem inspirar visões compartilhadas;

- Iniciativas de renovação do processo devem ser conduzidas de fora para dentro;

- Iniciativas de renovação do processo devem ser conduzidas de forma iterativa;

- Mudanças nos negócios são relacionadas com pessoas; e

- Mudanças nos negócios é uma jornada, e não um destino.

- Mudanças nos processos devem focadas nas necessidades dos stakeholders;

Segundo Jeston e Nelis (2006), a gestão por processos traz diversas vantagens, como tornar claras as relações dentro da organização e entre a organização e o mercado; facilitar a visão interdisciplinar, aumentando a integração e alinhar toda a organização em torno de um objetivo comum, pois está enfocada nas atividades que agregam valor ao processo e não apenas nas responsabilidades, hierarquias e funções individuais.

\subsection{Modelo de Referência}

Nesta seção, são apresentados os conceitos e definições. Em seguida são apresentados os benefícios do modelo de referência específico, a elaboração e a classificação do modelo de referência genérico. 
A opção de não apresentar a elaboração e classificação do modelo de referência específico se deve ao fato de que cada empresa apresenta um resultado particular e tem suas especificidades.

\subsubsection{Conceitos e Definições}

Segundo Vernadat (1996), um modelo pode ser definido como uma representação de algo com maior ou menor grau de formalidade. É uma abstração da realidade expressa em algum tipo específico de formalismo. Os modelos expressam-se por meio de símbolos, gráficos, textos ou, até mesmo, por meio de linguagem matemática (formalismos ou linguagem de modelagem) que permite transcrever a realidade abordada. As formas de representação do modelo consistem em um tipo de linguagem própria de representação da realidade.

Pidd (1998), por exemplo, apresenta elementos complementares para as definições de modelos que são encontradas na literatura. Primeiramente, em vez de ser uma simples representação da realidade, um modelo deve agregar a ideia de propósito, ou seja, deve-se considerar o motivo pelo qual o modelo está sendo construído, pois uma mesma realidade pode ser vislumbrada de diferentes formas por pessoas com diferentes objetivos quanto a ela. A ideia de propósito traz à tona a necessidade de definição do usuário do modelo. Nesse sentido, é fundamental pensar no responsável pelo gerenciamento e entendimento da realidade, ou seja, são pessoas que gerenciam processos ou atividades e que fazem parte da execução de atividades além de analisarem as atividades com o objetivo de propor melhorias a elas.

O modelo nunca descreve completamente uma realidade. Ele é sempre limitado aos propósitos do usuário. Nessa perspectiva, os modelos também possuem limitações quanto a sua abrangência. Nem sempre é possível contemplar toda a realidade em sua construção, já que uma mesma situação pode ser entendida e descrita de maneira distinta por pessoas com diferentes visões de mundo (modelos mentais internos e implícitos).

Uma questão a ser considerada é que um modelo retrata a realidade externa e explícita compartilhada por todos os envolvidos. Por isso, ele não deve ser confundido como formas de pensar ou arranjos mentais particulares. O que não é 
explícito não é um modelo, uma vez que não pode ser compartilhado com outros usuários da parte da realidade que é modelada.

O caráter externo e explícito do modelo é capturado por meio do que Vernadat (1996) chama de formalismo ou linguagem de modelagem, o que seria a forma de representação do modelo. O formalismo de um modelo é definido pelos construtos utilizados para representar uma dada realidade.

Um tipo especial de modelo são os chamados modelos de referência. Eles têm aplicação mais ampla e servem de base para o desenvolvimento de modelos específicos como os modelos de processos de negócios. Em virtude dessas características são denominados de modelos genéricos, conceituais ou universais. (FETTKE et al., 2006a).

Segundo Thomas (2005), o termo "modelo de referência" se estabeleceu na literatura no final da década de 1980 e está associado à compreensão e à sistematização de melhores práticas em determinada realidade, dando-lhe um significado prescritivo. Portanto, os modelos de referência são modelos conceituais que formalizam práticas recomendadas para uma área do conhecimento.

Os modelos de referência podem ser genéricos ou específicos para uma organização. Eles são em geral prescritivos (to-be) e possuem um conjunto de diretrizes de caráter genérico, que podem ser adaptadas para aplicação em diversos contextos. Usualmente modelos de referência genéricos são elaborados por grupos de pesquisas, instituições ou organizações. A partir do momento em que são "adaptados" (instanciados) para um determinado contexto, são denominados modelo de referência específico de caráter descritivo (as-is) (FETTKE et al., 2006a). Modelos específicos descritivos são utilizados para retratar e analisar o processo real de uma empresa, tal como ela ocorre (Figura 5). Modelos de referência específicos também são chamados de processos padrão (BROWNING, 2010). 


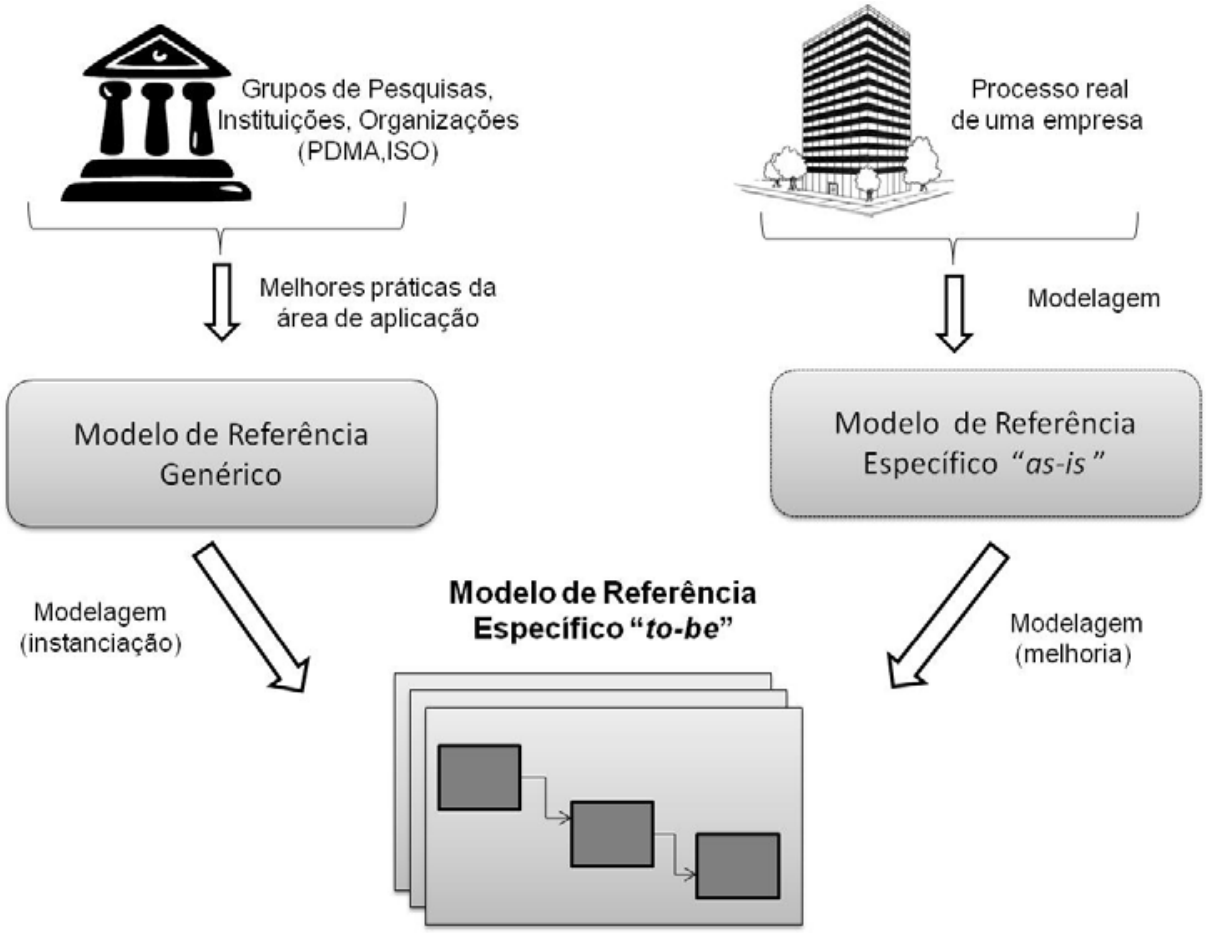

Figura 5 - Relação entre modelos de referência genéricos e específicos (elaborada pela autora).

Neste trabalho, o enfoque será no modelo de referência específico, pois serão analisados o uso do modelo de referência específico implantado no processo de desenvolvimento de produto das empresas selecionadas e as disfunções que ocorrem na implantação.

Vernadat (1996) define modelo de referência específico como um conjunto consistente de modelos direcionados e complementares que descrevem as várias facetas de uma empresa para satisfazer os propósitos dos usuários do negócio. Esse modelo pode ser utilizado como referência para a consolidação e implantação de diversos processos de negócio como também o PDP. Além disso, uma vez aplicado em uma determinada situação, ele irá constituir-se numa documentação do processo de desenvolvimento de produto e em um importante dispositivo para guiar intervenções futuras dentro deste processo. Assim, quando se relacionam e se analisam diversos modelos de empresa levantados para um segmento ou empresa específica, por exemplo, pode-se derivar um modelo de referência para aquele segmento ou empresa específica, ou seja, um modelo de maior nível de abstração e que compile as melhores práticas, de forma a servir como referência básica para diversos propósitos. 
A especificação de modelos de referência pode ocorrer de duas formas alternativas. Um modelo de referência pode ser criado de maneira indutiva, a partir da compilação do conhecimento de vários casos empíricos, de outros modelos, da documentação de sistemas de informação e de dados obtidos por meio de entrevistas nas empresas. Alternativamente, modelos de referência podem ser deduzidos da teoria da literatura, conforme ilustrada na Figura 6 (FETTKE; LOOS 2006b, p.05).

Pela perspectiva prática, Fettke e Loos (2007, p.05) ressaltam que os modelos de referência genéricos podem ser usados em diferentes cenários de aplicação conforme ilustrada na Figura 6:

- Na derivação de um modelo específico - um modelo que representa uma classe de domínio pode ser reutilizado e adaptado às necessidades de uma empresa específica;

- Na validação de modelos específicos da empresa - pode ser utilizado como uma referência padrão para avaliar os modelos existentes na empresa, identificando eventuais falhas;

- No desenvolvimento de aplicações práticas - modelos de referência representam classes de domínios, eles fornecem um quadro genérico para o desenvolvimento de aplicações práticas.

- Na seleção de pacotes ERP (Enterprise Resources Planning). Segundo Souza e Zwicker (2000), os sistemas de ERP possuem uma série de características importantes para a análise dos possíveis benefícios relacionados com a sua utilização e com os aspectos pertinentes ao sucesso de sua implantação, tais como a incorporação de modelos padrão de processos de negócios e a necessidade de procedimentos de ajuste. Assim, os modelos de referência genéricos podem ser usados para descrever as características de diferentes pacotes de ERP. Com base em tal descrição, é possível comparar e selecionar um pacote de ERP adequado para uma empresa. 


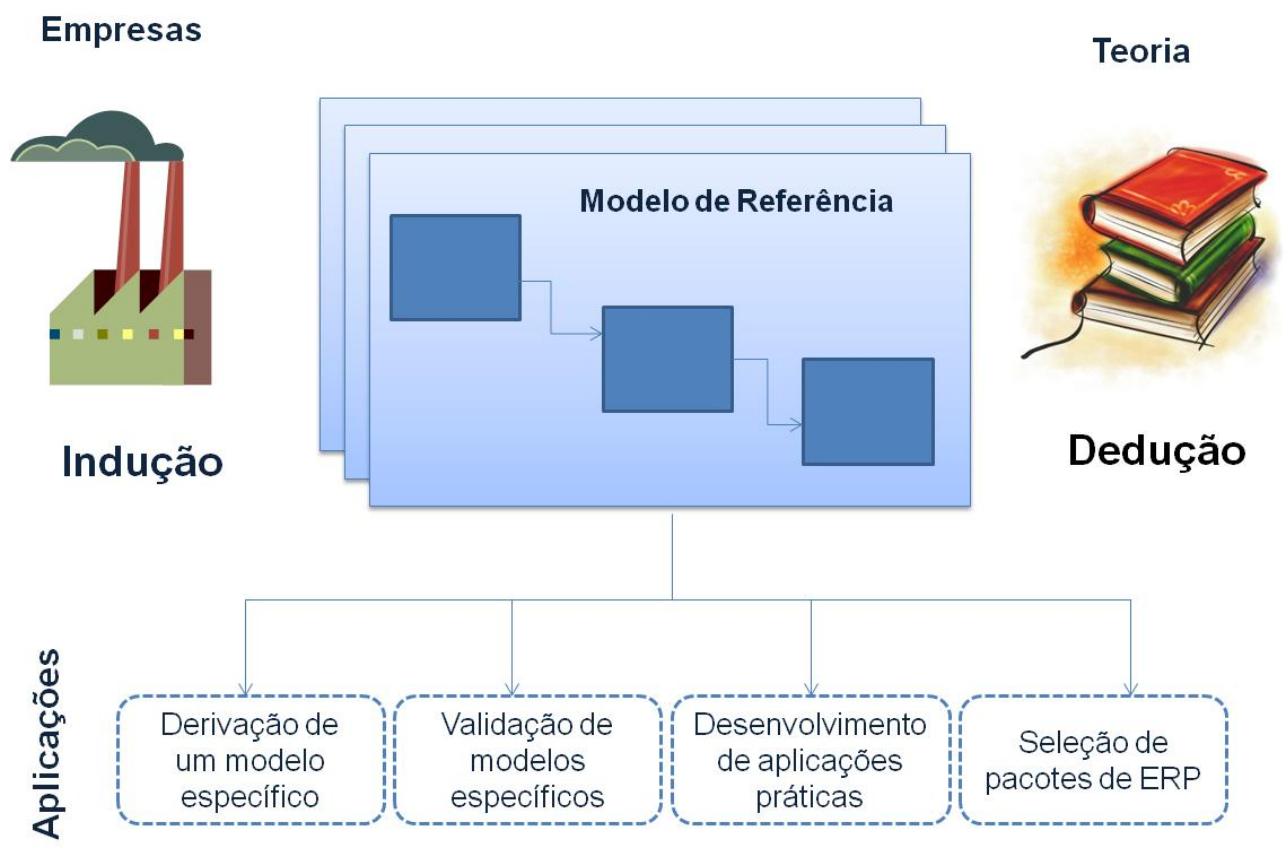

Figura 6 - Cenários de aplicação do modelo de referência (elaborada pela autora).

Ao analisar diversas definições, Fettke e Loos (2007, p.04) identificaram as três principais características dos modelos de referência genéricos:

$\checkmark \quad$ Melhores práticas - modelos de referência provê melhores práticas para conduzir negócios;

$\checkmark \quad$ Aplicabilidade universal - modelo de referência não representa uma determinada empresa, mas uma classe de domínios; e

$\checkmark \quad$ Replicabilidade - modelo de referência é uma estrutura conceitual que pode ser reutilizada em uma multiplicidade de projetos de sistemas de informação.

2.2.2 Benefícios do Modelo de Referência Específico

A implantação do modelo de referência específico nas empresas pode resultar um conjunto de benefícios, que são descritos a seguir: 
1. O modelo de referência alinha todas as funções da empresa a respeito do projeto (TARALLO; FORCELLINI, 2007, p.07);

2. O modelo de referência reforça a cultura do projeto como um empreendimento de toda a empresa, e não da área funcional de engenharia do produto (TARALLO; FORCELLINI, 2007, p.07);

3. O modelo de referência oferece agilidade na tomada de decisão e na criação de planos de ação corretiva mais eficaz (TARALLO; FORCELLINI, 2007, p.07);

4. O modelo de referência oferece uma linguagem comum à organização (TARALLO; FORCELLINI, 2007, p.07, ENGWALL et al., 2005, p.433);

5. O modelo de referência agiliza o diagnóstico de projetos, por pessoas externas aos times de desenvolvimento (TARALLO; FORCELLINI, 2007, p.07);

6. O modelo de referência agiliza a tomada de decisão (TARALLO; FORCELLINI, 2007, p.07);

7. A partir da adoção de um modelo unificado é possível o bom andamento do desenvolvimento de projetos conduzidos por times geograficamente dispersos, sendo que o modelo único traz alinhamento e agilidade a estes times (TARALLO; FORCELLINI, 2007, p.07);

8. Os modelos de referência foram vistos como apoio de cooperação eficaz e comunicação entre projetos (ENGWALL et al., 2005, p.433);

9. Os modelos de referência ajudaram a equipe do projeto a se concentrar nas tarefas mais importantes e assim evitar o retrabalho (ENGWALL et al., 2005, p.434);

10. Os modelos foram vistos como uma estrutura básica, o que permite a reutilização da experiência anterior de outros projetos (ENGWALL et al., 2005, p.434);

11. Modelo de referência oferece a padronização das atividades do desenvolvimento de produto (ENGWALL et al., 2005, p.436);

12. Modelos de referência fornece uma forma compartilhada de planejar e monitorar o projeto (ENGWALL et al., 2005, p.436);

13. Os modelos oferecem-nos uma maneira padronizada de medir o progresso do projeto (ENGWALL et al., 2005, p.432);

14. Os modelos de referência criam uma forma comum de trabalhar (ENGWALL et al., 2005, p.432); 


\subsubsection{Elaboração do Modelo de Referência}

A elaboração dos modelos de referência genéricos procura em geral referenciar as "melhores práticas" para condução dos negócios; manter sua universalidade não representando uma empresa, mas uma classe de domínio; e possibilitar a "reutilização" na construção de modelos específicos ou de outros modelos de referência (FETTKE; LOOS 2007, p.04).

Em geral, o processo de elaboração de um modelo de referência genérico apresenta quatro atividades, conforme podemos ver na Figura 7: definição do problema a ser abordado pelo modelo, desenvolvimento do modelo, avaliação e manutenção. E o processo de aplicação do modelo de referência específico compreende as seguintes atividades: seleção, adaptação, integração e utilização do modelo, de acordo com a Figura 7 (FETTKE, LOOS, 2007, p.09).

Segundo os autores, o termo "processo de elaboração" refere-se todas as atividades que são relevantes para o desenvolvimento de um modelo de referência genérico, enquanto o termo "processo de aplicação" refere-se a todas as etapas para o desenvolvimento de um modelo de referência específico em uma empresa.
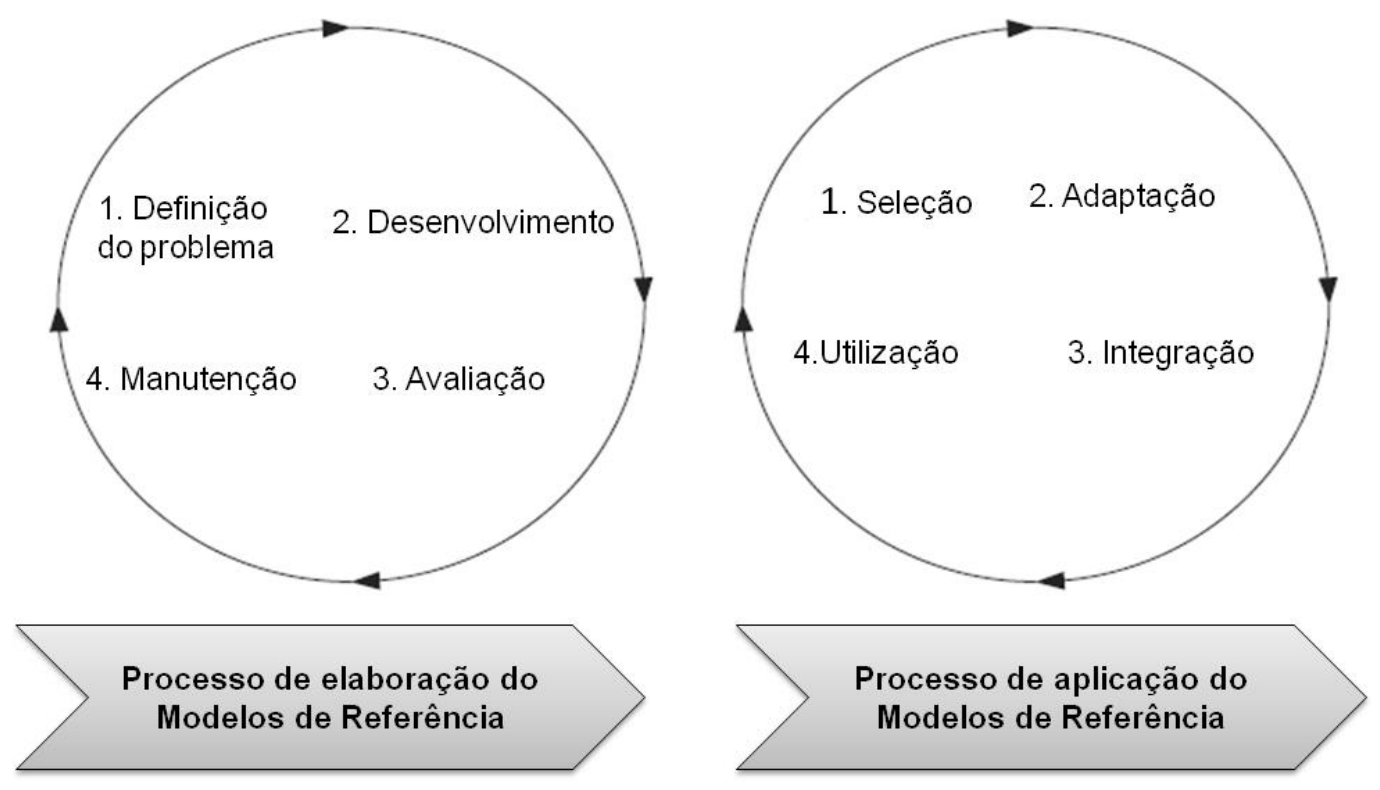

Figura 7 - Elaboração do Modelo de Referência (adaptado de FETTKE; LOOS, 2007). 
A proposta de construção do modelo de referência apresentada pelos autores demonstra a utilização PDCA ${ }^{2}$. Ahlemann e Gasti (2007, p 83-95) detalham a lógica proposta inicialmente por Fettke e Loos (2007), apresentando um processo composto pela definição do problema e mais 5 fases:

1. Identificação do Problema e Planejamento - É necessária primeiramente a identificação do problema para definição clara e precisa do domínio do modelo. A definição do problema deve ser feito em colaboração com especialistas de domínio para evitar erros. Em seguida é necessário observar algumas normas e padrões aplicáveis. Deve-se então selecionar a técnica de representação do modelo, os envolvidos no processo, a tecnologia requerida e um planejamento clássico de projeto.

2. Elaboração do Modelo - A elaboração do modelo deve sempre começar com uma análise do conhecimento do domínio atual. Uma primeira análise do domínio é por meio da elaboração de uma estrutura de referência. Essa estrutura é submetida às críticas de interesse para permitir a elaboração de modelo inicial.

3. Validação - O modelo inicial é submetido à avaliação permitindo o seu refinamento.

4. Teste Prático - Uma primeira aplicação do modelo pode permitir a resolução de problemas práticos de uma organização, oferecendo novos refinamentos e melhorias incrementais ao Modelo de Referência.

5. Documentação - Os resultados observados da pesquisa são um pré-requisito para compreensão e validade entre diferentes áreas de conhecimento. Recomendase fornecer a descrição do processo de construção, anotações dos elementos do modelo, documentação dos estudos de caso e uma tabela com os elementos do modelo.

Von Brocke (2007) propõe alguns princípios básicos para a construção dos Modelos de Referência: integração, agregação, especialização e analogia. A integração é caracterizada pela criação de um modelo de referência. A agregação compreende a combinação de um ou mais modelos de referência resultando em um

\footnotetext{
${ }^{2}$ PDCA - Conceito de abordagem de processos baseado em quatro etapas: Plan (planejamento), Do (execução), Check (Verificação) e Act (Ação).
} 
novo modelo. A especialização corresponde à derivação de um modelo de referência de um modelo original. A analogia caracteriza-se, finalmente, pela utilização de um modelo de referência original como principal orientação na construção do modelo resultante.

\subsubsection{Classificação do Modelo de Referência}

Segundo Fettke, Loss e Zwicker (2006b, p.2) modelos de referência podem ser classificados segundo inúmeros pontos de vista. A Figura 8 ilustra os critérios considerados para caracterizar e classificar um modelo de referência. Além das características universais, o modelo de referência necessita de uma análise dos critérios universais e específicos que se encontram descritos a seguir.

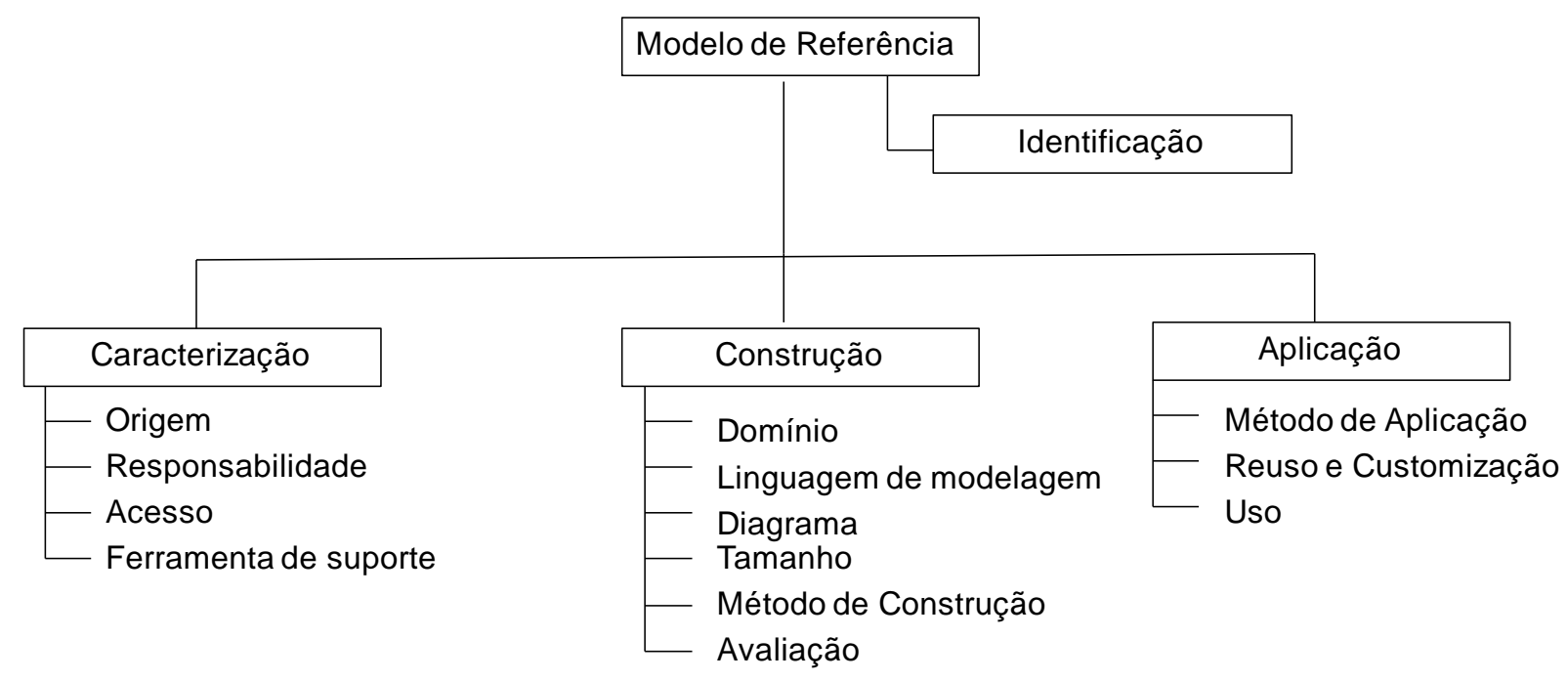

Figura 8 - Estrutura de classificação e caracterização do modelo de referência (adaptado de FETTKE, LOOS; ZWICKER, 2006b).

Os autores sugerem uma classificação do modelo de referência em três dimensões: Caracterização, Construção e Aplicação.

A identificação, na classificação proposta significa a denominação do modelo de referência.

A dimensão Caracterização corresponde aos aspectos estruturais do modelo, compostos por: 
$>$ Origem - informação sobre a classificação da(s) pessoa(s) que têm desenvolvido o modelo de referência. Nesse sentido, tanto a ciência e quanto a prática podem ser distinguidas.

> Responsabilidade - pessoa responsável pelo modelo de referência;

$>$ Acesso - acessibilidade das organizações quanto ao modelo, podendo ser "aberto", se o modelo de referência é obtido de forma teórica, ou acesso "fechado" quando a pessoa responsável ou instituição prevê qualquer possibilidade de usar e reconhecer o modelo de referência por terceiros. Se não for aberto nem fechado, o acesso é classificado como "limitado".

> Ferramenta de suporte - este critério descreve se o modelo de referência pode ser utilizado automaticamente por uma ferramenta de software ou se o modelo de referência está apenas disponível em papel ou em cópia digital.

A outra dimensão utilizada pelos autores é a de construção e refere-se aos aspectos associados ao conteúdo do modelo e método de construção e evolução, apresentando os seguintes componentes:

> Domínio - o domínio descreve o campo de aplicação a partir da perspectiva da(s) pessoa (s) ou instituição(ões) responsável(is) pelo desenvolvimento do modelo de referência. Os autores indicam duas composições: a primeira é o domínio de aplicação que se refere à abrangência de sua aplicação na organização: Institucional (aplicada aos principais aspectos da gestão da organização), funcional (aplicada a uma determinada área ou função da organização) ou processual (aplicada a processo específico dentro de uma organização). Por outro lado, a segunda subclassificação é o domínio de escopo no qual os autores não fixaram critérios de classificação.

> Linguagem de Modelagem - aborda que a linguagem de modelagem foi utilizada para representar o modelo de referência. Para isso, a descrição de modelos de referência, linguagens de modelagem ou tipos de diagramas usados para representar os modelos de modelo de referência são particularmente especificados.

> Diagrama ("Framework") do Modelo - esse critério de classificação está baseado na existência ou não de uma estrutura diagramática de explicação do modelo. Em geral, o diagrama tem a finalidade de reduzir a complexidade ou 
apresentar uma visão global dos elementos e relacionamentos existentes no modelo de referência.

Tamanho - métricas de tamanho para modelos de diferentes linguagens de modelagem não existem. Para dar uma impressão vaga sobre o tamanho da referência descrita dos modelos, várias métricas podem ser utilizadas.

$>$ Método de Construção - método utilizado para construção do modelo de referência;

$>\quad$ Avaliação - este critério descreve os métodos utilizados para avaliar a referência modelo pela(s) pessoa (s) ou instituição responsável(is) pelo desenvolvimento do modelo de referência.

A terceira dimensão sugerida é a Aplicação que se refere aos aspectos associados com a utilização do modelo de referência. Os autores FETTKE, LOSS; ZWICKER (2006b, p.4) sugerem três classificações para esta dimensão:

$>\quad$ Método de Aplicação - corresponde ao método utilizado para aplicar o modelo de referência;

Reutilização/Customização - este critério relaciona conceitos para reutilização ou customizações do modelo

$>\quad$ Uso - descreve como o modelo é normalmente aplicado.

A aplicação dessas três classificações nas pesquisas de Fettke, Loos e Zwicker (2006b) produziu resultados pouco significativos e em geral associados à forma de aplicação dos Modelos de Referência pelas organizações. 


\subsection{Processo de Desenvolvimento de Produto (PDP)}

Nesta seção são apresentados os conceitos e definições. Em seguida são apresentadas as características específicas do processo de desenvolvimento de produto e por fim o modelo de referência para o PDP.

\subsubsection{Conceitos e definições}

O processo de desenvolvimento de produto (PDP) situa-se na interface entre a empresa e o mercado, cabendo a ele identificar as necessidades do mercado ou até mesmo antecipar-se delas. Assim surge sua importância estratégica, buscando identificar as necessidades dos clientes em todas as fases do ciclo de vida do produto e procurando identificar as possibilidades tecnológicas e desenvolver o produto no tempo adequado e a um custo competitivo (ROZENFELD et al., 2006, p.4).

Nas pesquisas sobre o processo de desenvolvimento de produto (PDP), já é tradicional o emprego da abordagem por processos, no qual o PDP é compreendido como um conjunto de atividades técnicas além do escopo da engenharia, pois ele envolve várias atividades multifuncionais realizados por diversos profissionais de diferentes áreas da empresa tais como: marketing, pesquisa \& desenvolvimento, engenharia do produto, suprimentos, manufatura e distribuição, cada uma atuando vendo o produto por uma perspectiva diferente, mas complementares, conforme podemos ver na Figura 9 (ROZENFELD et al., 2006, p.10). 


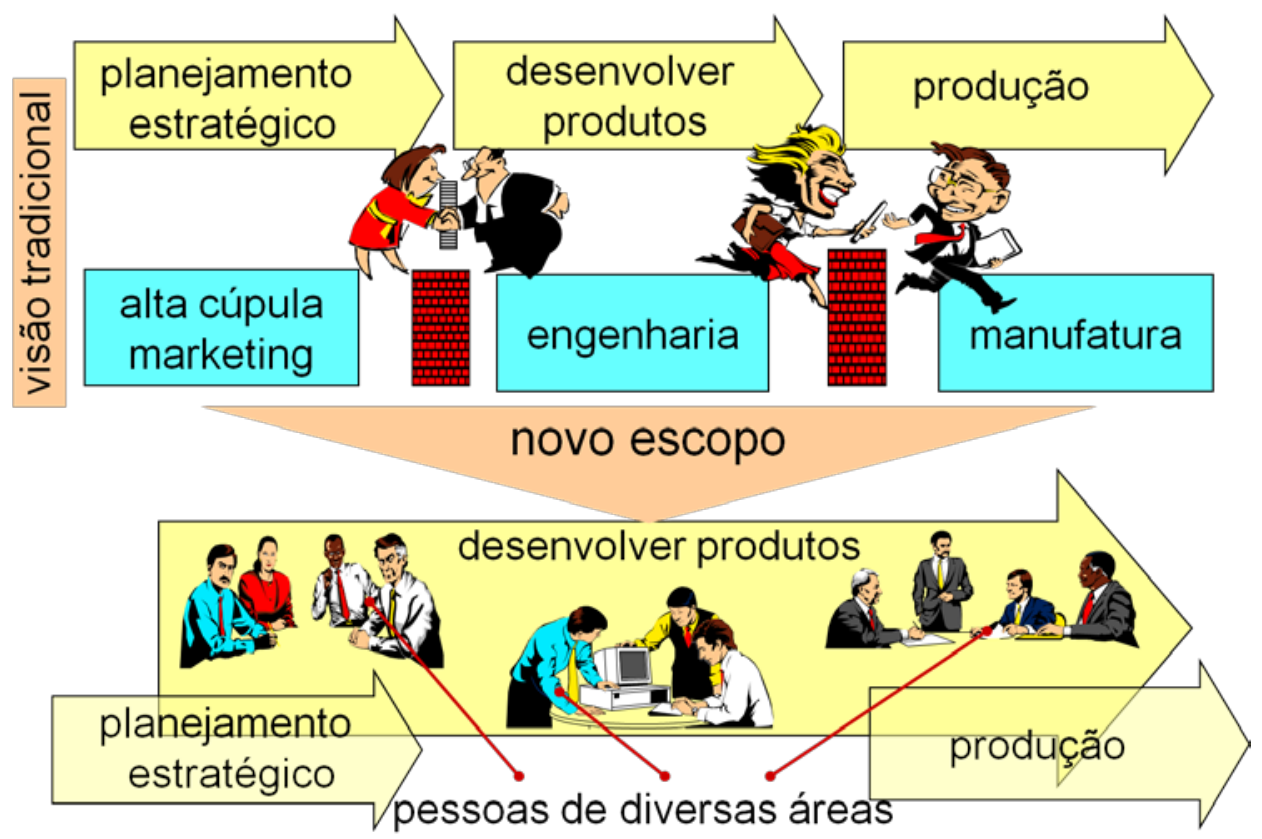

Figura 9 - Time Multifuncional do PDP (ROZENFELD et al., 2006).

Clark e Wheelwright (1993) afirmam que a aplicação da abordagem por processos para as atividades de desenvolvimento de produto implica em uma integração harmônica entre as diversas funções organizacionais.

Entre as definições mais clássicas, aquela defendida por Clark e Fujimoto (1991) adota essa abordagem. Ambos afirmam que o PDP corresponde ao "processo pelo qual uma organização transforma dados sobre oportunidades de mercado e possibilidades técnicas em bens e informações para a fabricação de um produto comercial". Os autores salientam que a maneira como a empresa realiza o desenvolvimento de produtos - sua velocidade, eficiência, e qualidade do trabalho irá determinar a competitividade do produto.

Neste trabalho, adota-se a definição Rozenfeld et al., (2006, p. 03), que definem o processo de desenvolvimento de produtos como:

[...] o conjunto de atividades por meio das quais busca-se a partir das necessidades do mercado e das possibilidades e restrições tecnológicas, e considerando as estratégias competitivas e de produto da empresa, chegar às especificações de projeto de um produto e de seu processo de produção.

Nas definições apresentadas é destacada a importância de acompanhar o mercado para atender às necessidades dos clientes na fase inicial do processo. Rozenfeld et al. (2006) explicam que os clientes estão cada vez mais exigentes, 
informados e com maiores possibilidades de escolhas no mercado. Assim, as empresas lançam com frequência novos produtos que buscam atender continuamente às mudanças e às necessidades dos clientes. Clark e Wheelwright (1993) enfatizam que as empresas que desenvolvem produtos e conseguem superar as expectativas dos clientes conquistam mercados mais rapidamente e com maior eficiência, criando assim uma significativa alavancagem competitiva.

A visão por processos no PDP significa analisar o desenvolvimento de produto como o conjunto de atividades ordenadas no tempo e com entradas e saídas claramente definidas. De acordo com Amaral (2002), as vantagens da aplicação dessa visão são:

- Tornar clara a relação dentro da organização e entre a organização e o mercado;

- Permitir a identificação de características que influenciam o desempenho deste processo que, muitas vezes, não estão relacionados às clássicas atividades de engenharia;

- Ter uma visão comum a diferentes abordagens tais como reengenharia e sistemas de garantia de qualidade, entre outras, facilitando, portanto, a visão interdisciplinar;

- Permitir a discussão de problemas específicos, sem perder de vista o contexto e as diferentes visões do processo;

- Fazer com que todas as pessoas possam visualizar o que elas fazem juntas e o que realmente agrega valor, ao invés do enfoque nas responsabilidades, hierarquias e funções individuais; e.

- Realçar o aprendizado, pois isso salienta claramente as penalidades decorrentes da falta de coordenação funcional.

A aplicação da visão por processos nas organizações que desenvolvem produtos tem sido um grande desafio. Em primeiro lugar porque as atividades que compõem o PDP envolvem criação muitas vezes em um longo prazo de tempo. Geralmente tem-se pouco conhecimento do resultado final a ser alcançado, tem-se apenas conhecimento de diretrizes gerais de desempenho esperado do produto ou serviço. A criação do produto envolve milhares de pequenas decisões 
interdependentes. Por exemplo: que material escolher, qual o melhor desenho da estrutura, como realizar as atividades de testes e assim por diante. É difícil sistematizá-las previamente a partir de uma regra. A situação torna-se mais crítica se consideramos que o conhecimento tecnológico avança rapidamente, trazendo novas possibilidades de soluções (ROZENFELD ET al., 2006, p.89).

Devido à natureza dinâmica, gerenciar o PDP pode ser considerado como um processo desafiador. Logo uma das formas de minimizar estas dificuldades é a descrição formalizada e integrada do processo, construindo, enfim, um modelo de referência.

\subsubsection{Características específicas do PDP}

O processo de desenvolvimento de produtos possui características específicas, como criatividade, inovação, é considerado interdisciplinar, dinâmico, iterativo e não é linear (BROWNING et al., 2006; JUN; SUH, 2008, p.103). Ao contrário de outros processos de negócio, que procuram obter o mesmo resultado repetidamente, o PDP tem por objetivo criar algo novo e único. As saídas das atividades do PDP não são tão tangíveis e verificáveis como as de outros processos, pois muitas vezes elas consistem apenas em informações (BROWNING et al., 2006; ROZENFELD, $\mathrm{H}$ et al., 2006).

O processo de desenvolvimento de produtos não é tão estruturado, pois cada projeto de desenvolvimento tem as suas particularidades, isto é, onde o tempo de duração e a sequência das atividades são diferentes, conforme as especificidades do projeto (AMARAL, 2002, p.7-8). Cada projeto realiza atividades específicas, pois apresentam problemas e históricos particulares. As atividades do desenvolvimento de produto não são rotineiras, como acontece em outros processos, como nos processos financeiros ou de produção (Rozenfeld et al. 2006,p.06)

Seguem algumas características específicas do PDP quando comparados com outros processos (ROZENFELD et al., 2006, p.06):

- $\quad$ Elevado grau de incertezas e riscos das atividades e resultados; 
- $\quad$ Decisões importantes devem ser tomadas no início do processo, quando as incertezas são ainda maiores;

- $\quad$ Dificuldades de mudar as decisões iniciais;

- Manipulação e geração de alto volume de informações;

- As informações e atividades provêm de diversas fontes e áreas da empresa e da cadeia de suprimentos; e

- $\quad$ Multiplicidade de requisitos a serem atendidos pelo processo, considerando todas as fases do ciclo de vida do produto e seus clientes.

Segundo Amaral (2002, p.7-8), outra característica importante do PDP é o emprego de pessoas com formação e visões muito distintas, oriundas de diferentes áreas do conhecimento e, portanto, geralmente mais afeitas a dar importância a um conjunto específico de fatores: aqueles mais próximos da sua área de formação. Assim, um grande desafio é obter uma visão integrada que é fundamental para aprimorar a colaboração e o compartilhamento dos conhecimentos entre estes diferentes especialistas.

Essas características fazem com que a natureza desse processo seja relativamente diferente dos demais processos da empresa, o que condicionará os modelos e as práticas de gestão adequadas ao processo, além do perfil e da capacitação requeridas dos profissionais que atuam no PDP (ROZENFELD, et al., 2006,p.06).

\subsubsection{Modelo de Referência para o PDP}

Vários modelos foram criados nas últimas décadas contendo regras, diretrizes e procedimentos para o gerenciamento do desenvolvimento de produtos (ENGWALL; KLING; WERR, 2005).

Há um consenso na literatura de que a aderência a um modelo torna a gestão do processo de desenvolvimento de produtos mais eficiente (ENGWALL; KLING; WERR, 2005). 
Um modelo de referência para o PDP é formado por um conjunto de etapas que possuem procedimentos destinados a transformar informações sobre demandas e oportunidades de mercado em especificações técnicas para a fabricação de um novo produto (PAHL, et al., 2005).

Uma das finalidades do modelo de referência do PDP é descrever suas fases, atividades, informações, recursos e outras dimensões do processo (ROZENFELD et al., 2006). Para analisar as disfunções que ocorrem na aplicação do modelo de referência específico para o PDP das empresas é importante conhecer as características desse processo, como suas fases e seus desdobramentos.

Os modelos existentes para o desenvolvimento de produtos envolvem doutrinas e conceitos que representam distintas visões de mundo (SUAREZ, 2009, p.40).

Há diferentes abordagens para idealizar modelos de referência para o processo de desenvolvimento de produto. Alguns deles tentam simplesmente descrever o processo, outros focam no processo de desenvolvimento de produto como um todo. Isto porque, esses últimos se preocupam em descrever com detalhes como cada atividade necessária à criação do novo produto deve ser efetivamente realizada. Enquanto os primeiros, por sua vez, enfatizam a descrição do fluxo lógico de realização do PDP, indicando assim as etapas e as atividades de maneira mais geral e apontando os recursos - como ferramentas, informações, estrutura organizacional - necessários para execução de cada uma delas (FORMOSO, et al., 2002; ALLIPRANDINI; TOLEDO, 2003).

Segundo McCarthy (2006), os modelos iniciais definiam o processo como um sistema linear, com estágios discretos e sequenciais, ao passo que estudos mais recentes consideram que a evolução do processo de desenvolvimento de produto se dá por meio de estágios, mas com sobreposições e loops.

Dentre os modelos de desenvolvimento de produto em fases, podem ser citados os de Clark e Fujimoto (1991), Pahl e Beitz (1996), Cooper (2001), Ulrich e Eppinger (2000), Clark e Wheelwright (1993), Rozenfeld et al. (2006) entre outros.

Pahl e Beitz (1996) propõem um modelo para o processo de desenvolvimento de produtos composto por quatro fases: planejamento e esclarecimento da tarefa, projeto conceitual, projeto preliminar e projeto detalhado. 
A primeira fase é o início do processo com a coleta das informações sobre os requisitos dos consumidores e com a geração das ideias iniciais para o produto. Essa fase termina com a elaboração detalhada da lista de requisitos de projeto. Em seguida, são trabalhadas as informações da fase anterior (especificações de projeto) com o objetivo de obter a concepção do produto. Durante essa fase, são realizadas várias atividades até a seleção da concepção do produto. Posteriormente são selecionados materiais e processos de fabricação, entre outros com o objetivo de concretizar a concepção do produto da fase anterior. E, por fim, na fase do projeto detalhado, a estrutura preliminar do produto é finalizada com todas as especificações técnicas para a produção do mesmo e sua documentação final.

Cooper (2001) divide o PDP em fases, e ao final de cada uma delas existe um processo sistemático de revisão. O modelo proposto por Cooper (2001) foi denominado de Stage-Gates ${ }^{3}$ que consiste nas seguintes etapas: geração da ideia, investigação preliminar, investigação detalhada, desenvolvimento, teste e validação, produção e lançamento e revisão pós-lançamento.

Cada etapa consiste em um conjunto de atividades multifuncionais, que ocorrem simultaneamente e devem ser realizadas e aprovadas gerencialmente antes da passagem para a próxima etapa (COOPER, 2001). A Figura 10 ilustra o processo descrito nesse parágrafo.

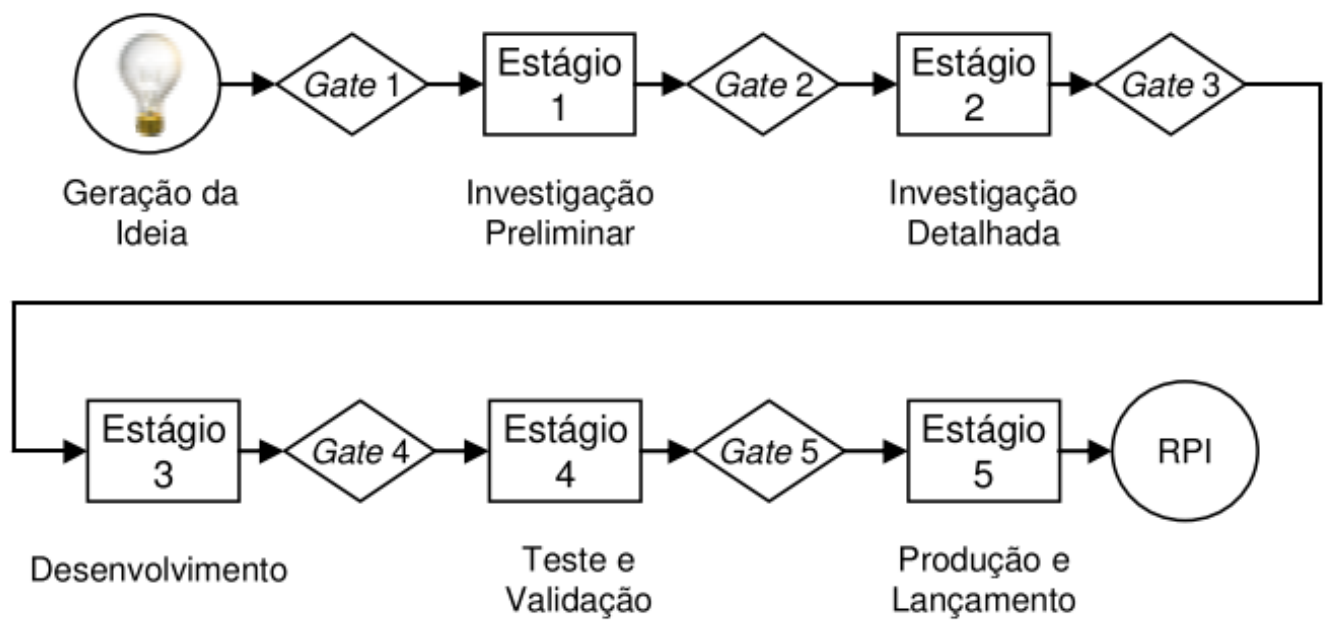

Figura 10 - Modelo de PDP (adaptado de COOPER, 2001).

\footnotetext{
${ }^{3}$ Stage Gates ${ }^{\circledR}$ é uma marca registrada do Product Development Institute Inc. Stage Gates são definidos como pontos do desenvolvimento de produtos nos quais são realizadas revisões de qualidade do produto e do processo de desenvolvimento. Em cada gate, o produto e o processo são avaliados em relação a parâmetros pré-estabelecidos (COOPER, 2001).
} 
Clark e Wheelwright (1993) apresentam as seguintes fases do PDP: desenvolvimento do conceito; planejamento do produto; engenharia do produto/processo; produção piloto e lançamento.

Nas primeiras fases, abrange-se um conjunto de informações fundamentais para desenvolver a arquitetura do novo produto, tais como: oportunidades de mercado, competidores, possibilidades tecnológicas e requisitos de produção. Posteriormente é realizado um detalhamento do projeto e dos processos de fabricação. Na fase de produção piloto, os componentes são produzidos, testados e o produto é montado na fábrica. Por fim, na fase de lançamento, chamada pelos autores de ramp-up, a empresa inicia a fabricação (CLARK; WHEELWRIGHT, 1993).

Rozenfeld et al.,(2006) apresentam o modelo unificado para o processo de desenvolvimento de produto. As fases do PDP deste modelo unificado são divididas em três macrofases: pré-desenvolvimento, desenvolvimento e pós-desenvolvimento, conforme pode ser observado na Figura 11. A seguir será resumidamente explicada cada uma das macrofases.

Este modelo foi desenvolvido a partir de conhecimentos compartilhados por uma parceria entre pesquisadores brasileiros que sintetizou a experiência de três grupos de pesquisa ${ }^{4}$ sobre gestão do desenvolvimento de produtos.

${ }^{4}$ COORDENADAS PELOS PROFESSORES: HENRIQUE ROZENFELD NO NUMA (NÚCLEO DE MANUFATURA INTEGRADA DA USP SÃO Carlos), José Carlos Toledo no GEPEQ (Grupo de Estudo e Pesquisa em Qualidade da UFSCar) e Fernando Antonio Forcellini GEPP (Grupo de Engenharia de Produto e Processo da UFSC). 


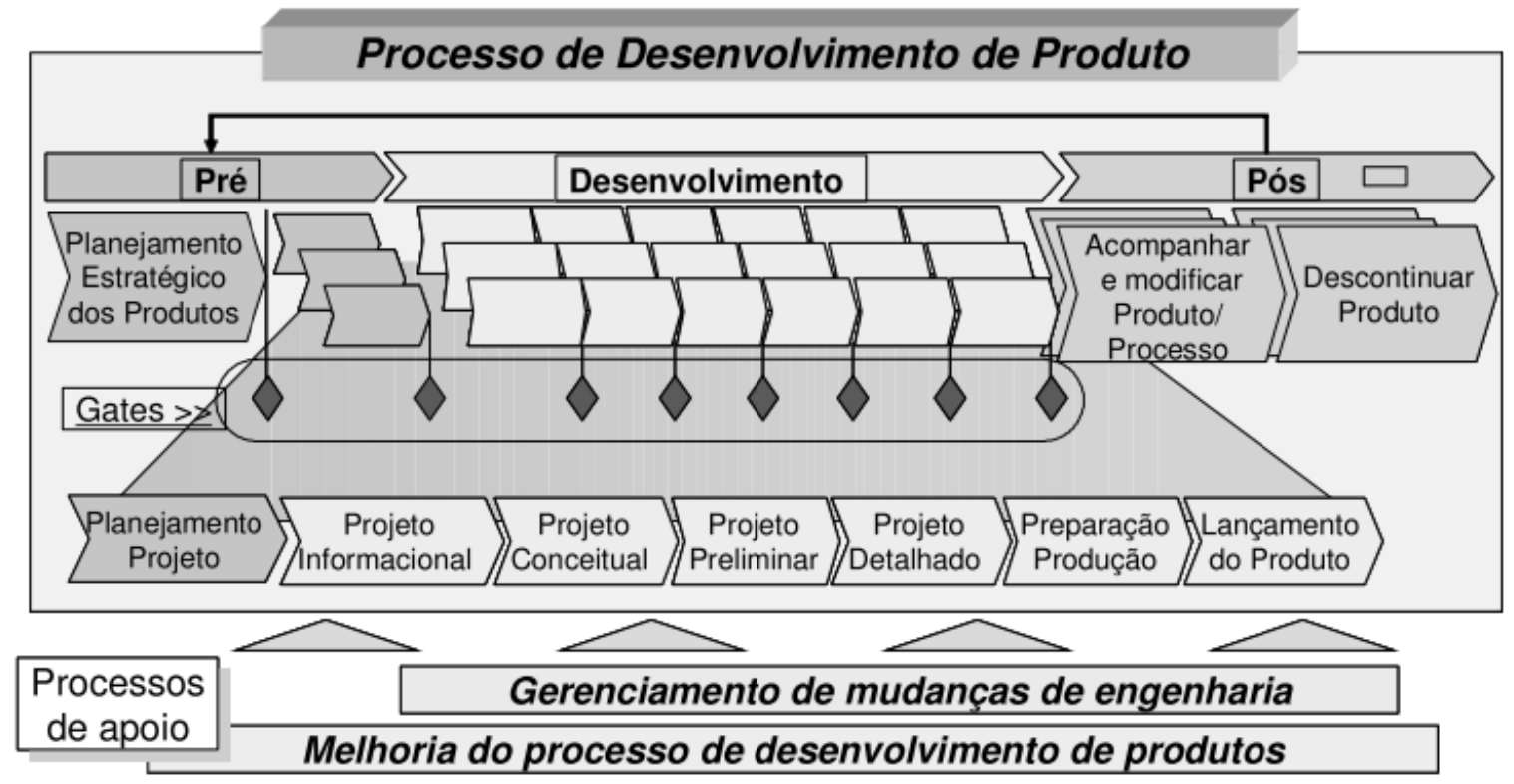

Figura 11 - Modelo de Referência Unificado do PDP (ROZENFELD et al., 2006).

Pré- desenvolvimento: é a ponte entre os objetivos da empresa e os projetos de desenvolvimento. Inicia-se com o planejamento estratégico da corporação e o planejamento estratégico da unidade de negócios. Essa macrofase envolve as atividades de definição do projeto de desenvolvimento, realizadas a partir da estratégia da empresa, delimitação das restrições de recursos e conhecimentos e informações sobre os consumidores e levantamento das tendências tecnológicas e mercadológicas.

Desenvolvimento: inicia após a definição do portfólio de produtos e o planejamento dos projetos. Tipicamente, o desenvolvimento parte das informações geradas pela macrofase de pré-desenvolvimento, e documentadas no plano do projeto. Ao final dessa macrofase, são produzidas informações técnicas detalhadas, de produção e comerciais relacionadas com o produto.

Pós- desenvolvimento: é composta pelas fases de acompanhamento do produto e processo e descontinuação do produto no mercado. Realiza o acompanhamento sistemático e produz a documentação correspondente às melhorias de um produto ao longo de sua fase de uso. Inclui a retirada sistemática do produto do mercado e a avaliação de todo o seu ciclo de vida, para que sirva de referência para desenvolvimentos futuros. 
Segundo Amaral (2008), o modelo de referência proposto por Rozenfeld et al., (2006) procura incorporar as características das propostas anteriores no seu modelo. Além disso, o modelo proposto i) destaca a integração com o planejamento estratégico da empresa juntamente com a gestão de portfólio; ii) integra os conceitos do PMBOK (2002) na fase de planejamento de projeto; iii) define ciclos integrados de detalhamento, aquisição e otimização dos produtos na fase de projeto detalhado; iv) inclui atividades de otimização e validação do processo produtivo e técnicas direcionadas para a ergonomia e meio ambiente; e v) propõe a fase de lançamento de produto integrada, na qual os processos de assistência técnica e vendas são desenhados e implementadas. O modelo proposto está integrado a dois outros processos de apoio: o de gerenciamento das mudanças de engenharia e melhoria do próprio PDP.

Apesar de todos os modelos de processo de desenvolvimento de produto, proposto pelos autores seguirem de fases, na prática as fases do PDP não são desempenhadas sequencialmente. A divisão do processo em etapas é uma simplificação didática. As fases podem ocorrer em paralelo, devido a sua natureza iterativa de gerar alternativas, construir e testar, que estão presentes nas atividades de projeto de um produto. Muitas vezes, essas fases se sobrepõem e interagem continuamente, assim como as pessoas envolvidas. Assim, a divisão em fases, embora ilustrativa, é uma das formas que permite a visualização do processo de desenvolvimento de produto (ZANCUL 2000; MUNDIM et al., 2002, p.03).

Nas primeiras fases do processo de desenvolvimento de produto, ocorrem as decisões de maior impacto e, ao mesmo tempo, existe um maior grau de incerteza. Isso ocorre devido às próprias características do PDP, tais como: basear-se num ciclo projetar, construir e testar - atividades essencialmente multidisciplinares e interativas; existência de uma quantidade grande de ferramentas, sistemas, metodologias desenvolvidas por profissionais/empresas de diferentes áreas, as quais não 'conversam' entre si e a consequente existência de visões parciais sobre o processo (MUNDIM et al., 2002, p.03).

No âmbito estratégico, as fases do PDP estão relacionadas com o alinhamento dos projetos de desenvolvimento com a estratégia do negócio, maximização do valor do portfólio de projetos levando em consideração os recursos disponíveis e o balanceamento entre projetos sob diversos critérios (CHENG, 2000, p.04). Contudo, 
no âmbito operacional, as fases estão relacionadas com um projeto específico de desenvolvimento de produto. Convém destacar que cada projeto de desenvolvimento é diferente dos outros, na medida em que pode apresentar dificuldades, problemas e históricos muito particulares. Assim, as fases, as atividades e/ou as tarefas podem ser alteradas, adaptando-as de acordo com o tipo de projeto do novo produto a ser desenvolvido (ONOYAMA, 2011, p.02). 


\title{
3 MÉTODO DE PESQUISA
}

\author{
Não há ciência sem o emprego de \\ métodos científicos (LAKATOS; \\ MARKONI, 1991, p.83).
}

A definição dos métodos e técnicas de pesquisa científica são importantes, pois descrevem como a pesquisa foi realizada, qual o objetivo e o tipo de pesquisa. Nas seções seguintes a pesquisa científica é caracterizada de acordo com as classificações apresentadas na literatura.

Descreve-se também, à luz desses conceitos, a metodologia de pesquisa e a justificativa para a escolha dos métodos.

\subsection{Caracterização da Pesquisa}

A pesquisa científica pode ser classificada em estudos como exploratórios, descritivos, correlacionais e explicativos. Esta classificação é importante, pois a estratégia de pesquisa depende do tipo de estudo (SAMPIERI, et al.,2006, p.98). Assim, este trabalho pode ser classificado como um estudo descritivo, pois procura organizar, compilar um conhecimento a fim de facilitar futuras aplicações.

A pesquisa descritiva tem como objetivo primordial a descrição das características de determinada população ou fenômeno. São inúmeros estudos que podem ser classificados sob este título, e uma de suas características mais significativas está na utilização de técnicas padronizadas de coleta de dados, tais como questionário (GIL, 1996, p.46).

Quanto à abordagem, as pesquisas científicas podem ser classificadas como quantitativas e qualitativas. Em relação a este critério, a abordagem desta pesquisa pode ser classificada como sendo qualitativa. A abordagem qualitativa está relacionada com interpretação e percepção, ao invés de identificação de uma verdade racional e objetiva. Reconhece-se e leva-se em consideração o significado 
de interpretação, percepção e interação no processo de definição, coleta e análise de evidências de investigação (KARLSSON, 2008, p.66-67).

A pesquisa qualitativa dá profundidade aos dados e também oferece um ponto de vista holístico dos fenômenos, assim como flexibilidade (SAMPIERI, et al. 2006, p.15).

Os métodos da pesquisa científica podem ser classificados em diferentes maneiras: pesquisa bibliográfica, pesquisa documental, levantamento tipo survey, pesquisa experimental, estudo de caso, pesquisa ex-post-facto, pesquisa-ação e pesquisa participante (GIL, 1991, p.48).

Como método de pesquisa, foram utilizados dois métodos neste trabalho: revisão bibliográfica para realizar o levantamento das disfunções encontradas na literatura. E o estudo de caso para verificar se essas disfunções são confirmadas na prática, ou seja, se estão presentes na realidade das empresas selecionadas e para possibilitar o levantamento de outras possíveis disfunções.

A revisão bibliográfica é usada para o estudo do estado da arte do tema abordado. Assim é preciso definir o escopo de interesse, as palavras-chave de busca e as fontes a serem utilizadas. As principais fontes consideradas nesta pesquisa foram teses, livros, revistas e congressos acadêmicos e bases de dados, como Web of Science, Scopus e ScienceDirect.

O estudo de caso como estratégia de pesquisa compreende um método que abrange, desde a lógica do planejamento, das técnicas das coletas de dados, das abordagens específicas até a análise dos mesmos (YIN, 2005, p.33). O estudo de caso é uma pesquisa empírica que investiga um fenômeno contemporâneo dentro de seu contexto da vida real, especialmente quando os limites entre o fenômeno e o contexto não estão claramente definidos (YIN, 2005, p.32).

De acordo com Yin (2005), o aspecto diferenciador do estudo de caso reside em sua capacidade de lidar com uma ampla variedade de evidências-documentos, artefatos, entrevistas e observações.

A pesquisa do estudo de caso inclui tanto estudo de caso único quanto de casos múltiplos (YIN, 2005, p.68). Neste trabalho, foi utilizada a pesquisa de caso único. 
O critério de seleção para realizar o estudo de caso nas duas empresas selecionadas, se justifica pelo nível de maturidade que elas se encontram e por possuírem o modelo de referência consolidado em seu processo de desenvolvimento de produto.

Para finalizar esta seção a Tabela 2 sumariza a caracterização deste trabalho quanto aos fins, sua abordagem e, por fim, quanto aos meios de pesquisa.

Tabela 2 - Caracterização da pesquisa

\begin{tabular}{ccc}
\hline Abordagem & Quanto aos fins & Quanto aos meios \\
\hline Qualitativa & Estudo Descritivo & Revisão Bibliográfica \\
& & Estudo de Caso \\
\hline
\end{tabular}

\subsection{Etapas de Pesquisa}

Essa seção apresenta os procedimentos de condução da pesquisa por meio das etapas de pesquisa que são descritas a seguir.

A dissertação está dividida em 3 etapas de pesquisa: Revisão Bibliográfica, Planejamento e Condução do Estudo de Caso e Descrição e Análise dos Resultados, conforme apresentado na Figura 12. 


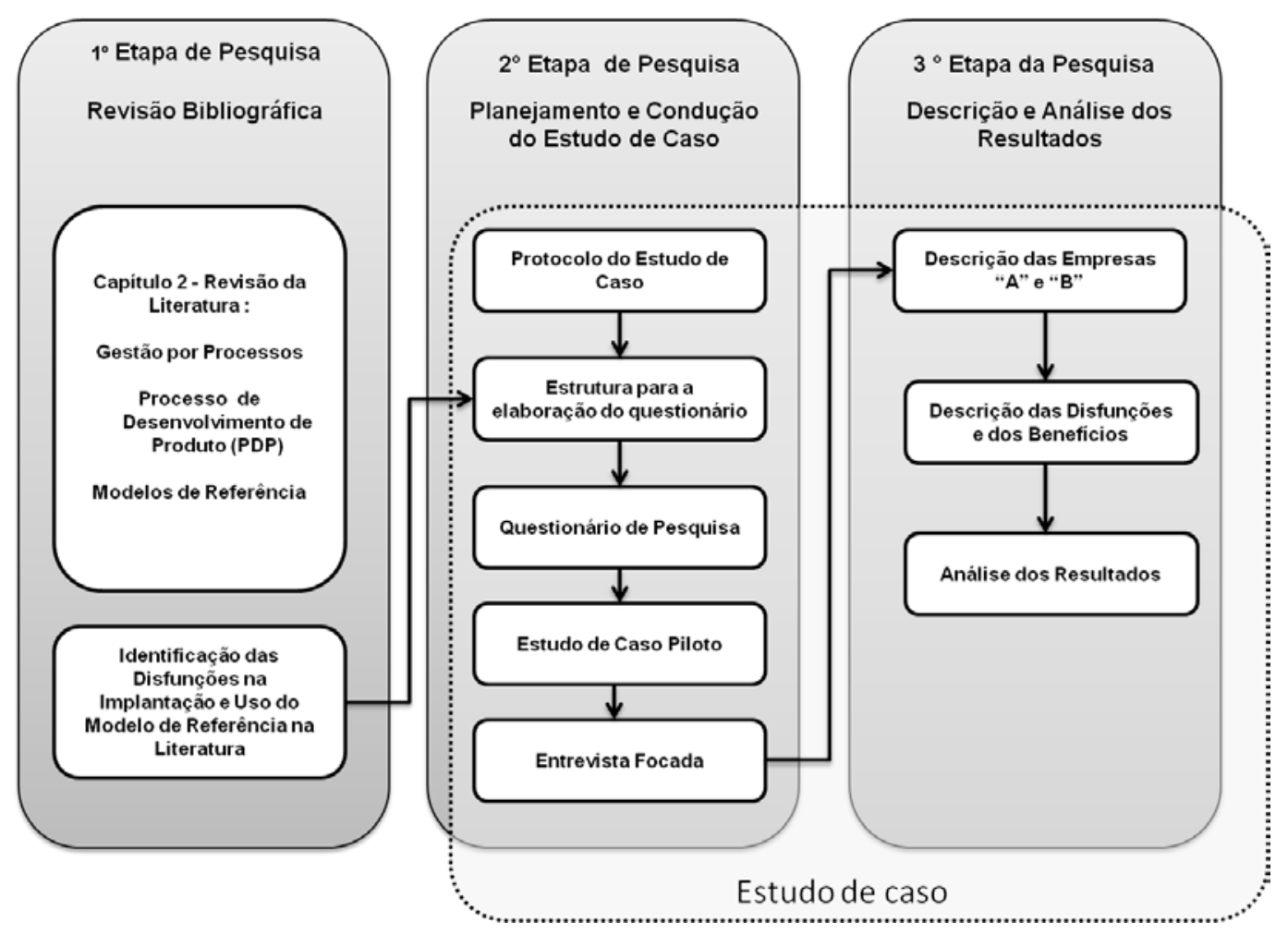

Figura 12 - Etapas de Pesquisa (elaborada pela autora).

$1^{\circ}$ Etapa de Pesquisa - "Revisão Bibliográfica" possui a finalidade de:

- Identificar as disfunções na implantação e uso do modelo de referência específico na literatura; e.

- $\quad$ Contribuir parcialmente em responder à questão de pesquisa apresentada no trabalho com as disfunções encontradas na literatura.

$2^{\circ}$ Etapa de Pesquisa - "Planejamento e Condução do Estudo de Caso" possui a finalidade de:

- Identificar novas disfunções no estudo de caso; e.

- Confirmar se as disfunções encontradas na literatura estão presentes ou não na realidade das empresas selecionadas.

$3^{\circ}$ Etapa de Pesquisa - "Descrição e Análise dos Resultados" possui a finalidade de:

- $\quad$ Descrever as empresas "A" e "B";

- Descrever as Disfunções e os Benefícios. 
- $\quad$ Analisar os resultados e concluir

Nas subseções seguintes, descreve-se como cada etapa, foi realizada. Os resultados são apresentados no capítulo 4.

\subsection{1 $1^{\circ}$ Etapa de Pesquisa - Revisão Bibliográfica}

A revisão bibliográfica deste trabalho considerou artigos de periódicos, anais de congressos, livros e base de dados (Scopus, Web of science e ScienceDirect). As buscas foram feitas nas bases de dados por meio das seguintes palavras-chave apresentadas na Tabela 3.

Tabela 3 - Palavras-chave para a busca nas bases de dados

\begin{tabular}{|c|c|c|}
\hline Tema & Palavra-Chave em inglês & Palavra-Chave em Português \\
\hline Modelo de Referência & $\begin{array}{c}\text { Reference model, Reference } \\
\text { modeling, Reference process, } \\
\text { Process model }\end{array}$ & $\begin{array}{l}\text { Modelo de Referência, Modelo } \\
\text { de processo, Processo padrão. }\end{array}$ \\
\hline $\begin{array}{l}\text { Processo de desenvolvimento } \\
\text { de produto }\end{array}$ & $\begin{array}{l}\text { New product development } \\
\text { (NPD), Product development } \\
\text { process }\end{array}$ & $\begin{array}{l}\text { Desenvolvimento de novos } \\
\text { produtos, Processo de } \\
\text { desenvolvimento de produto } \\
\text { (PDP). }\end{array}$ \\
\hline Processo de negócio & Business Process & Processo de negócio \\
\hline Gestão por processos & Business process management & $\begin{array}{c}\text { Gestão de processos de } \\
\text { negócios }\end{array}$ \\
\hline
\end{tabular}

Posteriormente foram elaboradas as strings de pesquisa, baseadas no padrão proposto pela ISI Web of Science, e pela SciVerse Scopus. As palavras definidas nos grupos foram conectadas por operadores lógicos "AND", "OR", conforme o padrão indicado para buscas booleanas. A busca foi realizada considerando os campos "título", "resumo" e "palavras-chave". As strings definitivas estão descritas na Tabela 4. 
Tabela 4 - Strings para a busca nas bases de dados

TITLE-ABS-KEY-AUTH((problem OR shortcoming OR dysfunction OR

Busca 1 defect OR deficiency OR deficiencies OR issue) AND ("product development process" OR "new product development" OR "reference Scopus model" OR "process model" OR "reference modeling" OR "reference process"))

$T S=($ problem $O R$ shortcoming $O R$ dysfunction $O R$ defect $O R$ Busca 2 deficiency OR issue ) AND TS=("product development process" OR "new product development" OR "reference model" OR "process model" Web of Science $O R$ "reference process" OR "reference modeling")

Os resultados desta etapa são apresentados no capítulo 2, desde a seção 2.1 até a seção 2.3. A lista de disfunções e benefícios encontradas na pesquisa bibliográfica estão nos apêndices 4 e 5, respectivamente.

\subsection{2 $2^{\circ}$ Etapa de Pesquisa - Planejamento e Condução do Estudo de Caso}

Segundo Yin (2005, p.81), a realização de um estudo de caso começa com a definição do problema de pesquisa a ser estudado para posteriormente realizar a preparação para a coleta de dados deste tipo de estudo. O autor propõe cinco tópicos para essa preparação para a coleta de dados do estudo de caso: 1) habilidades prévias por parte do pesquisador; 2) treinamento; 3) desenvolvimento de um protocolo de estudo de caso; 4) triagem dos possíveis estudos de casos e 5) condução do estudo de caso. Neste trabalho foi utilizada a preparação de coleta de dados proposta por Yin (2005), porém adaptada conforme descrita na Tabela 5. 
Tabela 5 - Preparação para a Coleta de Dados (YIN, 2005).

\begin{tabular}{c}
\hline Preparação para a coleta de dados \\
\hline Protocolo do estudo de caso \\
Procedimento para Elaboração do Questionário \\
Questionário de pesquisa \\
Estudo de caso piloto \\
Entrevista Focada
\end{tabular}

A elaboração do protocolo é o ponto de partida para o estudo de caso, pois ele vai delinear o estudo, ou seja, guiar todo o processo de coleta de dados. O protocolo é uma das táticas principais para aumentar a confiabilidade da pesquisa (YIN, 2005 p.92-103). O protocolo do estudo de caso proposto por Yin (2005) apresenta quatro seções: 1) visão geral do projeto do estudo de caso; 2) procedimentos de campo; 3) questões do estudo de caso; e 4) guia para o relatório do estudo de caso.

Com base no protocolo proposto por Yin (2005), foi elaborado o protocolo de estudo de caso deste trabalho que contém as seguintes seções: visão geral do projeto e procedimentos de campo que são descritas a seguir nas Tabela 6 e Tabela 7 , respectivamente.

Tabela 6 - Protocolo do Estudo de Caso- visão geral do projeto (YIN, 2005).

\section{Visão Geral do Projeto}

Objetivo da Pesquisa; Analisar as disfunções que ocorrem na implantação e uso de modelos de referência no PDP.

Objetivo do Estudo de Caso: Identificar as experiências das empresas em relação à implantação e ao uso do modelo de referência específico no processo de desenvolvimento de produtos, verificando quais as expectativas desde a implantação até a situação atual em que ela se encontra, constatando os principais problemas e verificar se atingiu o objetivo proposto. 
Tabela 7 Protocolo do Estudo de Caso - procedimento de campo (YIN, 2005).

\section{Procedimento de Campo}

Empresas/setor: Os estudos de casos devem ocorrer em empresas desenvolvedoras de produtos de qualquer setor, cuja área de desenvolvimento esteja localizada no Brasil.

Unidade de análise: A unidade de análise são empresas que possui o modelo de referência específico no seu processo de desenvolvimento de produto.

Entrevistados: Serão selecionados para a entrevista os responsáveis pelo processo de desenvolvimento de produto da empresa.

Fontes de evidência: Entrevistas.

Tipo de questionário: Questionário aberto e fechado

Tempo previsto: As entrevistas foram previstas para durar no máximo 1 hora.

Após a criação do protocolo foi desenvolvido uma estrutura para a elaboração do questionário (APÊNDICE 2) que é composto pelas seguintes etapas: objetivo principal da pesquisa, objetivos específicos, desdobramentos dos objetivos, características, variáveis e, por fim, as questões de pesquisa.

Além da estrutura para a elaboração do questionário, a lista das disfunções encontradas na literatura (APÊNDICE 4) foi fundamental para a criação dessas questões de pesquisa. O questionário de pesquisa (APÊNDICE 3) contém 24 questões e está organizado em 3 partes:

\section{Parte I- Dados Gerais}

Parte II- Questões de pesquisa

Parte III- Disfunções e Benefícios

A parte II do questionário corresponde às questões abertas e a parte III as questões fechadas. O questionário teve como objetivo analisar a experiência das empresas durante a implantação e uso de um modelo de referência específico no processo do desenvolvimento de produtos (PDP) e compreender as disfunções encontradas na literatura. 
Após a finalização do questionário, foi realizado o teste piloto com os alunos da pós-graduação do Grupo El2 - Engenharia Integrada e de Integração da Escola Engenharia de São Carlos EESC /USP São Carlos, com a finalidade de aprimorar a coleta de dados e os procedimentos que devem ser seguidos. Além de ajudar a desenvolver o alinhamento relevante das questões, providenciando algumas elucidações conceituais. Posteriormente ao teste piloto, foram realizadas as entrevistas com o auxílio do questionário de pesquisa.

Segundo Yin (2005, p.116), as entrevistas são as mais importantes fontes de informações para um estudo de caso. O autor apresenta três tipos de entrevista: entrevista espontânea, entrevista focada e entrevista sob a forma de um levantamento formal. Neste estudo, optou-se por uma entrevista focada, que permite que muitos detalhes fossem explorados além do roteiro. Segundo Yin (2005, p.117118), na entrevista focada, o respondente é entrevistado por um curto período de tempo. Nesses casos, as entrevistas ainda são espontâneas e assumem o caráter de uma conversa informal, mas provavelmente o pesquisador estará seguindo um conjunto de perguntas que se originam do protocolo do estudo de caso.

As entrevistas aconteceram no mês de janeiro de 2013. Todas as entrevistas foram gravadas e duraram aproximadamente 1 hora. Quando pertinente, o pesquisador considerou discutir outros pontos levantados pelos entrevistados.

Na Tabela 8 e na Tabela 9 estão descritos os entrevistados das empresas "A" e "B" respectivamente.

Tabela 8 - Descrição dos entrevistados da empresa "A"

\begin{tabular}{ccc}
\hline Entrevistados & Função & Tempo de Função \\
\hline Entrevistado 1 & $\begin{array}{c}\text { Gerente de Projetos } \\
\text { Planejadora Sênior de } \\
\text { projetos }\end{array}$ & 06 meses \\
Entrevistado 2 & $\begin{array}{c}\text { Gestor de projetos } \\
\text { Sênior }\end{array}$ & 1 ano \\
Entrevistado 3 & $\begin{array}{c}\text { Coordenador de } \\
\text { Projetos }\end{array}$ & 07 meses \\
Entrevistado4 & . \\
\hline
\end{tabular}


Vale ressaltar que na empresa "A" todos os entrevistados são novos na função, mas não são novos na empresa, exceto o entrevistado 1 que foi recém contratado.

Tabela 9 - Descrição dos entrevistados da empresa "B"

\begin{tabular}{|c|c|c|}
\hline Entrevistados & Função & Tempo de Função \\
\hline Entrevistado 1 & $\begin{array}{c}\text { Supervisor de gestão } \\
\text { de projetos }\end{array}$ & 4 anos \\
\hline Entrevistado 2 & $\begin{array}{l}\text { Gerente Global de } \\
\text { produtos }\end{array}$ & 5 anos \\
\hline & Supervisor de & \\
\hline Entrevistado 3 & $\begin{array}{c}\text { Pesquisa e } \\
\text { Desenvolvimento }\end{array}$ & 10 anos \\
\hline Entrevistado4 & Diretor de Engenharia & 5 anos \\
\hline
\end{tabular}

Durante as entrevistas houve também, uma análise dos documentos das empresas que incluem documentos internos descritivos dos produtos, apresentações institucionais, catálogos de produtos e documentos descritivos de processos. Esses documentos auxiliam na elaboração da descrição da empresa, do processo e dos produtos produzidos.

O uso desses instrumentos na investigação do estudo de caso aumenta substancialmente a sua qualidade. Esses instrumentos podem ser utilizados isoladamente ou pode ser combinado, o que garante uma maior precisão e riqueza dos dados (YIN, 2005, p.109).

Os resultados desta etapa são apresentados detalhadamente no capítulo 4.

\subsection{3 $3^{\circ}$ Etapa de Pesquisa - Descrição e Análise dos Resultados}

Esta seção corresponde à terceira etapa de pesquisa, constituindo assim:

- Descrição das empresas "A" e "B"; 
- Descrição das Disfunções e dos Benefícios.

- Analisar os resultados e concluir

Para realizar a descrição das empresas "A" e "B, são utilizados os dados obtidos das respostas das questões abertas (questões 1 a 22) da parte II do questionário de pesquisa (APÊNDICE 3) para ter uma melhor compreensão do processo de implantação e uso do modelo de referência específico nessas empresas.

Posteriormente à descrição das empresas "A" e "B", foi realizada a descrição das disfunções e benefícios referentes às questões fechadas (questões 23 e 24), respectivamente, da parte III do questionário de pesquisa (APÊNDICE 3).

$\mathrm{Na}$ descrição das disfunções e benefícios, calculam-se inicialmente a média de acordo com as respostas assinaladas pelos entrevistados (APÊNDICES 5 e 6) utilizando a seguinte escala de respostas proposto no questionário de pesquisa, conforme apresentado na Tabela 10.

Tabela 10 - Escala de respostas

\begin{tabular}{ccccc} 
Não sei & $\begin{array}{c}\text { Discordo } \\
\text { Totalmente }\end{array}$ & $\begin{array}{c}\text { Discordo } \\
\text { Parcialmente }\end{array}$ & $\begin{array}{c}\text { Concordo } \\
\text { Parcialmente }\end{array}$ & $\begin{array}{c}\text { Concordo } \\
\text { Totalmente }\end{array}$ \\
\hline 0 & 1 & 2 & 3 & 4 \\
\hline
\end{tabular}

A escala de respostas proposta no questionário de pesquisa foi elaborada, porém adaptada com base na escala likert ou escala somadas, criada por Rensis Likert em 1932. A Escala Likert é um tipo de escala de resposta usada comumente em questionários. É a escala mais usada em pesquisas de opinião, pois diz respeito a uma série de afirmações relacionadas com o objeto pesquisado, isto é, representam várias assertivas sobre um assunto. Nesta pesquisa, optou-se pela escala de 4 pontos entre dois extremos, onde o entrevistado deve-se posicionar em relação às disfunções e aos benefícios apresentados.

A fim de identificar se as disfunções e os benefícios estão presentes ou não nas empresas de acordo com as perspectivas dos entrevistados, foram propostas as seguintes classes para os valores da média conforme apresentado na Tabela 11. 
Tabela 11 - Classe para os valores da média

\begin{tabular}{c}
\hline Classe para os valores das médias \\
\hline $1,0-1,75=$ discordam totalmente \\
$1,75-2,5=$ discordam parcialmente \\
$2,5-3,25=$ concordam parcialmente \\
$3,25-4,0=$ concordam totalmente \\
\hline
\end{tabular}

Em seguida são calculados o índice de concordância das disfunções e benefícios referentes às questões fechadas (questões 23 e 24). Segundo James, Damaree e Wolf (1984, p.86), o índice de concordância refere-se ao grau de alinhamento e à similaridade entre as respostas dos usuários para determinar se eles concordam ou não entre si, ou seja, se há ou não consenso entre eles em relação a uma dada resposta. Pode variar entre zero e um: quanto mais próximo de um, mais forte é o índice de concordância, ou seja, mais homogêneas são as opiniões dos respondentes. Para esta pesquisa, o valor 0,7 é considerado como mínimo para concluir que houve concordância entre os entrevistados.

O índice de concordância $I C$, onde $i$ designa cada nota dos respondes $(i=$ $1, \ldots, i)$, é calculado de acordo com a equação a seguir:

$$
I C_{i}=1-\left(D P_{i}^{2} / \sigma_{i}^{2}\right) \text { (Equação 1) }
$$

Onde DP é o desvio padrão observado das notas atribuídas pelos respondentes, enquanto que $\sigma_{i}^{2}$ é a variância esperada devido ao erro aleatório. Assumindo que as notas atribuídas a cada uma das questões formuladas possuem uma distribuição uniforme, ou seja, as notas apresentam a mesma probabilidade de ocorrência, a variância é calculada de acordo com a seguinte equação (JAMES, DEMAREE, WOLF, 1984, p.86):

$$
\sigma^{2}=\left(A^{2}-1\right) / 12 \text { (Equação 2) }
$$

Onde $A$ corresponde ao número de alternativas de resposta para cada questão, com números discretos. Os estudos concluem que o valor de 7 acrescido ou decrescido de 2 para A é o mais eficiente para gerar valores melhores de 
variância (JAMES, DEMAREE, WOLF, 1984, p.87). No caso do presente questionário, o valor de $A$ é de 4.

Para a aplicação do índice de concordância, James, Demaree e Wolf (1993, p.308), discutem três suposições que necessitam atenção do pesquisador. A primeira consiste no fato de que o índice não deve ser usado em equações que necessitam estimativas de confiabilidade. A segunda suposição sugere que o índice de concordância é melhor utilizado em situações onde os respondentes interpretam a escala de notas de maneira similar. Por fim, a terceira suposição refere-se ao fato de que o real comportamento do índice de concordância é uma questão empírica que será mais bem entendida no futuro quando mais dados empíricos tiverem sido acumulados.

Na análise do índice de concordância proposto por James, Demaree e Wolf, os autores não admitem valores negativos. No entanto, ao se utilizar a escala proposta no questionário de pesquisa, de quatro níveis, a fórmula de cálculo admite valores negativos para o índice de concordância. Assim para complementar e com a finalidade de analisar a dispersão dos dados, é calculado, também, o coeficiente de variação(CV) das disfunções e benefícios. O coeficiente de variação é uma medida de dispersão utilizada para comparação de distribuições diferentes; é igual ao desvio padrão,divido pela média, ou seja:

$$
\mathrm{CV}=\frac{D P_{i}}{\overline{X_{l}}}
$$

Onde, $D P_{i}$ é o desvio padrão observado das notas atribuídas pelos respondentes, enquanto que $\bar{X}_{l}$ é a média dos dados obtidos no questionário de pesquisa.

O coeficiente de variação permite comparações entre variáveis de naturezas distintas e fornece uma ideia de precisão dos dados. A princípio considera-se quanto menor for o CV,mais homogêneos são os dados.

Calculados a média o índice de concordância e o coeficiente de variação, realize-se a discussão de cada disfunção e o benefício de ambas as empresas. Para realizar a discussão, foram estruturados quatro grupos, todos apresentados a seguir na Tabela 12. 
Tabela 12 - Descrição dos Grupos

\begin{tabular}{|c|c|}
\hline Grupos & Descrição \\
\hline $\begin{array}{c}\text { Grupo } 1 \\
\text { Discordam Totalmente e Índice de Concordância } \\
\text { Alto }\end{array}$ & $\begin{array}{l}\text { O grupo } 1 \text { representa as disfunções e os } \\
\text { benefícios não confirmados que os entrevistados } \\
\text { obtiveram consenso nas respostas do } \\
\text { questionário. }\end{array}$ \\
\hline $\begin{array}{c}\text { Grupo } 2 \\
\text { Discordam e Concordam Parcialmente e Índice } \\
\text { de Concordância Alto }\end{array}$ & $\begin{array}{l}\text { O grupo } 2 \text { representa as disfunções e os } \\
\text { benefícios confirmados em algum momento nas } \\
\text { empresas que os entrevistados obtiveram } \\
\text { consenso nas respostas do questionário. }\end{array}$ \\
\hline $\begin{array}{c}\text { Grupo } 3 \\
\text { Concordam Totalmente e Índice de Concordância } \\
\text { Alto }\end{array}$ & $\begin{array}{l}\text { O grupo } 3 \text { representa as disfunções e os } \\
\text { benefícios confirmados que os entrevistados } \\
\text { obtiveram consenso nas respostas do } \\
\text { questionário. }\end{array}$ \\
\hline \multicolumn{2}{|l|}{ Grupo 4} \\
\hline Concordam Totalmente & \\
\hline $\begin{array}{l}\text { Concordam Parcialmente } \\
\text { Discordam Parcialmente } \\
\text { Discordam Totalmente } \\
\text { Índice de Concordância Baixo }\end{array}$ & $\begin{array}{l}\text { O grupo } 4 \text { representa as disfunções e os } \\
\text { benefícios que não obtiveram consenso entre os } \\
\text { entrevistados nas respostas do questionário. }\end{array}$ \\
\hline
\end{tabular}

Os grupos foram estruturados por meio da média e do índice de concordância. A média mostra se a disfunções e os benefícios são ou não confirmados nas empresas, enquanto o índice de concordância mostra se os entrevistados possuíram ou não o consenso nas respostas do questionário de pesquisa.

A discussão é baseada também nas questões abertas (questões 1 a 22) parte II do questionário de pesquisa (APÊNDICE 3), que, por meio da entrevista focada, permitiu que muitos detalhes e observações adicionais comentados pelos entrevistados fossem explorados, além do roteiro de pesquisa. 
Para a realização da análise dos resultados inicialmente, foram identificadas as disfunções e os benefícios comuns entre os grupos estabelecidos em ambas as empresas e que obtiveram consenso entre os entrevistados. Posteriormente, foram analisadas as inconsistências das respostas assinaladas dos entrevistados, ou seja, a contradição das respostas entre a presença das disfunções e dos benefícios que são explicadas na seção 4.3 .3 no capítulo 4 deste trabalho. 


\section{RESULTADOS E ANÁLISES}

Este capítulo está relacionado com a $3^{\circ}$ etapa de pesquisa - "Descrição e Análise dos Resultados" que constitui:

- Descrição das empresas "A" e "B";

- Descrição das disfunções e dos benefícios.

- Analisar os resultados e concluir

Os dados obtidos resultaram das respostas ao questionário de pesquisa (APÊNDICE 3) por meio da entrevista focada das questões abertas e questões fechadas, parte II e III do questionário respectivamente.

\subsection{Descrição das empresas "A" $e$ "B"}

Esta seção apresenta a descrição das empresas "A" e "B" e está relacionada com a terceira etapa de pesquisa. Para realizar a descrição de ambas as empresas, foram utilizados os dados obtidos das respostas das questões abertas (questões $1 \mathrm{a}$ 22) do questionário de pesquisa (APÊNDICE 3).

\subsubsection{Descrição do estudo de caso - Empresa A}

A empresa " $A$ " é uma multinacional reconhecida no mercado pela diversidade de seus produtos, pois comercializa para 175 países, desde produtos farmacêuticos e médicos hospitalares até para o uso direto do consumidor.

É uma empresa de referência em áreas como pesquisa e desenvolvimento, manufatura e engenharia. Para atuar com eficiência em todos os segmentos, a empresa mantém uma gestão descentralizada, que reúne três grandes linhas de negócio: 1) foco em produtos de bens de consumo organizados em várias franquias; 2) foco no setor farmacêutico; e 3) foco em inovação, que concentra seus esforços e investimentos na pesquisa, fabricação e comercialização de soluções em 
dispositivos médico-hospitalares, tanto para diagnósticos quanto para cirurgias e tratamentos.

A empresa possui implantado no seu processo de desenvolvimento de produtos um modelo de referência específico que decorreu do modelo de referência da matriz. Este modelo de referência especifico é direcionado somente aos novos produtos de lançamento da empresa. A matriz apresentou o modelo de referência e a empresa teve alguns meses para estudar e avaliar propostas e realizar adaptações necessárias para estar de acordo com a realidade local. Na implantação ocorreram alterações, porém foram sutis como: uniformização da nomenclatura de todos os processos e ainda algumas atividades foram adicionadas devido às particularidades da organização. Assim, de acordo com o entrevistado 3,

Hoje o processo idealizado é o mesmo para todas as regiões. Quando eu converso com um gestor da Europa sobre os processos, atividades, ele entende o que eu estou falando. Claro, que existem diferenças, pois cada país tem suas especificidades, parte regulatória e fabril, mas o processo desenhado é o mesmo para todas as regiões do planeta em que a empresa atua.

O modelo de referência existe na matriz há mais de 15 anos. Na América Latina, o modelo de referência específico foi implantado no ano de 2005. A finalidade da implantação do modelo de referência em todas as filiais era deixar o processo mais robusto e uniforme. Antes da implantação, a matriz fez um grande estudo para ver se a empresa estava alinhada com o mercado e com seu planejamento estratégico para os próximos anos.

Durante a implantação houve interação entre todas as pessoas envolvidas no processo de desenvolvimento de produto da empresa (P\&D, marketing, manufatura e distribuição e embalagem), e principalmente com o escritório de processos que, em 2006, foi criado para ajudar na melhor execução da implantação.

A implantação do modelo de referência inicialmente causou certo desconforto em todos envolvidos no PDP, pois gerou uma burocracia maior nos projetos. Os Stage Gates, as datas e as participações nas reuniões passaram a ser mais rígidas. O entrevistado 3 explica que: "antes as coisas aconteciam por e-mail, fóruns informais, que teoricamente andavam mais rápido, com o modelo de referência 
tivemos que esperar 15 dias para ter a próxima reunião para fazer a aprovação de um projeto".

A solução para esses problemas iniciais foram as reuniões quinzenais com todas as áreas que participam do PDP a fim de esclarecer o propósito do modelo de referência específico na empresa. O entrevistado 3 conclui:

Inicialmente você pode não enxergar as melhorias, pois as pessoas
reclamavam de preencher os documentos padrões e argumentavam que o
tempo de implantação do projeto aumentou, mas tem que considerar o
contexto como um todo, pois com a robustez do processo, você consegue
diminuir, minimizar e mitigar os problemas que você tinha antes.

O mesmo entrevistado ainda completa: "Com o processo estruturado você consegue ganhar tempo e alocação de recursos. Quando você trabalha de forma desorganizada, você não está alocando as pessoas, e elas não estão trabalhando no seu potencial total."

Com o processo estruturado há uma melhor priorização dos projetos. Sendo assim, em vez de trabalhar em dois projetos simultaneamente com desvantagem de tempo do lançamento do produto em relação aos concorrentes, a empresa prioriza um único projeto para ser lançado no mercado.

Atualmente, não há um treinamento sobre o modelo de referência específico na prática de admissão de funcionários da empresa. Há um treinamento específico para as pessoas que vão trabalhar na área de lançamento de novos produtos. Neste caso, cada gestor é responsável por explicar o que é o gerenciamento de projeto e como se caracterizam os processos que compõem o modelo de referência. Esses treinamentos são reuniões agendadas pelos próprios gestores. O entrevistado 3 enfatiza que o entendimento é de forma lenta, que demora cerca de 2 a 3 meses para o novo funcionário entender e começar a realizar as entregas de fato. Quanto à utilidade desses treinamentos, os quatro entrevistados concordam ser útil no primeiro momento da pessoa na empresa, mas ressaltam que a verdadeira aprendizagem dos processos como um todo ocorre no dia a dia.

Atualmente há um grupo de gestores do escritório de processos que estão com uma iniciativa de fazer vídeo-aulas, pois possibilitaria alguns benefícios, como por exemplo: só agendaria uma reunião para dúvidas pontuais, não teria mais o problema de a pessoa ingressar na empresa após o treinamento oferecido pelos gestores, pois os treinamentos são gravados, além de renovar o conhecimento para 
as demais áreas da empresa. O entrevistado 3 acredita que "a intenção da vídeoaula não é entrar no detalhe, mas sim entender o processo como um todo, explicar as fases e quais os seus objetivos, quais áreas que participam e quais são as entregas dessas fases."

A representação do modelo está clara para todos os envolvidos no PDP, mas não para toda a empresa, pois o modelo de referência específico da empresa "A" é exclusivamente para o lançamento de novos produtos. Assim, somente as áreas que participam do processo para lançamento de novos produtos utilizam o modelo de referência específico no seu dia a dia, ao contrário de outras áreas da empresa que sabem da existência do modelo de referência, mas não têm contato com o modelo rotineiramente. Diante disso, o entrevistado 3 explica: "mesmo as pessoas que trabalham na empresa, quando mudam para área de escritório de processo, têm uma dificuldade no início como qualquer funcionário novo." Além disso, o entrevistado 2 destaca que "a maneira como o modelo está escrito, como, por exemplo, suas entregas, é confuso."(sic)

Atualmente, há total adesão do modelo de referência específico na empresa "A". O entrevistado 2 afirma: "eu não me vejo sem consultar o modelo de referência, ele é inerente em tudo que eu faço no meu dia a dia de trabalho". Mas, apesar disso, os gestores ainda precisam exigir das áreas as suas responsabilidades e o preenchimento dos documentos padrões nas reuniões quinzenais.

A consulta do modelo de referência específico da empresa é feita por meio do site global onde se encontram todos os projetos localizados na rede interna da empresa e em papel impresso. Porém, a visualização do modelo é restrita somente para as pessoas envolvidas no processo de desenvolvimento de produtos e não para toda a organização.

Os quatro entrevistados afirmam que o modelo de referência específico da empresa "A" condiz com a realidade de seu processo de desenvolvimento de produto. Os gestores da empresa possuem autonomia para realizar algumas alterações como, por exemplo, mudar as datas, duração das atividades ou mesmo antecipar alguma atividade, mas desde que seja aprovado pela matriz.

Os objetivos que a empresa "A" pretendia alcançar com a implantação do modelo de referência são os seguintes: a) que todos pudessem ter a visão geral do 
projeto com uma linguagem em comum; b) garantir uma execução sem falha; c) organizar o processo e d) evitar o retrabalho. O entrevistado 2 acrescenta que "o modelo oferece uma segurança, de tudo que você está fazendo, possibilita o entender que está acontecendo no projeto, seu andamento e etc." O entrevistado 4 finaliza dizendo que o modelo proporcionou um alinhamento global, com lançamento bem estruturado em todos os países que a empresa atua.

\subsubsection{Descrição do estudo de caso - Empresa B}

A empresa "B" é uma multinacional fabricante de compressores herméticos para refrigeração e também unidades condensadoras para uso interno ou externo, evaporadores, bombas de calor, sistemas completos de refrigeração e serviço autorizado de componentes de reposição. Possui implantado no seu processo de desenvolvimento de produtos um modelo de referência específico que decorreu do modelo de referência da matriz. A implantação do modelo de referência específico envolveu todas as áreas ( $P \& D$, engenharia, suprimentos, marketing, manufatura e distribuição, vendas, financeiro e RH) que participam do PDP.

Em 2008, a matriz apresentou o modelo que seria implantado em todas as empresas filiais. Naquela época, a empresa tinha realizado uma parceria com uma universidade com a finalidade de ter um processo estruturado. Para isso, realizou-se um diagnóstico do processo de desenvolvimento de produto no qual foram definidos 14 projetos de melhoria do PDP. Posteriormente, foram selecionados e realizados 7 projetos. Esse diagnóstico ajudou no processo de implantação do modelo de referência específico na empresa. Assim, o entrevistado 1 declara que ele foi um guia de apoio. O entrevistado 2 afirma que "quando a matriz nos apresentou o modelo de referência, nós já estávamos com o conhecimento teórico bem consolidado devido ao diagnóstico e comparado com as outras filiais. A empresa " $B$ " é a que melhor aplicou a ferramenta."

A empresa matriz ofereceu um prazo de oito meses para que os projetos da empresa começassem a seguir o modelo de referência específico. O modelo de referência apresentado pela matriz teve alterações para se adequar à realidade 
local, como por exemplo: mudança de atividades, documentos padrões eliminados ou alterados.

Durante a implantação do modelo de referência específico na empresa "B", ocorreu uma série de disfunções. Os entrevistados listaram as principais:

- Conscientizar a empresa que o PDP não é só da área de engenharia;

- Mostrar que a finalidade do modelo é organizar o processo e não torná-lo burocrático;

- Resistência em usar os documentos padrões por parte dos funcionários;

- Dificuldade em manter a disciplina de um time multifuncional nas reuniões, pois ficava estabelecido o conflito para qual gerente responder, o gerente funcional ou gerente de projeto. Ele era visto como uma figura fraca, pois não tinha muita autoridade para obrigar as pessoas a participar ativamente de todas as reuniões.

Essas disfunções foram solucionadas por meio de reuniões periódicas, workshops e incentivo aos funcionários a criticarem os documentos padrões estabelecidos pelo modelo de referência, com a finalidade de melhorar esses documentos e deixá-los mais próximo da realidade da empresa. Sobre este aspecto, o entrevistado 1 acrescenta: "Muitas vezes, as pessoas devolviam os documentos padrões preenchidos sem nenhuma crítica, avaliação".

Nota-se então que outra solução foi tornar as reuniões mais flexíveis, ou seja, selecionar as pessoas das áreas somente quando o assunto das reuniões fosse pertinente à área dela e não obrigar as pessoas a participar de todas as reuniões.

Inicialmente, quando o modelo de referência específico na empresa foi implantado, aconteceu um treinamento geral para todos os funcionários que posteriormente foi dividido em treinamentos parciais direcionados às pessoas envolvidas no PDP. Atualmente não há um treinamento do modelo de referência no procedimento de admissão dos funcionários.

Depois de implantado, o modelo de referência específico da empresa "B" sofreu alterações somente nos dois primeiros anos, mas nada significativo, como por exemplo: mudança de atividades, eliminação ou alterações de documentos padrões. Os documentos padrões que a empresa "B" já utilizava, como os de custos e orçamento de ferramentas, permaneceram, por se achar mais pertinente e de melhor uso no dia a dia. 
O time responsável pelas alterações nos dois primeiros anos era representado por duas pessoas de cada país em que a empresa atua com a finalidade de discutir os problemas e melhorar o modelo. Atualmente os gestores têm autonomia para realizar as alterações, desde que seja aprovado pela matriz.

O modelo de referência específico da empresa "B" pode ser consultado por meio de um portal na internet com acesso para todas as filiais, onde estão todos os projetos e documentos padrões disponíveis, além de estar disponível na rede interna da empresa. Porém, só as pessoas envolvidas no PDP possuem acesso.

Os entrevistados destacaram os objetivos principais que a empresa "B" pretendia alcançar com o modelo de referência: velocidade e melhoria na precisão das informações; reduzir o tempo de entrega do produto no mercado; linguagem comum dos processos entre todos os países nos quais a empresa atua; tornar o processo multifuncional; organizar os processos e a documentação; ter a visão global do processo; melhorar a comunicação interna e a interação entre as áreas; oferecer produtos mais competitivos; ter disciplina no PDP e atender ao escopo do projeto. O entrevistado 2 destaca que antigamente a empresa "B" demorava cerca de 3 a 5 anos para lançar um produto no mercado e atualmente, com o modelo de referência, esse tempo diminui para 2 anos.

O objetivo ainda não alcançado pela empresa é desenvolver tecnologia de prateleira, ou seja, estabelecer um processo de desenvolvimento de tecnologia. $\mathrm{O}$ entrevistado 1 complementa: "nós ainda não conseguimos fazer um planejamento de todas as etapas da tecnologia."

Um benefício adicional obtido com o modelo de referência específico na empresa "B" foi que ele proporcionou uma melhor comunicação entre as áreas, principalmente com a área de marketing. O entrevistado 1 afirma que "antigamente $o$ PDP era visto como exclusivamente da engenharia." Logo, além dessa integração entre as áreas, o modelo de referência proporcionou uma evolução cultural na empresa. O entrevistado 2 finaliza dizendo que "a cultura do uso da técnica foi se disseminando ao longo do tempo, das pessoas e das áreas e foi se consolidando nos valores da empresa".

Os entrevistados afirmam que o modelo de referência específico que a empresa possui condiz com a realidade do seu processo de desenvolvimento de 
produtos. Porém, o entrevistado 1 ressalta que "atualmente a empresa está oferecendo uma linha de produtos mais customizados e estamos enfrentando alguns problemas. Talvez tenhamos que criar outro modelo de referência específico para esse novo negócio".

Atualmente há total adesão do modelo de referência específico na empresa por todas as pessoas envolvidas no PDP. Porém, ainda há uma resistência por parte dos funcionários em preencher os documentos padrões estabelecidos no modelo de referência específico. Geralmente os gestores têm que pedir os documentos padrões preenchidos quando a avaliação e a aprovação de cada fase do PDP estão próximas. Quanto à representação do modelo de referência específico na empresa "B", todos os entrevistados concordaram que ela é clara para a utilização. O entrevistado 2 finaliza dizendo:

Nós ainda não atingimos a plenitude, mas não está relacionado ao modelo em si, pois existe uma falha na execução, a gente precisa atuar mais fortemente nas reuniões periódicas das diferentes equipes ao longo do desenvolvimento do projeto, isto que precisa ser melhorado.

\subsection{Descrição das Disfunções e Benefícios}

A descrição das disfunções e dos benefícios está relacionada com a terceira etapa de pesquisa. Nesta seção, são apresentados o cálculo das médias $\left(\bar{X}_{I}\right)$, desvios padrão $\left(D P_{i}\right)$ e índices de concordância $\left(I C_{i}\right)$ das questões fechadas (questões 23 e 24) do questionário de pesquisa (APÊNDICE 3) que corresponde às disfunções e benefícios conforme exposto na Tabela 13 e na Tabela 14. 
Tabela 13- Resultado do cálculo da média, índice de concordância e coeficiente de variação das respostas dos entrevistados referentes às disfunções

\begin{tabular}{|c|c|c|c|c|c|c|c|c|c|}
\hline \multirow{2}{*}{ ID } & \multirow[b]{2}{*}{ Disfunções } & \multicolumn{4}{|c|}{ Empresa A } & \multicolumn{4}{|c|}{ Empresa B } \\
\hline & & $\overline{X_{l}}$ & $D P_{i}$ & $I C_{i}$ & $\frac{D P_{i}}{\overline{X_{t}}}$ & $\overline{X_{\iota}}$ & $D P_{i}$ & $I C_{i}$ & $\frac{D P_{i}}{\overline{X_{l}}}$ \\
\hline D1 & $\begin{array}{l}\text { Falta de comprometimento da alta direção (Ex: } \\
\text { Stakeholders). }\end{array}$ & 1,25 & 0,50 & 0,80 & 0,40 & 1,00 & 0,00 & 1,00 & 0,00 \\
\hline D2 & $\begin{array}{l}\text { Modelo de referência interpretado de maneiras diferentes } \\
\text { pelos funcionários. }\end{array}$ & 2,25 & 0,96 & 0,27 & 0,43 & 2,00 & 1,16 & $-0,07$ & 0,58 \\
\hline D3 & $\begin{array}{l}\text { Os funcionários trabalham em um constante estado de } \\
\text { dissonância com a prática. }\end{array}$ & 2,25 & 0,96 & 0,27 & 0,43 & 2,00 & 0,82 & 0,47 & 0,41 \\
\hline D4 & $\begin{array}{l}\text { Falta de recursos para implantação do modelo de } \\
\text { referência. }\end{array}$ & 1,75 & 0,96 & 0,27 & 0,55 & 1,25 & 0,50 & 0,80 & 0,40 \\
\hline D5 & Implantação demorada do modelo de referência. & 2,50 & 1,29 & $-0,33$ & 0,52 & 1,50 & 1,00 & 0,20 & 0,67 \\
\hline D6 & Modelo de referência é considerado dispendioso. & 2,00 & 0,82 & 0,47 & 0,41 & 1,00 & 0,00 & 1,00 & 0,00 \\
\hline D7 & Imprecisão do modelo de referência & 1,25 & 0,50 & 0,80 & 0,40 & 1,75 & 0,96 & 0,27 & 0,55 \\
\hline D8 & $\begin{array}{l}\text { Cultura organizacional não apoia os modelos de } \\
\text { referência. }\end{array}$ & 1,00 & 0,00 & 1,00 & 0,00 & 2,25 & 1,26 & $-0,27$ & 0,56 \\
\hline D9 & Modelo de referência considerado abstrato e ambíguo. & 1,25 & 0,50 & 0,80 & 0,40 & 2,25 & 0,96 & 0,27 & 0,43 \\
\hline
\end{tabular}

Continuação... 


\begin{tabular}{|c|c|c|c|c|c|c|c|c|c|}
\hline \multirow{2}{*}{ ID } & \multirow[b]{2}{*}{ Disfunções } & \multicolumn{4}{|c|}{ Empresa A } & \multicolumn{4}{|c|}{ Empresa B } \\
\hline & & $\overline{X_{\imath}}$ & $D P_{i}$ & $I C_{i}$ & $\frac{D P_{i}}{\overline{X_{\imath}}}$ & $\overline{X_{\imath}}$ & $D P_{i}$ & $I C_{i}$ & $\frac{D P_{i}}{\overline{X_{i}}}$ \\
\hline D10 & $\begin{array}{l}\text { Modelo de referência não ajuda os funcionários na } \\
\text { autogestão. }\end{array}$ & 1,75 & 0,50 & 0,80 & 0,29 & 1,75 & 0,96 & 0,27 & 0,55 \\
\hline D11 & $\begin{array}{l}\text { Modelo de referência não define exatamente quais } \\
\text { informações devem fluir ou em que estado devem estar. }\end{array}$ & 1,25 & 0,50 & 0,80 & 0,40 & 1,50 & 1,00 & 0,20 & 0,67 \\
\hline D12 & $\begin{array}{l}\text { As informações do modelo de referência que são } \\
\text { documentadas não são próximas do usuário. }\end{array}$ & 1,50 & 0,58 & 0,73 & 0,39 & 2,00 & 0,82 & 0,47 & 0,41 \\
\hline D13 & $\begin{array}{l}\text { Funcionários não entendem os benefícios do modelo de } \\
\text { referência. }\end{array}$ & 2,25 & 0,50 & 0,80 & 0,22 & 2,50 & 1,29 & $-0,33$ & 0,52 \\
\hline D14 & $\begin{array}{l}\text { Há uma relutância em compartilhar conhecimento e } \\
\text { colaborar. }\end{array}$ & 1,50 & 0,58 & 0,73 & 0,39 & 2,50 & 1,29 & $-0,33$ & 0,52 \\
\hline D15 & $\begin{array}{l}\text { Modelo de referência é considerado uma restrição à } \\
\text { oportunidade de aprendizado. }\end{array}$ & 1,25 & 0,50 & 0,80 & 0,40 & 1,00 & 0,00 & 1,00 & 0,00 \\
\hline D16 & Modelo de referência considerado burocrático. & 3,25 & 0,96 & 0,27 & 0,30 & 3,25 & 0,50 & 0,80 & 0,15 \\
\hline D17 & Modelo de referência não oferece autonomia aos gestores. & 1,75 & 0,96 & 0,27 & 0,55 & 2,00 & 1,41 & $-0,60$ & 0,71 \\
\hline D18 & $\begin{array}{l}\text { Não há documentos formais que descrevem o modelo de } \\
\text { referência. }\end{array}$ & 1,75 & 1,50 & $-0,80$ & 0,86 & 1,00 & 0,00 & 1,00 & 0,00 \\
\hline
\end{tabular}

Continuação... 
Conclusão.

\begin{tabular}{|c|c|c|c|c|c|c|c|c|c|}
\hline \multirow{2}{*}{ ID } & \multirow[b]{2}{*}{ Disfunções } & \multicolumn{4}{|c|}{ Empresa A } & \multicolumn{4}{|c|}{ Empresa B } \\
\hline & & $\overline{X_{\iota}}$ & $D P_{i}$ & $I C_{i}$ & $\frac{D P_{i}}{\overline{X_{l}}}$ & $\overline{X_{\imath}}$ & $D P_{i}$ & $I C_{i}$ & $\frac{D P_{i}}{\overline{X_{\imath}}}$ \\
\hline D19 & $\begin{array}{l}\text { Não há distinção entre modelo de referência e diretrizes } \\
\text { administrativas da empresa. }\end{array}$ & 1,75 & 1,50 & $-0,80$ & 0,86 & 1,50 & 0,58 & 0,73 & 0,39 \\
\hline D20 & $\begin{array}{l}\text { Modelo de referência não atende aos desafios específicos } \\
\text { da realidade. }\end{array}$ & 2,75 & 1,26 & $-0,27$ & 0,46 & 1,00 & 0,00 & 1,00 & 0,00 \\
\hline D21 & $\begin{array}{l}\text { Modelo de referência limitado na questão de apoiar à } \\
\text { gestão dos aspectos humanos. }\end{array}$ & 2,50 & 1,29 & $-0,33$ & 0,52 & 2,00 & 1,41 & $-0,60$ & 0,71 \\
\hline D22 & $\begin{array}{l}\text { Modelo de referência visto como carga administrativa ao } \\
\text { invés de suporte. }\end{array}$ & 1,50 & 0,58 & 0,73 & 0,39 & 1,75 & 0,96 & 0,27 & 0,55 \\
\hline D23 & $\begin{array}{l}\text { Modelo de referência está distante da realidade do } \\
\text { desenvolvimento de produtos. }\end{array}$ & 1,75 & 0,96 & 0,27 & 0,55 & 1,00 & 0,00 & 1,00 & 0,00 \\
\hline D24 & $\begin{array}{l}\text { Modelos de referência não são importantes no sentido de } \\
\text { guiar as ações. }\end{array}$ & 1,25 & 0,50 & 0,80 & 0,40 & 1,00 & 0,00 & 1,00 & 0,00 \\
\hline D25 & $\begin{array}{l}\text { O modelo de referência oferece uma grande liberdade de } \\
\text { interpretação. }\end{array}$ & 2,25 & 0,50 & 0,80 & 0,22 & 1,75 & 0,50 & 0,80 & 0,29 \\
\hline
\end{tabular}


Tabela 14 - Resultado do cálculo da média , índice de concordância e coeficiente de variação das respostas dos entrevistados referentes aos benefícios

\begin{tabular}{|c|c|c|c|c|c|c|c|c|c|}
\hline \multirow{2}{*}{ ID } & \multirow[b]{2}{*}{ Benefícios } & \multicolumn{4}{|c|}{ Empresa A } & \multicolumn{4}{|c|}{ Empresa B } \\
\hline & & $\overline{X_{L}}$ & $D P_{i}$ & $I C_{i}$ & $\frac{D P_{i}}{\overline{X_{t}}}$ & $\overline{X_{l}}$ & $D P_{i}$ & $I C_{i}$ & $\frac{D P_{i}}{\overline{X_{t}}}$ \\
\hline B1 & $\begin{array}{l}\text { Modelo de referência oferece uma linguagem comum a } \\
\text { todos os envolvidos no processo de desenvolvimento de } \\
\text { produto (PDP). }\end{array}$ & 3,00 & 0,00 & 1,00 & 0,00 & 4,00 & 0,00 & 1,00 & 0,00 \\
\hline B2 & $\begin{array}{l}\text { Modelo de referência oferece uma maneira padronizada de } \\
\text { medir o progresso do projeto. }\end{array}$ & 3,75 & 0,50 & 0,80 & 0,13 & 4,00 & 0,00 & 1,00 & 0,00 \\
\hline B3 & $\begin{array}{l}\text { Modelo de referência assegura que todos trabalham da } \\
\text { mesma maneira. }\end{array}$ & 3,00 & 0,00 & 1,00 & 0,00 & 3,25 & 0,50 & 0,80 & 0,15 \\
\hline B4 & $\begin{array}{l}\text { Modelos de referência foram vistos como apoio à } \\
\text { cooperação e à comunicação eficazes entre os projetos. }\end{array}$ & 3,25 & 0,50 & 0,80 & 0,15 & 4,00 & 0,00 & 1,00 & 0,00 \\
\hline B5 & $\begin{array}{l}\text { Modelo de referência permitiu maior comunicação dentro } \\
\text { da equipe do projeto bem como as partes interessadas } \\
\text { externas e outros projetos. }\end{array}$ & 3,50 & 0,58 & 0,73 & 0,17 & 3,75 & 0,50 & 0,80 & 0,13 \\
\hline
\end{tabular}

Continuação... 
Conclusão.

\begin{tabular}{|c|c|c|c|c|c|c|c|c|c|}
\hline \multirow{2}{*}{ ID } & \multirow[b]{2}{*}{ Benefícios } & \multicolumn{4}{|c|}{ Empresa A } & \multicolumn{4}{|c|}{ Empresa B } \\
\hline & & $\overline{X_{t}}$ & $D P_{i}$ & $I C_{i}$ & $\frac{D P_{i}}{\overline{X_{l}}}$ & $\overline{X_{\imath}}$ & $D P_{i}$ & $I C_{i}$ & $\frac{D P_{i}}{\overline{X_{l}}}$ \\
\hline B6 & $\begin{array}{l}\text { Modelo de referência oferece agilidade na tomada de } \\
\text { decisão. }\end{array}$ & 3,00 & 0,82 & 0,47 & 0,27 & 3,75 & 0,50 & 0,80 & 0,13 \\
\hline B7 & $\begin{array}{l}\text { Modelo de referência oferece maior agilidade no } \\
\text { diagnóstico de projetos. }\end{array}$ & 3,00 & 0,82 & 0,47 & 0,27 & 3,75 & 0,50 & 0,80 & 0,13 \\
\hline B8 & $\begin{array}{l}\text { Modelo de referência reforça a cultura do projeto como } \\
\text { empreendimento de toda a empresa e não somente da } \\
\text { área funcional da engenharia de produto. }\end{array}$ & 3,25 & 1,50 & $-0,80$ & 0,46 & 4,00 & 0,00 & 1,00 & 0,00 \\
\hline B9 & $\begin{array}{l}\text { Modelo de referência oferece uma redução de tempo do } \\
\text { projeto. }\end{array}$ & 2,60 & 1,15 & $-0,06$ & 0,44 & 4,00 & 0,00 & 1,00 & 0,00 \\
\hline B10 & $\begin{array}{l}\text { Modelo de referência oferece resultados finais mais } \\
\text { eficazes na melhoria da gestão das organizações. }\end{array}$ & 2,75 & 1,26 & $-0,27$ & 0,46 & 4,00 & 0,00 & 1,00 & 0,00 \\
\hline B11 & $\begin{array}{l}\text { Modelo de referência oferece uma redução no custo do } \\
\text { projeto. }\end{array}$ & 2,60 & 1,53 & $-0,87$ & 0,59 & 3,50 & 0,58 & 0,73 & 0,17 \\
\hline B12 & $\begin{array}{l}\text { Modelo de referência oferece disseminação de boas } \\
\text { práticas. }\end{array}$ & 3,75 & 0,50 & 0,80 & 0,13 & 4,00 & 0,00 & 1,00 & 0,00 \\
\hline B13 & $\begin{array}{l}\text { Modelo de referência possibilita a construção de soluções } \\
\text { organizadas e integradas, capazes de serem entendidas e } \\
\text { internalizadas. }\end{array}$ & 3,25 & 0,96 & 0,27 & 0,30 & 3,50 & 0,58 & 0,73 & 0,17 \\
\hline
\end{tabular}


Inicialmente para descrever os resultados das questões fechadas, utilizam-se as classes para os valores da média propostas a seguir:

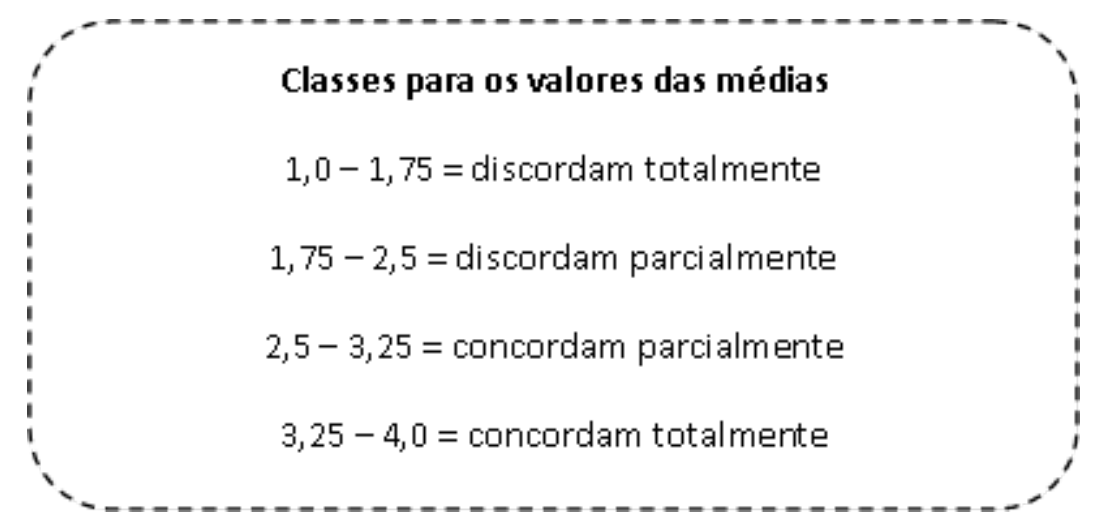

Figura 13 - Classe para valores das médias (elaborada pela autora).

A finalidade do cálculo da média é de identificar se as disfunções e os benefícios levantados na literatura são confirmados ou não nas empresas "A" e "B" de acordo com as respostas dos entrevistados.

Posteriormente são calculados o índice de concordância das disfunções e os benefícios com o objetivo de identificar se as respostas dos entrevistados foram similares. Segundo James, Damaree e Wolf (1984, p.86), o índice de concordância (IC) pode variar entre zero (0) e um (1): quanto mais próximo de 1, mais homogêneas são as opiniões dos entrevistados. Assim, para esta pesquisa, o valor 0,7 é considerado como mínimo para concluir que houve concordância entre os entrevistados. Com esse índice, pode-se analisar se, apesar de uma média alta, existem grandes variações nas notas atribuídas, o que indica percepções diferentes para um mesmo assunto, conforme explicado na subseção 3.2.2.

\subsubsection{Disfunções}

Nesta seção para descrever as disfunções das empresas "A" e "B", foram estruturados quatro grupos, conforme apresentado na Tabela 15. 
Tabela 15 - Descrição dos Grupos (Disfunções)

\begin{tabular}{|c|c|}
\hline Grupos & Descrição \\
\hline $\begin{array}{c}\text { Grupo } 1 \\
\text { Discordam Totalmente e Índice de Concordância } \\
\text { Alto }\end{array}$ & $\begin{array}{l}\text { O grupo } 1 \text { representa as disfunções não } \\
\text { confirmadas que os entrevistados obtiveram } \\
\text { consenso nas respostas do questionário. }\end{array}$ \\
\hline $\begin{array}{c}\text { Grupo } 2 \\
\text { Discordam e Concordam Parcialmente e Índice } \\
\text { de Concordância Alto }\end{array}$ & $\begin{array}{l}\text { O grupo } 2 \text { representa as disfunções confirmadas } \\
\text { em algum momento nas empresas que os } \\
\text { entrevistados obtiveram consenso nas respostas } \\
\text { do questionário. }\end{array}$ \\
\hline $\begin{array}{c}\text { Grupo } 3 \\
\text { Concordam Totalmente e Índice de Concordância } \\
\text { Alto }\end{array}$ & $\begin{array}{l}\text { O grupo } 3 \text { representa as disfunções confirmadas } \\
\text { que os entrevistados obtiveram consenso nas } \\
\text { respostas do questionário. }\end{array}$ \\
\hline \multicolumn{2}{|l|}{ Grupo 4} \\
\hline $\begin{array}{l}\text { Concordam Parcialmente } \\
\text { Discordam Parcialmente } \\
\text { Discordam Totalmente }\end{array}$ & $\begin{array}{l}\text { O grupo } 4 \text { representa as disfunções que não } \\
\text { obtiveram consenso entre os entrevistados nas } \\
\text { respostas do questionário. }\end{array}$ \\
\hline Índice de & \\
\hline
\end{tabular}

Os grupos definidos na Tabela 15 foram estruturados com base nos resultados dos valores da média e dos índices de concordância de cada disfunção.

A discussão das disfunções apresentadas é fundamentada nas respostas assinaladas pelos entrevistados nas questões fechadas (questões 23 e 24) parte III do questionário de pesquisa (APÊNDICE 3) e nos relatos dos entrevistados na entrevista focada (questões 1 a 22), parte II do questionário de pesquisa.

A Figura 14 mostra o gráfico das médias e dos índices de concordância(IC) das disfunções das empresas A e B. Conforme apresentado no gráfico, a empresa "A" possui um total de treze disfunções que têm o (IC) acima de 0,7 enquanto a empresa "B" tem um total de dez. 


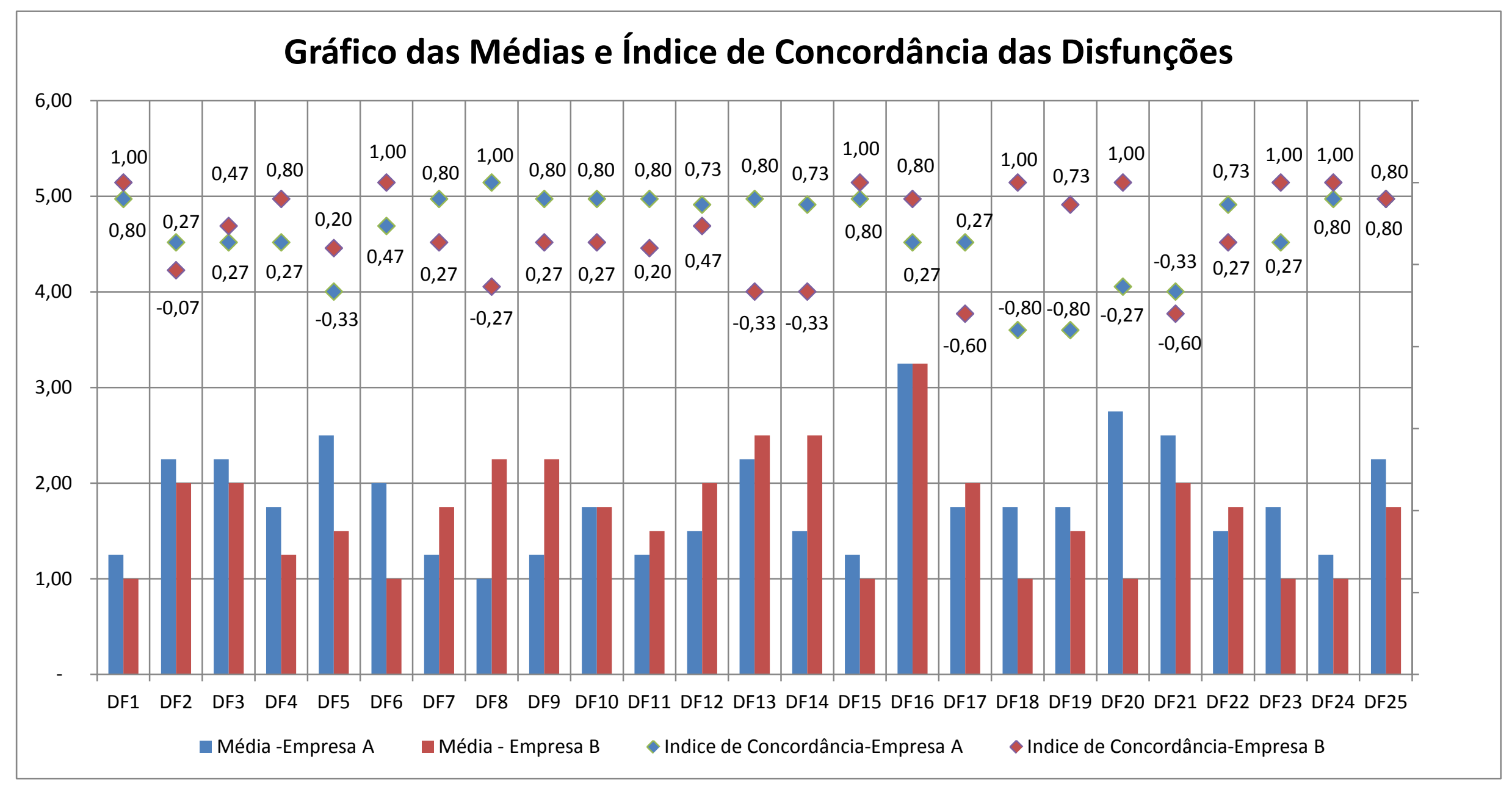

Figura 14 - Gráfico das médias e índice de concordância das empresas A e B (elaborado pela autora). 


\subsubsection{Empresa A}

Dentre os 4 grupos apresentados, de acordo com as respostas dos entrevistados, as disfunções da empresa "A" foram estruturadas em 3 grupos que são descritos a seguir.

$\mathrm{Na}$ Tabela 16, são apresentadas as disfunções que por meio das respostas dos entrevistados foram classificadas no grupo 1.

\section{Tabela 16 - Grupo 1 - Disfunções (Empresa A)}

Grupo 1- Discordam Totalmente e Índice de Concordância Alto

\begin{tabular}{|c|c|c|c|c|}
\hline ID & Disfunções & $\overline{X_{l}}$ & $I C_{i}$ & $\frac{D P_{i}}{\overline{X_{l}}}$ \\
\hline D1 & $\begin{array}{l}\text { Falta de comprometimento da alta direção (Ex.: } \\
\text { Stakeholders). }\end{array}$ & 1,25 & 0,80 & 0,40 \\
\hline D7 & Imprecisão do modelo de referência. & 1,25 & 0,80 & 0,40 \\
\hline D8 & $\begin{array}{l}\text { Cultura organizacional não apoia os modelos de } \\
\text { referência. }\end{array}$ & 1,00 & 1,00 & 0,00 \\
\hline D9 & Modelo de referência considerado abstrato e ambíguo. & 1,25 & 0,80 & 0,40 \\
\hline D10 & $\begin{array}{l}\text { Modelo de referência não ajuda os funcionários na } \\
\text { autogestão. }\end{array}$ & 1,75 & 0,80 & 0,29 \\
\hline D11 & $\begin{array}{l}\text { Modelo de referência não define exatamente quais } \\
\text { informações devem fluir ou em que estado devem estar. }\end{array}$ & 1,25 & 0,80 & 0,40 \\
\hline D12 & $\begin{array}{l}\text { As informações do modelo de referência que são } \\
\text { documentadas não são próximas do usuário. }\end{array}$ & 1,50 & 0,73 & 0,39 \\
\hline D14 & $\begin{array}{l}\text { Há uma relutância em compartilhar conhecimento e } \\
\text { colaborar. }\end{array}$ & 1,50 & 0,73 & 0,39 \\
\hline D15 & $\begin{array}{l}\text { Modelo de referência é considerado uma restrição à } \\
\text { oportunidade de aprendizado. }\end{array}$ & 1,25 & 0,80 & 0,40 \\
\hline D22 & $\begin{array}{l}\text { Modelo de referência visto como carga administrativa ao } \\
\text { invés de suporte. }\end{array}$ & 1,50 & 0,73 & 0,39 \\
\hline D24 & $\begin{array}{l}\text { Modelos de referência não são importantes no sentido de } \\
\text { guiar as ações. }\end{array}$ & 1,25 & 0,80 & 0,40 \\
\hline
\end{tabular}


No grupo 1 houve consenso nas respostas dos entrevistados da empresa "A". De acordo com as respostas assinaladas no questionário de pesquisa (APÊNDICE 3) e com os relatos dos entrevistados na entrevista focada, podem-se realizar algumas reflexões descritas a seguir.

Disfunção (D1) - Na entrevista focada foi salientado pelos entrevistados 2 e 3 que a alta direção esteve sempre presente e comprometida desde a implantação do modelo de referência específico até nos dias atuais, quando é necessário realizar algum tipo de alteração no modelo.

Disfunção (D7) - Os entrevistados 1, 2 e 3, na entrevista focada, explicaram que o modelo de referência específico da empresa "A" não é considerado impreciso, pois é clara a sua representação em fases e atividades.

Disfunção (D8) - Segundo um relato individual na entrevista focada, o entrevistado explicou que modelo de referência específico está inserido nos valores da empresa "A". Dessa forma, se os funcionários não apoiam o modelo de referência específico, eles estão sendo contra os valores da própria empresa.

Disfunção (D9) - Os entrevistados 1 e 2 relataram que, anteriormente à implantação do modelo de referência específico, houve um estudo na matriz em conjunto com as filiais para analisar as adaptações à realidade local e os treinamentos ajudaram a consolidar o modelo. Por estas razões, esta disfunção não condiz com a realidade da empresa.

Disfunção (D10) - Os entrevistados discordaram totalmente desta disfunção, pois segundo eles o modelo de referência específico da empresa proporciona uma visão holística do desenvolvimento de produto. O modelo possui informações necessárias para a realização de cada atividade e etapa do projeto que, ao contrário da disfunção descrita, auxilia os funcionários na autogestão.

Disfunção (D11) - Os entrevistados 1 e 4 relataram, ao contrário da disfunção descrita, que o modelo de referência define as informações durante todo o PDP. Na empresa "A", as informações de todo o processo estão localizadas no sistema de apoio, que os envolvidos no PDP têm acesso. 
Disfunção (D12) - Os entrevistados discordaram totalmente da disfunção descrita, pois a empresa possui um sistema de apoio, onde estão localizados todos os projetos e documentos padrões acessados pelas pessoas envolvidas no PDP. Os entrevistados 2 e 4 explicam que não há possibilidade de existir essa disfunção na empresa, pois todas as ações dos funcionários dependem das informações dos projetos. Essas informações, por sua vez, são encontradas somente no sistema de apoio ao modelo de referência específico da empresa.

Disfunção (D14) - Ao contrário da disfunção descrita, os entrevistados relataram que desde a implantação do modelo de referência específico houve a colaboração de todos os envolvidos no PDP e que os próprios gestores são proativos na questão de compartilhar o conhecimento por meio das reuniões quinzenais e por meio da proposta de vídeo-aulas conforme se apresenta na Descrição do estudo de caso Empresa A.

Disfunção (D15) - Os entrevistados explicaram que o modelo de referência específico proporcionou uma linguagem e nomenclatura comum em todas as filiais e com isso proporcionou aos gestores das filiais e da empresa matriz uma troca de experiências e informações quanto aos processos. Por esses motivos eles discordaram totalmente da disfunção descrita.

Disfunção (D22) - Os entrevistados 1 e 2 ressaltaram que de maneira geral o modelo de referência não é visto pelas pessoas envolvidas no PDP como carga administrativa.

Disfunção (D24) - Os entrevistados explicaram que o modelo de referência específico é um direcionador do que é preciso ser realizado e quais são as entregas de cada fase e como é realizada a aprovação para seguir para a próxima fase. Assim, ele é importante no sentido de guiar as ações dos gestores e, por isso, discordam totalmente da disfunção descrita.

Na Tabela 17, são apresentadas as disfunções que, por meio das respostas dos entrevistados, foram classificadas no grupo 2. 
Tabela 17 - Grupo 2 - Disfunções (Empresa A)

\begin{tabular}{lllll}
\hline \multicolumn{5}{c}{ Grupo 2 - Discordam e concordam parcialmente e índice de Concordância Alto } \\
\hline ID & \multicolumn{1}{c}{ Disfunções } & $\overline{\boldsymbol{X}_{\boldsymbol{\imath}}}$ & $\boldsymbol{I C}_{\boldsymbol{i}}$ & $\frac{\boldsymbol{D P}_{\boldsymbol{i}}}{\overline{\boldsymbol{X}_{\boldsymbol{\iota}}}}$ \\
\hline D13 & $\begin{array}{l}\text { Funcionários não entendem os benefícios do modelo de } \\
\text { referência. }\end{array}$ & 2,25 & 0,80 & 0,22 \\
D25 & $\begin{array}{l}\text { O modelo de referência oferece uma grande liberdade de } \\
\text { interpretação. }\end{array}$ & 2,25 & 0,80 & 0,22 \\
\hline
\end{tabular}

No grupo 2 houve consenso nas respostas dos entrevistados da empresa "A". De acordo com as respostas assinaladas no questionário de pesquisa (APÊNDICE 3) e com os relatos dos entrevistados na entrevista focada, podem-se realizar algumas reflexões vistas com a seguinte descrição.

Disfunção (D13) - Na entrevista, três entrevistados explicaram que discordaram parcialmente da disfunção, pois ainda há certa resistência pela área de marketing, que indaga aos gestores de projeto nas reuniões se os benefícios do modelo são tão significativos comparados a um produto lançado mais cedo e alinhado com o que mercado necessita.

Disfunção (D25) - Na entrevista, dois entrevistados relataram que a linguagem utilizada nos documentos padrões do modelo de referência específico não é suficientemente clara.

Na Tabela 18 são apresentadas as disfunções que por meio das respostas dos entrevistados foram classificadas no grupo 4. 
Tabela 18 - Grupo 4 - Disfunções (Empresa A)

\begin{tabular}{|c|c|c|c|c|}
\hline \multicolumn{5}{|c|}{$\begin{array}{l}\text { Grupo } 4 \text { - Concordam Totalmente / Concordam Parcialmente / Discordam } \\
\text { Parcialmente I Discordam Totalmente e Índice de Concordância Baixo }\end{array}$} \\
\hline ID & Disfunções & $\overline{X_{t}}$ & $I C_{i}$ & $\frac{D P_{i}}{\overline{X_{t}}}$ \\
\hline D2 & $\begin{array}{l}\text { Modelo de referência interpretado de maneiras diferentes } \\
\text { pelos funcionários. }\end{array}$ & 2,25 & 0,27 & 0,43 \\
\hline D3 & $\begin{array}{l}\text { Os funcionários trabalham em um constante estado de } \\
\text { dissonância com a prática. }\end{array}$ & 2,25 & 0,27 & 0,43 \\
\hline D4 & $\begin{array}{l}\text { Falta de recursos para implantação do modelo de } \\
\text { referência. }\end{array}$ & 1,75 & 0,27 & 0,55 \\
\hline D5 & Implantação demorada do modelo de referência. & 2,50 & $-0,33$ & 0,52 \\
\hline D6 & Modelo de referência é considerado dispendioso. & 2,00 & 0,47 & 0,41 \\
\hline D16 & Modelo de referência considerado burocrático. & 3,25 & 0,27 & 0,30 \\
\hline D17 & $\begin{array}{l}\text { Modelo de referência não oferece autonomia aos } \\
\text { gestores. }\end{array}$ & 1,75 & 0,27 & 0,55 \\
\hline D18 & $\begin{array}{l}\text { Não há documentos formais que descrevem o modelo de } \\
\text { referência. }\end{array}$ & 1,75 & $-0,80$ & 0,86 \\
\hline D19 & $\begin{array}{l}\text { Não há distinção entre modelo de referência e diretrizes } \\
\text { administrativas da empresa. }\end{array}$ & 1,75 & $-0,80$ & 0,86 \\
\hline D20 & $\begin{array}{l}\text { Modelo de referência não atende aos desafios } \\
\text { específicos da realidade. }\end{array}$ & 2,75 & $-0,27$ & 0,46 \\
\hline D21 & $\begin{array}{l}\text { Modelo de referência limitado na questão de apoiar à } \\
\text { gestão dos aspectos humanos. }\end{array}$ & 2,50 & $-0,33$ & 0,52 \\
\hline D23 & $\begin{array}{l}\text { Modelo de referência está distante da realidade do } \\
\text { desenvolvimento de produtos. }\end{array}$ & 1,75 & 0,27 & 0,55 \\
\hline
\end{tabular}

No grupo 4, não houve consenso nas respostas dos entrevistados da empresa "A". De acordo com as respostas assinaladas no questionário de pesquisa (APÊNDICE 3) e com os relatos dos entrevistados na entrevista focada, podem-se realizar algumas reflexões. Observe a descrição. 
Disfunção (D2) - O entrevistado 1 relatou que as pessoas admitidas na área têm inicialmente uma dificuldade de compreender o modelo devido à quantidade de documentos padrões. E o entrevistado 3 ressaltou que a linguagem utilizada nos documentos padrões do modelo de referência específico não é suficientemente clara. Logo, ocasionalmente os funcionários pedem auxílio aos seus gestores para entender o significado das entregas de cada fase. Somente o entrevistado 2 atribuiu uma nota totalmente diferente dos demais entrevistados, mas isso se deve ao fato de o entrevistado estar na área há apenas seis meses.

Disfunção (D3) - Os entrevistados 2 e 3 explicaram que na fase da implantação do modelo de referência específico essa disfunção existia na empresa. Contudo, o entrevistado 1 explicou que é difícil as pessoas trabalharem em estado de dissonância com a prática devido o modelo de referência específico da empresa " $A$ " ter o suporte de um sistema de informação. No sistema de informação, estão inseridos os processos e os projetos, que precisam ser mantidos com informações de todas as pessoas envolvidas no PDP para obter aprovação e continuidade nas próximas fases.

Disfunção (D4) - O entrevistado 3 afirmou que a disfunção descrita não existiu na empresa em momento algum e ressaltou que a empresa possui desde a implantação todos os recursos necessários. Apenas os entrevistados 2 e 4 atribuíram uma nota totalmente diferente dos demais entrevistados, mas isso se deve ao fato dos entrevistados estarem na área há apenas seis e sete meses respectivamente.

Disfunção (D5) - Os entrevistados apresentaram percepções totalmente diferentes sobre a disfunção descrita. Isso se deve ao fato de que nenhum dos entrevistados ter participado da fase de implantação. Exceto o entrevistado 1 que, na época, pôde acompanhar o momento da implantação do modelo de referência específico na empresa. O entrevistado 1 ainda ressaltou que o tempo de implantação do modelo de referência específico na empresa " $A$ " foi coerente devido à complexidade do processo da empresa e também da própria cultura organizacional que precisou se adaptar à nova realidade.

Disfunção (D6) - Os entrevistados não chegaram a um consenso, pois o modelo decorreu da matriz, e eles não têm o conhecimento dessa informação. 
Disfunção (D16) - Os entrevistados 2 e 4 relataram que a implantação do modelo de referência específico resultou em uma maior burocracia nos projetos devido às aprovações rígidas nos gates.

Disfunção (D17) - Os entrevistados 1 e 3 explicaram que qualquer alteração no processo precisa necessariamente ser aprovada pela matriz. Logo os gestores possuem uma autonomia limitada.

Disfunção (D18) - Apenas a resposta de um entrevistado divergiu em relação às respostas dos demais. Isto se justifica pelo fato de o entrevistado 1 ser recémcontratado e não possuir experiência e conhecimento em relação aos outros entrevistados. O modelo de referência específico da empresa "A" possui vários documentos padrões que estão no sistema de apoio e que todos os envolvidos no PDP têm acesso.

Disfunção (D19) - Apenas a resposta de um entrevistado divergiu em relação às respostas dos demais. Isto se deve ao fato, que o entrevistado 1 ser recémcontratado e não possuir experiência em relação aos outros entrevistados. No caso da empresa "A" há essa distinção devido ao modelo de referência ter o apoio do sistema.

Disfunção (D20) - Os entrevistados 2 e 4 ressaltaram que os produtos da empresa "A" ainda são lançados com atraso em relação aos concorrentes e com isso o modelo não atende aos desafios específicos da realidade. O entrevistado 1 divergiu das respostas dos demais entrevistados. Ele explicou que, apesar de os produtos da empresa terem sido lançados com atraso, o modelo de referência específico consegue atender aos desafios específicos da realidade.

Disfunção (D21) - Os entrevistados atribuíram notas totalmente diferentes e na entrevista focada não foram obtidos relatos para compreender a falta de consenso entre os entrevistados.

Disfunção (D23) - Apesar da divergência das notas atribuídas no questionário de pesquisa, os entrevistados relataram na entrevista focada que o modelo de referência específico da empresa "A" não é distante do seu desenvolvimento de produto. 


\subsubsection{Empresa $B$}

Dentre os 4 grupos apresentados, de acordo com as respostas dos entrevistados, as disfunções da empresa "B" foram estruturadas em 3 grupos que são descritos a seguir.

Na Tabela 19, são apresentadas as disfunções que, por meio das respostas dos entrevistados, foram classificadas no grupo1.

Tabela 19 - Grupo 1 - Disfunções (Empresa B)

Grupo 1 - Discordam Totalmente e Índice de Concordância Alto

\begin{tabular}{|c|c|c|c|c|}
\hline ID & Disfunções & $\overline{X_{\imath}}$ & $I C_{i}$ & $\frac{\overline{D P}}{\overline{X_{l}}}$ \\
\hline D1 & $\begin{array}{l}\text { Falta de comprometimento da alta direção (Ex.: } \\
\text { Stakeholders). }\end{array}$ & 1,00 & 1,00 & 0,00 \\
\hline D4 & $\begin{array}{l}\text { Falta de recursos para implantação do modelo de } \\
\text { referência. }\end{array}$ & 1,25 & 0,80 & 0,40 \\
\hline D6 & Modelo de referência é considerado dispendioso. & 1,00 & 1,00 & 0,00 \\
\hline D15 & $\begin{array}{l}\text { Modelo de referência é considerado uma restrição à } \\
\text { oportunidade de aprendizado. }\end{array}$ & 1,00 & 1,00 & 0,00 \\
\hline D18 & $\begin{array}{l}\text { Não há documentos formais que descrevem o modelo de } \\
\text { referência. }\end{array}$ & 1,00 & 1,00 & 0,00 \\
\hline D19 & $\begin{array}{l}\text { Não há distinção entre modelo de referência e diretrizes } \\
\text { administrativas da empresa. }\end{array}$ & 1,50 & 0,73 & 0,39 \\
\hline D20 & $\begin{array}{l}\text { Modelo de referência não atende aos desafios } \\
\text { específicos da realidade. }\end{array}$ & 1,00 & 1,00 & 0,00 \\
\hline D23 & $\begin{array}{l}\text { Modelo de referência está distante da realidade do } \\
\text { desenvolvimento de produtos. }\end{array}$ & 1,00 & 1,00 & 0,00 \\
\hline D24 & $\begin{array}{l}\text { Modelos de referência não são importantes no sentido de } \\
\text { guiar as ações. }\end{array}$ & 1,00 & 1,00 & 0,00 \\
\hline D25 & $\begin{array}{l}\text { O modelo de referência oferece uma grande liberdade de } \\
\text { interpretação. }\end{array}$ & 1,75 & 0,80 & 0,29 \\
\hline
\end{tabular}


No grupo 1, houve consenso nas respostas dos entrevistados da empresa "B". De acordo com as respostas assinaladas no questionário de pesquisa (APÊNDICE 3) e com os relatos dos entrevistados na entrevista focada podem-se realizar algumas reflexões, que são descritas a seguir.

Disfunção (D1) - Segundo os entrevistados, a alta direção da empresa possuiu um papel importante durante a implantação do modelo de referência. A alta direção esteve presente nas reuniões, workshops e nos dois primeiros anos montou uma equipe para melhoria do modelo com os gestores de projeto de cada filial.

Disfunção (D4) - Os entrevistados discordam totalmente da disfunção descrita, pois durante a implantação do modelo de referência específico, a empresa possuiu recursos para desenvolver toda uma estrutura para a realização das reuniões, workshops e divulgação.

Disfunção (D6) - Apesar dos entrevistados discordarem totalmente da disfunção descrita, na entrevista focada eles relataram que como o modelo de referência decorreu da matriz, eles não possuem conhecimento dessa informação.

Disfunção (D15) - Os entrevistados discordaram totalmente dessa disfunção, pois explicam que com o modelo de referência específico foi possível discutir melhorias no processo da empresa e questionar se os documentos padrões que as pessoas já utilizavam no seu dia a dia podiam ser substituídos pelos documentos padrões do modelo de referência específico.

Disfunção (D18) - Ao contrário da disfunção citada, na empresa "B" há documentos padrões que descrevem o modelo de referência.

Disfunção (D19) - Segundo os entrevistados, há a distinção entre o modelo de referência específico e as diretrizes administrativas, pois o modelo com seus processos e projetos estão inseridos em um portal na intranet da empresa onde somente pessoas envolvidas no PDP têm acesso.

Disfunção (D20) - Um dos entrevistados relatou que essa disfunção não condiz com a realidade da empresa "B", pois com o processo organizado, o lançamento do 
produto é mais rápido e alinhado com o mercado. Assim o modelo de referência atende aos desafios da realidade.

Disfunção (D23) - Os entrevistados discordaram totalmente da disfunção descrita, pois o modelo de referência condiz com a realidade do PDP da empresa.

Disfunção (D24) - Segundo os entrevistados, o modelo de referência possibilita ter uma visão holística do processo, é um direcionador do que é preciso ser realizado e quais são as entregas de cada fase, ao contrário da disfunção descrita.

Disfunção (D25) - Os entrevistados discordam totalmente, pois, essa disfunção esteve presente durante a implantação do modelo de referência específico, mas que, nos dias atuais, não está mais presente na empresa.

Na Tabela 20, são apresentadas as disfunções que, por meio das respostas, dos entrevistados foram classificadas no grupo 3.

Tabela 20 - Grupo 3 - Disfunções (Empresa B)

\begin{tabular}{|c|c|c|c|c|}
\hline \multicolumn{5}{|c|}{ Grupo 3 - Concordam Totalmente e Índice de Concordância Alto } \\
\hline ID & Disfunções & $\overline{X_{\imath}}$ & $I C_{i}$ & $\frac{D P_{i}}{\overline{X_{t}}}$ \\
\hline D16 & Modelo de referência considerado burocrático. & 3,25 & 0,80 & 0,15 \\
\hline
\end{tabular}

No grupo 3, houve consenso nas respostas dos entrevistados da empresa "B". De acordo com as respostas assinaladas no questionário de pesquisa (APÊNDICE 3) e com os relatos dos entrevistados na entrevista focada, podem-se realizar algumas reflexões, que são descritas a seguir.

Disfunção (D16) - Segundo os entrevistados, devido à grande quantidade de documentos padrões que o modelo de referência específico da empresa possui, ele é considerado burocrático e há muitas reclamações por parte dos funcionários da empresa. 
$\mathrm{Na}$ Tabela 21, são apresentadas as disfunções que, por meio das respostas dos entrevistados, foram classificadas no grupo 4.

Tabela 21 - Grupo 4 - Disfunções (Empresa B)

\begin{tabular}{|c|c|c|c|c|}
\hline \multicolumn{5}{|c|}{$\begin{array}{l}\text { Grupo } 4 \text { - Concordam Totalmente / Concordam Parcialmente / Discordam } \\
\text { Parcialmente I Discordam Totalmente e Índice de Concordância Baixo }\end{array}$} \\
\hline ID & Disfunções & $\overline{X_{\imath}}$ & $I C_{i}$ & $\frac{D P_{i}}{\overline{X_{l}}}$ \\
\hline D2 & $\begin{array}{l}\text { Modelo de referência interpretado de maneiras diferentes } \\
\text { pelos funcionários. }\end{array}$ & 2,00 & $-0,07$ & 0,58 \\
\hline D3 & $\begin{array}{l}\text { Os funcionários trabalham em um constante estado de } \\
\text { dissonância com a prática. }\end{array}$ & 2,00 & 0,47 & 0,41 \\
\hline D5 & Implantação demorada do modelo de referência. & 1,50 & 0,20 & 0,67 \\
\hline D7 & Imprecisão do modelo de referência. & 1,75 & 0,27 & 0,55 \\
\hline D8 & $\begin{array}{l}\text { Cultura organizacional não apoia os modelos de } \\
\text { referência. }\end{array}$ & 2,25 & 0,27 & 0,56 \\
\hline D9 & Modelo de referência considerado abstrato e ambíguo. & 2,25 & 0,27 & 0,43 \\
\hline D10 & $\begin{array}{l}\text { Modelo de referência não ajuda os funcionários na } \\
\text { autogestão. }\end{array}$ & 1,75 & 0,27 & 0,55 \\
\hline D11 & $\begin{array}{l}\text { Modelo de referência não define exatamente quais } \\
\text { informações devem fluir ou em que estado devem estar. }\end{array}$ & 1,50 & 0,20 & 0,67 \\
\hline D12 & $\begin{array}{l}\text { As informações do modelo de referência que são } \\
\text { documentadas não são próximas do usuário. }\end{array}$ & 2,00 & 0,47 & 0,41 \\
\hline D13 & $\begin{array}{l}\text { Funcionários não entendem os benefícios do modelo de } \\
\text { referência. }\end{array}$ & 2,50 & $-0,33$ & 0,52 \\
\hline D14 & $\begin{array}{l}\text { Há uma relutância em compartilhar conhecimento e } \\
\text { colaborar. }\end{array}$ & 2,50 & $-0,33$ & 0,52 \\
\hline D17 & $\begin{array}{l}\text { Modelo de referência não oferece autonomia aos } \\
\text { gestores. }\end{array}$ & 2,00 & $-0,60$ & 0,71 \\
\hline D21 & $\begin{array}{l}\text { Modelo de referência limitado na questão de apoiar à } \\
\text { gestão dos aspectos humanos. }\end{array}$ & 2,00 & $-0,60$ & 0,71 \\
\hline D22 & $\begin{array}{l}\text { Modelo de referência visto como carga administrativa ao } \\
\text { invés de suporte. }\end{array}$ & 1,75 & 0,27 & 0,55 \\
\hline
\end{tabular}


No grupo 4, não houve consenso nas respostas dos entrevistados da empresa "B". De acordo com as respostas assinaladas no questionário de pesquisa (APÊNDICE 3) e com os relatos dos entrevistados na entrevista focada, podem-se realizar algumas reflexões.

Disfunção (D2) - Os entrevistados 1 e 4 relataram que esta disfunção já esteve presente durante a fase de implantação do modelo de referência. E os entrevistados 2 e 3 discordaram totalmente, pois responderam com base nos dias atuais, que esta disfunção não existe na empresa.

Disfunção (D3) - Os entrevistados 3 relatou que esta disfunção já esteve presente durante a fase de implantação do modelo de referência específico na empresa "B" e dificilmente acontece nos dias atuais devido à existência do portal para realizar o download dos documentos padrões necessários no dia a dia de trabalho. Mas, os entrevistados 1 e 4 têm uma percepção diferente. Eles explicam que ainda é possível observar essa disfunção no dia a dia de alguns funcionários.

Disfunção (D5) - A maioria dos entrevistados discorda totalmente dessa disfunção, exceto o entrevistado 3. Os entrevistados salientaram que, no caso da empresa "B", foram 8 meses de implantação. Esse tempo foi satisfatório para implantação e divulgação do modelo de referência específico para todas as pessoas envolvidas no PDP. O entrevistado 3, por estar há mais tempo na função, tem uma percepção diferente em relação aos demais.

Disfunção (D7) - Os entrevistados 2 e 3 relataram que esta disfunção já esteve presente durante a fase de implantação do modelo de referência, enquanto os entrevistados 2 e 4 explicaram que atualmente modelo de referência específico da empresa "B" não é considerado impreciso. Ele é claro quanto a sua representação, atividades e entregas em cada fase.

Disfunção (D8) - Não houve consenso entre os entrevistados, pois essa disfunção esteve presente durante a implantação do modelo de referência específico da empresa "B" e não mais nos dias atuais. Segundo o entrevistado 1, as pessoas envolvidas no PDP da empresa tiveram uma resistência inicial para usar o modelo, devido ao fato de já estarem habituados a usar os seus documentos padrões no sua 
rotina. Outro fato é que o PDP sempre foi visto pelas outras áreas como função apenas da engenharia.

Disfunção (D9) - Os entrevistados relataram que a representação do modelo de referência é clara a todos os envolvidos no PDP e todos compreendem as fases e as entregas em cada atividade. Porém, os entrevistados 3 e 4 explicaram que o modelo de referência específico da empresa "B" é ambíguo em algumas atividades e documentos padrões propostos.

Disfunção (D10) - Os entrevistados 1 e 4 relataram na entrevista focada que a empresa "B" possui um portal na internet onde estão localizados todos os documentos padrões e onde estão descritas as entregas de cada fase. Além disso, todas as pessoas envolvidas no PDP têm acesso ao portal com todas essas informações. Este fato contribuiria para a autogestão dos funcionários.

Disfunção (D11) - A maioria dos entrevistados, exceto o entrevistado 3, relatou que as entregas descritas em cada fase do modelo de referência são claras e fornecem todas as informações necessárias para as próximas fases. Com o modelo, os envolvidos no PDP conseguem ver o processo holisticamente, e isso possibilita saber quais informações devem fluir ou em que estado devem estar.

Disfunção (D12) - Os entrevistados relataram que a empresa "B" possui um portal na internet onde estão localizados todos os projetos e documentos padrões de acesso livre a todos envolvidos no PDP.

Disfunção (D13) - Os entrevistados 1, 2 e 4 relataram que essa disfunção esteve presente durante a implantação do modelo de referência específico, mas nos dias atuais as pessoas envolvidas no PDP entendem os benefícios do modelo de referência específico na empresa "B". Enquanto, o entrevistado 3 discordou totalmente, pois respondeu ao questionário com base nos dias atuais.

Disfunção (D14) - Os entrevistados 1, 2 e 4 relataram que essa disfunção esteve presente durante a implantação do modelo de referência específico, mas que nos dias atuais não está presente na realidade da empresa. Porém, o entrevistado 3 discordou totalmente, pois respondeu ao questionário com base nos dias atuais.

Disfunção (D17) - O entrevistado 1 explica que inicialmente, quando o modelo de referência foi implantado, foi criado um time global com participação dos gestores de projetos da matriz e de cada filial para realizar alterações no modelo de referência 
específico na empresa "B". Durante os dois primeiros anos, este time possuía autonomia para realizar as alterações. Atualmente, eles não têm autonomia para realizar alterações sem aprovação da matriz. Devido a este fato, não houve consenso entre os entrevistados.

Disfunção (D21) - Durante a entrevista focada não houve relatos para compreender a falta de consenso entre os entrevistados sobre esta disfunção.

Disfunção (D22) - Os entrevistados 1 e 3 explicaram que esta disfunção esteve presente durante a implantação do modelo de referência específico na empresa e que ainda é possível observar essa disfunção na empresa nos dias atuais. Enquanto, os entrevistados 2 e 4 têm uma percepção totalmente diferente e enfatizam que a disfunção não é presente nos dias atuais.

\subsubsection{Benefícios}

Nesta seção, para descrever os benefícios das empresas "A" e "B", foram estruturados quatro grupos, conforme apresentado na Tabela 22.

Tabela 22 - Descrição dos Grupos (Benefícios)

\begin{tabular}{|c|c|}
\hline Grupos & Descrição \\
\hline $\begin{array}{c}\text { Grupo } 1 \\
\text { Discordam Totalmente e Índice de Concordância } \\
\text { Alto }\end{array}$ & $\begin{array}{c}\text { Representam os benefícios que não foram } \\
\text { confirmados nas empresas e que os } \\
\text { entrevistados possuíram consenso nas } \\
\text { respostas. }\end{array}$ \\
\hline $\begin{array}{c}\text { Grupo } 2 \\
\text { Discordam e Concordam Parcialmente e Índice } \\
\text { de Concordância Alto }\end{array}$ & $\begin{array}{c}\text { Representam os benefícios que estiveram } \\
\text { presentes em algum momento nas empresas e } \\
\text { que os entrevistados possuíram consenso nas } \\
\text { respostas. }\end{array}$ \\
\hline
\end{tabular}

Continua... 
Conclusão.

\begin{tabular}{|c|c|}
\hline Grupos & Descrição \\
\hline $\begin{array}{l}\text { Grupo } 3 \\
\text { Concordam Totalmente e Índice de Concordância } \\
\text { Alto }\end{array}$ & $\begin{array}{l}\text { Representam os benefícios que foram } \\
\text { confirmados nas empresas e que os } \\
\text { entrevistados possuíram consenso nas } \\
\text { respostas. }\end{array}$ \\
\hline $\begin{array}{c}\text { Grupo } 4 \\
\text { Concordam Totalmente }\end{array}$ & . \\
\hline $\begin{array}{l}\text { Concordam Parcialmente } \\
\text { Discordam Parcialmente } \\
\text { Discordam Totalmente } \\
\text { Índice de Concordância Baixo }\end{array}$ & $\begin{array}{c}\text { Representam os benefícios em que os } \\
\text { entrevistados não possuíram consenso nas } \\
\text { respostas. }\end{array}$ \\
\hline
\end{tabular}

Os grupos acima foram estruturados por meio dos resultados dos valores da média e dos índices de concordância de cada benefício.

A discussão dos benefícios apresentados é fundamentada nas respostas assinaladas pelos entrevistados nas questões fechadas (questões 23 e 24) parte III do questionário de pesquisa (APÊNDICE 3) e nos relatos dos entrevistados na entrevista focada (questões 1 a 22), parte II do questionário de pesquisa.

A Figura 15 mostra o gráfico das médias e o índice de concordância das empresas A e B. Conforme apresentado no gráfico, a empresa "B" possui todos os seus benefícios com índice de concordância acima de 0,7 diferentemente da empresa "A" que possui um total de seis benefícios que têm o índice de concordância acima de 0,7. 


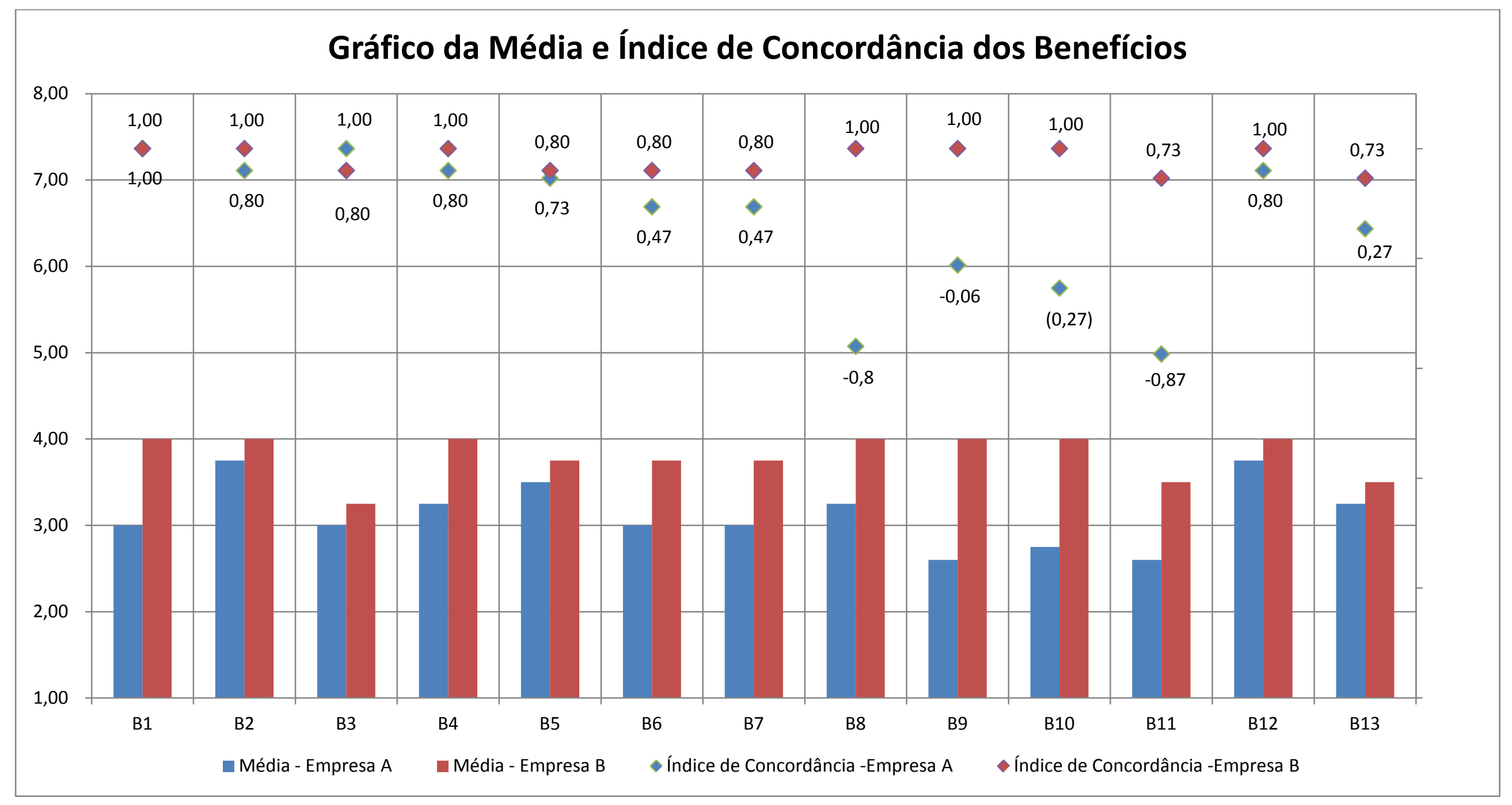

Figura 15 - Gráfico da média e índice de concordância dos benefícios das empresas A e B (elaborado pela autora). 


\subsubsection{Empresa A}

Dentre os 4 grupos apresentados, de acordo com as respostas dos entrevistados, os benefícios da empresa "A" foram estruturados em 3 grupos que são descritos a seguir.

Na Tabela 23 são apresentados os benefícios que, por meio das respostas dos entrevistados, foram classificadas no grupo 2.

Tabela 23 - Grupo 2 - Benefícios (Empresa A)

\begin{tabular}{|c|c|c|c|c|}
\hline \multicolumn{5}{|c|}{ Grupo 2 - Discordam e Concordam Parcialmente e Índice de Concordância Alto } \\
\hline ID & Disfunções & $\overline{X_{\imath}}$ & $I C_{i}$ & $\frac{D P_{i}}{\overline{X_{l}}}$ \\
\hline B1 & $\begin{array}{l}\text { Modelo de referência oferece uma linguagem comum a } \\
\text { todos os envolvidos no processo de desenvolvimento de } \\
\text { produto (PDP). }\end{array}$ & 3,00 & 1,00 & 0,00 \\
\hline B3 & $\begin{array}{l}\text { Modelo de referência assegura que todos trabalham da } \\
\text { mesma maneira. }\end{array}$ & 3,00 & 1,00 & 0,00 \\
\hline
\end{tabular}

No grupo 2, houve consenso nas respostas dos entrevistados da empresa "A". De acordo com as respostas assinaladas no questionário de pesquisa (APÊNDICE 3) e com os relatos dos entrevistados na entrevista focada, podem-se realizar algumas reflexões, que são descritas a seguir.

Benefício (B1) - Segundo os entrevistados, anteriormente à implantação, cada filial possuía seus documentos padrões e os processos não possuíam a mesma nomenclatura. A implantação do modelo de referência possibilitou uma linguagem comum a todos os envolvidos no PDP.

Benefício (B3) - Os entrevistados concordaram parcialmente, pois relataram que o modelo de referência não assegura, mas direciona para que todos trabalhem da mesma maneira.

Na Tabela 24 são apresentados os benefícios que por meio das respostas dos entrevistados foram classificadas no grupo 3. 
Tabela 24 - Grupo 3 - Benefícios (Empresa A)

\begin{tabular}{|c|c|c|c|c|}
\hline \multicolumn{5}{|c|}{ Grupo 3 - Concordam Totalmente e Índice de Concordância Alto } \\
\hline ID & Disfunções & $\overline{X_{\imath}}$ & $I C_{i}$ & $\frac{D P_{i}}{\overline{X_{t}}}$ \\
\hline B2 & $\begin{array}{l}\text { Modelo de referência oferece uma maneira padronizada } \\
\text { de medir o progresso do projeto. }\end{array}$ & 3,75 & 0,80 & 0,13 \\
\hline B4 & $\begin{array}{l}\text { Modelos de referência foram vistos como apoio à } \\
\text { cooperação e comunicação eficazes entre os projetos. }\end{array}$ & 3,25 & 0,80 & 0,15 \\
\hline B5 & $\begin{array}{l}\text { Modelo de referência permitiu maior comunicação dentro } \\
\text { da equipe do projeto bem como as partes interessadas } \\
\text { externas e outros projetos. }\end{array}$ & 3,50 & 0,73 & 0,17 \\
\hline B12 & $\begin{array}{l}\text { Modelo de referência oferece disseminação de boas } \\
\text { práticas. }\end{array}$ & 3,75 & 0,80 & 0,13 \\
\hline
\end{tabular}

No grupo 3, houve consenso nas respostas dos entrevistados da empresa "A". De acordo com as respostas assinaladas no questionário de pesquisa (APÊNDICE 3) e com os relatos dos entrevistados na entrevista focada, podem-se realizar algumas reflexões, que são descritas a seguir.

Benefício (B2) - Os entrevistados 3 e 4 relataram que o modelo de referência, com suas fases e atividades, possibilita de maneira padronizada e fácil, medir o progresso do projeto.

Benefício (B4) - Os entrevistados destacam que o modelo de referência definiu uma mesma nomenclatura para os processos, que facilitou a comunicação entre os projetos da matriz e as filiais.

Benefício (B5) - Os entrevistados concordaram com este benefício, pois, com o modelo de referência, as reuniões começaram a ser quinzenais, o que permitiu maior comunicação dentro da equipe de projeto.

Benefício (B12) - Segundo os entrevistados 2 e 4, as informações e especificações, tanto dos projetos finalizados quanto dos projetos congelados e cancelados, ficam registradas no sistema de suporte do modelo de referência específico da empresa 
"A" e com isso possibilita um banco de dados de boas práticas para os futuros projetos.

$\mathrm{Na}$ Tabela 25, são apresentados os benefícios que, por meio das respostas dos entrevistados, foram classificadas no grupo 4.

\section{Tabela 25 - Grupo 4 - Benefícios (Empresa A)}

\begin{tabular}{|c|c|c|c|c|}
\hline \multicolumn{5}{|c|}{$\begin{array}{c}\text { Grupo } 4 \text { - Concordam Totalmente / Concordam Parcialmente / Discordam } \\
\text { Parcialmente / Discordam Totalmente e Índice de Concordância Baixo Índice de } \\
\text { Concordância Baixo }\end{array}$} \\
\hline ID & Disfunções & $\overline{X_{\imath}}$ & $I C_{i}$ & $\frac{D P_{i}}{\overline{X_{l}}}$ \\
\hline B6 & $\begin{array}{l}\text { Modelo de referência oferece agilidade na tomada de } \\
\text { decisão. }\end{array}$ & 3,00 & 0,47 & 0,27 \\
\hline B7 & $\begin{array}{l}\text { Modelo de referência oferece maior agilidade no } \\
\text { diagnóstico de projetos. }\end{array}$ & 3,00 & 0,47 & 0,27 \\
\hline B8 & $\begin{array}{l}\text { Modelo de referência reforça a cultura do projeto como } \\
\text { empreendimento de toda a empresa e não somente da } \\
\text { área funcional da engenharia de produto. }\end{array}$ & 3,25 & $-0,80$ & 0,46 \\
\hline B9 & $\begin{array}{l}\text { Modelo de referência oferece uma redução de tempo do } \\
\text { projeto. }\end{array}$ & 2,60 & $-0,06$ & 0,44 \\
\hline B10 & $\begin{array}{l}\text { Modelo de referência oferece resultados finais mais } \\
\text { eficazes na melhoria da gestão das organizações. }\end{array}$ & 2,75 & $-0,27$ & 0,46 \\
\hline B11 & $\begin{array}{l}\text { Modelo de referência oferece uma redução no custo do } \\
\text { projeto. }\end{array}$ & 2,60 & $-0,87$ & 0,59 \\
\hline B13 & $\begin{array}{l}\text { Modelo de referência possibilita a construção de } \\
\text { soluções organizadas e integradas, capazes de serem } \\
\text { entendidas e internalizadas. }\end{array}$ & 3,25 & 0,27 & 0,30 \\
\hline
\end{tabular}

No grupo 4, não houve consenso nas respostas dos entrevistados da empresa "A". De acordo com as respostas assinaladas no questionário de pesquisa (APÊNDICE 3) e com os relatos dos entrevistados na entrevista focada, podem-se realizar algumas reflexões, que são descritas a seguir. 
Benefício (B6) - Todos os entrevistados, exceto o entrevistado 4, explicaram que devido ao modelo de referência ser, muitas vezes, burocrático, ao contrário do benefício descrito, não resulta na agilidade na tomada de decisão. $O$ entrevistado 4 , por sua vez, tem a percepção diferente dos demais entrevistados e afirma que o benefício é presente na empresa.

Benefício (B7) - Todos os entrevistados, exceto o entrevistado 4, explicaram que com o modelo de referência é possível detectar erros com maior rapidez, mas nem sempre oferece uma maior agilidade no diagnóstico de projetos. 0 entrevistado 4 , por sua vez, tem a percepção diferente dos demais entrevistados e afirma que é possível observar o benefício na empresa.

Benefício (B8) - Todos os entrevistados concordaram totalmente com o benefício descrito, exceto o entrevistado 4. Segundo o entrevistado 4, somente a área de lançamento de novos produtos possui o modelo de referência. Assim, o modelo de referência específico reforçou a cultura somente dessa área e não de toda empresa. O entrevistado 4 possui uma percepção diferente dos demais, por ele ter assumido recentemente sua função na área de PDP.

Benefício (B9) - Os entrevistados 2 e 3 relataram que o tempo de projeto aumentou devido à burocracia e às aprovações nos gates. Ao mesmo tempo, o entrevistado 4 ressaltou que, com o modelo de referência, evitou-se o retrabalho e, com isso, possibilitou-se a redução de tempo no final do projeto.

Benefício (B10) - O entrevistado 1 explica que, devido ao modelo de referência oferecer uma visão holística do processo e possibilitar uma maior padronização, as pessoas envolvidas no PDP conseguem obter resultados mais eficazes na melhoria da gestão. Porém, os entrevistados 2 e 3 ressaltaram que, muitas vezes, o modelo demora em ser compreendido pelas pessoas envolvidas no PDP, principalmente aos recém-contratados da área e assim não é possível observar o benefício descrito.

Benefício (B11) - O entrevistado 2 relatou que, após a implantação do modelo de referência, não foi possível observar o benefício descrito na empresa, enquanto o entrevistado 4 explicou que, com a implantação do modelo de referência, evitou-se o retrabalho e isso possibilitou a redução do custo no projeto final.

Benefício (B13) - Os entrevistados 1 e 3 ressaltaram que o modelo de referência há uma maior comunicação entre o time de projeto e com isso possibilita a construção 
de soluções organizadas e integradas, capazes de ser entendidas e internalizadas. Porém, os entrevistados 2 e 4 têm percepções diferentes dos demais, o que pode ser explicado pelo fato de eles serem recentes na função na empresa.

\subsubsection{Empresa B}

Dentre os 4 grupos apresentados, de acordo com as respostas dos entrevistados, os benefícios da empresa "B" foi estruturada em 1 grupo que são descritos a seguir. Na Tabela 26, são apresentados os benefícios que, por meio das respostas dos entrevistados, foram classificadas no grupo 3.

Tabela 26 - Grupo 3 - Benefícios (Empresa B)

Grupo 3 - Concordam Totalmente e Índice de Concordância Alto

\begin{tabular}{|c|c|c|c|c|}
\hline ID & Disfunções & $\overline{X_{\imath}}$ & $I C_{i}$ & $\frac{\overline{D P_{i}}}{\overline{X_{t}}}$ \\
\hline B1 & $\begin{array}{l}\text { Modelo de referência oferece uma linguagem comum a } \\
\text { todos os envolvidos no processo de desenvolvimento de } \\
\text { produto (PDP). }\end{array}$ & 4,00 & 1,00 & 0,00 \\
\hline B2 & $\begin{array}{l}\text { Modelo de referência oferece uma maneira padronizada } \\
\text { de medir o progresso do projeto. }\end{array}$ & 4,00 & 1,00 & 0,00 \\
\hline B3 & $\begin{array}{l}\text { Modelo de referência assegura que todos trabalham da } \\
\text { mesma maneira. }\end{array}$ & 3,25 & 0,80 & 0,15 \\
\hline B4 & $\begin{array}{l}\text { Modelos de referência foram vistos como apoio à } \\
\text { cooperação e comunicação eficazes entre os projetos. }\end{array}$ & 4,00 & 1,00 & 0,00 \\
\hline B5 & $\begin{array}{l}\text { Modelo de referência permitiu maior comunicação dentro } \\
\text { da equipe do projeto bem como as partes interessadas } \\
\text { externas e outros projetos. }\end{array}$ & 3,75 & 0,80 & 0,13 \\
\hline B6 & $\begin{array}{l}\text { Modelo de referência oferece agilidade na tomada de } \\
\text { decisão. }\end{array}$ & 3,75 & 0,80 & 0,13 \\
\hline B7 & $\begin{array}{l}\text { Modelo de referência oferece maior agilidade no } \\
\text { diagnóstico de projetos. }\end{array}$ & 3,75 & 0,80 & 0,13 \\
\hline B8 & $\begin{array}{l}\text { Modelo de referência reforça a cultura do projeto como } \\
\text { empreendimento de toda a empresa e não somente da } \\
\text { área funcional da engenharia de produto. }\end{array}$ & 4,00 & 1,00 & 0,00 \\
\hline
\end{tabular}


Conclusão.

\begin{tabular}{|c|c|c|c|c|}
\hline \multicolumn{5}{|c|}{ Grupo 3 - Concordam Totalmente e Índice de Concordância Alto } \\
\hline ID & Disfunções & $\overline{X_{\imath}}$ & $I C_{i}$ & $\frac{D P_{i}}{\overline{X_{1}}}$ \\
\hline B9 & $\begin{array}{l}\text { Modelo de referência oferece uma redução de tempo do } \\
\text { projeto. }\end{array}$ & 4,00 & 1,00 & 0,00 \\
\hline B10 & $\begin{array}{l}\text { Modelo de referência oferece resultados finais mais } \\
\text { eficazes na melhoria da gestão das organizações. }\end{array}$ & 4,00 & 1,00 & 0,00 \\
\hline B11 & $\begin{array}{l}\text { Modelo de referência oferece uma redução no custo do } \\
\text { projeto. }\end{array}$ & 3,50 & 0,73 & 0,17 \\
\hline B12 & $\begin{array}{l}\text { Modelo de referência oferece disseminação de boas } \\
\text { práticas. }\end{array}$ & 4,00 & 1,00 & 0,00 \\
\hline B13 & $\begin{array}{l}\text { Modelo de referência possibilita a construção de } \\
\text { soluções organizadas e integradas, capazes de serem } \\
\text { entendidas e internalizadas. }\end{array}$ & 3,50 & 0,73 & 0,17 \\
\hline
\end{tabular}

No grupo 3, houve consenso nas respostas dos entrevistados da empresa "B". De acordo com as respostas assinaladas no questionário de pesquisa (APÊNDICE 3) e com os relatos dos entrevistados na entrevista focada, podem-se realizar algumas reflexões, que são descritas a seguir.

Benefício (B1) - Os entrevistados relataram que a implantação do modelo de referência não somente possibilitou a linguagem comum de todas as áreas envolvidas no PDP na empresa "B", como também da empresa matriz e de todas as suas filiais.

Benefício (B2) - Os entrevistados relataram que o modelo de referência e o processo estruturado possibilitaram uma maneira padronizada e fácil de medir 0 progresso do projeto.

Benefício (B3) - Os entrevistados relataram que o modelo de referência direciona que todos os envolvidos no PDP trabalhem da mesma maneira. 
Benefício (B4) - Os entrevistados relataram que o modelo de referência específico foi fundamental para aumentar a comunicação e a cooperação dos projetos não somente da empresa "B" mas também dos projetos entre as filiais.

Benefício (B5) - Segundo os entrevistados, o modelo de referência foi fundamental para aumentar comunicação dentro da equipe de projeto, principalmente com a área de marketing.

Benefício (B6) - Os entrevistados relataram que com o modelo de referência e o processo estruturado, a tomada de decisões nos projetos ficou mais fácil e mais rápida.

Benefício (B7) - Os entrevistados relataram que com o modelo de referência foi possível detectar falhas durante o processo de desenvolvimento de produto e com isso ele resulta em uma maior agilidade no diagnóstico de projetos.

Benefício (B8) - Segundo os entrevistados, a implantação do modelo de referência foi um marco importante na empresa "B", pois mudou os paradigmas até então estabelecidos de que somente a área de engenharia era responsável pelo PDP. A implantação do modelo de referência reforçou a cultura do projeto como empreendimento de toda a empresa.

Benefício (B9) - Os entrevistados relataram que com o modelo de referência específico, a empresa "B" teve uma redução de tempo de projeto quando comparado com os anos anteriores.

Benefício (B10) - Segundo os entrevistados, o modelo de referência possibilita que todos os envolvidos no PDP tenham uma visão holística do processo. Isso possibilita a obtenção de resultados mais eficazes e também a melhoria da gestão do PDP.

Benefício (B11) - Os entrevistados relataram que no caso da empresa "B", posteriormente a implantação do modelo de referência, foi possível observar uma redução no custo final dos projetos.

Benefício (B12) - Os entrevistados explicaram que o modelo de referência na empresa "B" está inserido no portal da internet onde estão localizadas as informações e especificações dos projetos finalizados, congelados e cancelados e que isso possibilita um banco de dados de boas práticas para os futuros projetos.

Benefício (B13) - Os entrevistados relataram que o modelo de referência possibilitou uma maior comunicação entre o time de projeto e permitiu a construção 
de soluções organizadas e integradas, e com isso, muitas vezes, essas soluções foram capazes de serem entendidas e internalizadas.

\subsection{Análise dos Resultados}

Para realizar a análise das disfunções e benefícios comuns, foram utilizados os dados das respostas dos entrevistados (APÊNDICE 6) e (APÊNDICE 7) referente às questões fechadas (questões 23 e 24) do questionário de pesquisa (APÊNDICE 3) e dos relatos dos entrevistados na entrevista focada das questões abertas (questões 1 a 22).

Assim, foram considerados somente as disfunções e benefícios com índices de concordância acima de 0,7 , pois as demais não possuíram consenso nas respostas assinaladas no questionário de pesquisa.

\subsubsection{Disfunções}

Dentre os 4 grupos apresentados, as disfunções comuns em ambas as empresas, estão localizadas no: "Grupo 1 - Discordam Totalmente e Índice de Concordância Alto". Nesse grupo, foram identificadas nas empresas A e B três disfunções em comum, que são descritas a seguir.

\section{Disfunção (1) - Falta de comprometimento da alta direção (Ex.: Stakeholders)}

Nas empresas A e B, a alta direção foi a principal motivadora em implantar o modelo de referência específico e foi fundamental em disseminar o propósito e os benefícios do modelo para a empresa como um todo. Acompanhou toda a fase de implantação do modelo de referência em conjunto com as filiais e não esteve apenas comprometida e dedicada durante toda fase de implantação do modelo de referência específico, mas também posteriormente à implantação, ou seja, até os dias atuais, quando ainda é necessária realizar alguma mudança. 


\section{Disfunção (D15) - Modelo de referência é considerado uma restrição à oportunidade de aprendizado.}

Por meio dos relatos dos entrevistados de ambas as empresas, foi possível notar que aconteceu justamente ao contrário da disfunção descrita. Posteriormente à implantação do modelo de referência específico, houve uma maior comunicação entre as áreas e entre as equipes de projetos. Isso possibilitou a troca de informações e a experiência entre os gestores das filiais em relação aos processos e aos documentos padrões utilizados.

\section{Disfunção (24) - Modelos de Referência não são importantes no sentido de guiar as ações}

Ambas as empresas possuem um suporte de tecnologia de informação (TI) para apoiar o uso do modelo de referência específico. Os sistemas de informação das empresas armazenam informações do processo de desenvolvimento de produto, as fases e atividades do modelo, a descrição das entregas e quais os times de aprovação. Todo esse conjunto auxilia os envolvidos no PDP a guiar as ações no dia a dia de trabalho.

A Tabela 27 sumariza o panorama das disfunções de ambas as empresas que possuíram índice de concordância acima de 0,7 de acordo com a escala proposta no questionário de pesquisa.

Tabela 27 - Total da Categoria das Disfunções com concordância acima de 0,7

\begin{tabular}{cccc}
\hline & \multicolumn{2}{c}{ Total de 25 Disfunções } & \\
\hline & Discordam Totalmente & $\begin{array}{c}\text { Discordam e } \\
\text { Concordam } \\
\text { Parcialmente }\end{array}$ & $\begin{array}{c}\text { Concordam } \\
\text { Totalmente }\end{array}$ \\
Empresa A & 11 & 2 & 0 \\
Empresa B & 10 & 0 & 1 \\
\hline
\end{tabular}

Pode-se notar que, nas duas empresas, diante da escala apresentada no questionário de pesquisa, as disfunções em sua maioria receberam notas de "discordam totalmente" com (IC) acima de 0,7. Isso mostra que o modelo de referência específico nessas empresas é considerado uma melhor prática, pois, com 
a sua implantação, resultaram em conjunto de benefícios. É importante considerar que essas empresas são consolidadas no mercado e que o modelo de referência específico delas foi implantado em 2004 e 2008, respectivamente, e que muitas disfunções que existiram na implantação não estão mais presentes nos dias atuais.

\subsubsection{Benefícios}

Dentre os 4 grupos apresentados, os benefícios comuns em ambas as empresas estão localizadas no Grupo 3 - "Concordam Totalmente e Índice de Concordância Alto". Neste grupo, foram identificadas nas empresas A e B, quatro benefícios em comum, que são descritos a seguir:

Benefício (B2) - Modelo de referência oferece uma maneira padronizada de medir o progresso do projeto.

$\mathrm{Na}$ entrevista focada, os entrevistados de ambas as empresas explicaram que o modelo de referência e o processo estruturado possibilitam a todos os envolvidos no PDP uma maneira padronizada, fácil e rápida de medir o progresso do projeto.

Benefício (B4) - Modelos de referência foram vistos como apoio à cooperação e à comunicação eficazes entre os projetos.

Este benefício foi destacado pelos entrevistados de ambas as empresas. Durante a entrevista focada, os entrevistados relataram que o modelo de referência específico foi fundamental para aumentar a comunicação e a cooperação dos projetos não somente com a empresa matriz, mas também com os projetos das filiais localizadas em outros continentes em que as empresas atuam.

Benefício (B5) - Modelo de Referência permitiu uma maior comunicação dentro da equipe do projeto bem como nas partes interessadas externas e outros projetos.

$\mathrm{Na}$ entrevista focada, os entrevistados relataram que a maior comunicação entre as áreas possibilitou uma evolução em ambas as empresas. No caso da empresa "A", com a implantação do modelo de referência, entre uma das melhores práticas adotadas, observam-se reuniões quinzenais, que possibilitaram uma maior interação com a equipe de projeto. Na empresa "B", o modelo de referência foi 
fundamental para aumentar a comunicação, principalmente com a área de marketing.

Benefício (B12) - Modelo de referência oferece disseminação de boas práticas.

Os entrevistados de ambas as empresas confirmaram este benefício e explicaram que as empresas possuem um portal na internet no caso da empresa $B$ e um sistema de informação no caso da empresa $A$, onde estão localizadas as informações e especificações dos projetos finalizados, congelados e cancelados e que isso possibilita um banco de dados de boas práticas para os futuros projetos.

A Tabela 28 sumariza o panorama dos benefícios de ambas às empresas que possuíram índice de concordância acima de 0,7 de acordo com a escala proposta no questionário de pesquisa.

Tabela 28 - Total da Categoria dos Benefícios com concordância acima de 0,7

\begin{tabular}{cccc}
\hline & \multicolumn{3}{c}{ Total de 13 Benefícios } \\
\hline Empresa A & 0 & $\begin{array}{c}\text { Discordam e } \\
\text { Concordam } \\
\text { Parcialmente }\end{array}$ & $\begin{array}{c}\text { Concordam } \\
\text { Totalmente }\end{array}$ \\
Empresa B & 0 & 2 & 4 \\
\hline
\end{tabular}

Os benefícios apresentados, no questionário de pesquisa, receberam notas em sua maioria "concordo totalmente" e "concordo parcialmente" com (IC) acima de 0,7 .

\subsubsection{Inconsistência entre as Disfunções e Benefícios}

Existe uma inconsistência nos resultados obtidos na empresa "A". As respostas dos entrevistados para as disfunções foram classificadas, em sua maioria, no grupo 1 - "discordo totalmente". Isso significa que ao discordarem das disfunções levantadas na literatura, elas não ocorrem na empresa, ou seja, a implantação e o uso do modelo são considerados uma prática com bons resultados. Porém, os entrevistados não tiveram um consenso ao avaliarem os benefícios, ou seja, apesar 
de os entrevistados terem confirmado que as disfunções não estão presentes na realidade atual da empresa, simultaneamente não existe um consenso sobre os benefícios. Isso poderia ser explicado pelo fato de os entrevistados terem pouco tempo de função na área e também de não terem participado da fase de implantação do modelo de referência específico na empresa. Uma interpretação é que eles não possuem a percepção do beneficio se comparado com a situação anterior. No entanto, é importante salientar que eles não percebem os benefícios atuais. Na empresa "B", todos os entrevistados participaram do momento de implantação e possuem um tempo maior na função. Além de discordarem das disfunções levantadas, eles possuem um consenso quanto aos benefícios trazidos pelo modelo de referência.

Outra inconsistência a destacar é que a presença de algumas disfunções contradiz a presença de alguns benefícios, conforme o Quadro 1 a seguir.

\section{Quadro 1 - Descrição das Disfunções e Benefícios}

\begin{tabular}{|c|c|}
\hline Descrição das Disfunções & Descrição dos Benefícios \\
\hline $\begin{array}{l}\text { D2- Modelo de referência interpretado de } \\
\text { maneiras diferentes pelos funcionários. }\end{array}$ & $\begin{array}{l}\text { B1- Modelo de referência oferece uma } \\
\text { linguagem comum a todos os envolvidos no } \\
\text { processo de desenvolvimento de produto (PDP). }\end{array}$ \\
\hline $\begin{array}{l}\text { D3- Os funcionários trabalham em um constante } \\
\text { estado de dissonância com a prática. }\end{array}$ & $\begin{array}{l}\text { B3- Modelo de referência assegura que todos } \\
\text { trabalhem da mesma maneira. }\end{array}$ \\
\hline $\begin{array}{l}\text { D10- Modelo de referência não ajuda os } \\
\text { funcionários na autogestão }\end{array}$ & $\begin{array}{l}\text { B6- Modelo de referência oferece agilidade na } \\
\text { tomada de decisão. }\end{array}$ \\
\hline $\begin{array}{l}\text { D11- Modelo de referência não define } \\
\text { exatamente quais informações devem fluir ou em } \\
\text { que estado devem estar. }\end{array}$ & $\begin{array}{l}\text { B2- Modelo de referência oferece uma maneira } \\
\text { padronizada de medir o progresso do projeto. }\end{array}$ \\
\hline $\begin{array}{l}\text { D14 - Há uma relutância em compartilhar } \\
\text { conhecimento e colaborar. }\end{array}$ & $\begin{array}{l}\text { B4- Modelos de referência foram vistos como } \\
\text { apoio à cooperação e comunicação eficazes } \\
\text { entre os projetos. } \\
\text { B5- Modelo de referência permitiu maior } \\
\text { comunicação dentro da equipe do projeto bem } \\
\text { como as partes interessadas externas e outros } \\
\text { projetos. } \\
\text { B8- Modelo de referência reforça a cultura do } \\
\text { projeto como empreendimento de toda a } \\
\text { empresa e não somente da área funcional da } \\
\text { engenharia de produto. }\end{array}$ \\
\hline $\begin{array}{l}\text { D15- Modelo de referência é considerado uma } \\
\text { restrição à oportunidade de aprendizado. }\end{array}$ & $\begin{array}{l}\text { B12- Modelo de referência oferece disseminação } \\
\text { de boas práticas. } \\
\text { B13- Modelo de referência possibilita a } \\
\text { construção de soluções organizadas e } \\
\text { integradas, capazes de serem entendidas e } \\
\text { internalizadas. }\end{array}$ \\
\hline
\end{tabular}


Na empresa "A", os entrevistados não obtiveram consenso sobre a presença das disfunções (D2) e (D3). Todavia, eles obtiveram consenso quanto aos benefícios (B1) e (B3). No caso da empresa "A", essa inconsistência pode ser explicada por dois motivos: o primeiro é em relação aos entrevistados serem recentes na função da área da empresa, já o segundo motivo tem a ver com algumas disfunções apesar de não obterem consenso entre os entrevistados. É possível ainda observar a sua presença na empresa, como por exemplo, a disfunção (D2). No caso da empresa "B", essa inconsistência pode ser explicada devido ao fato de alguns entrevistados responderem ao questionário com base nos dias atuais e outros responderem-lhe com base no momento da implantação do modelo de referência específico na empresa.

Os entrevistados discordaram totalmente sobre a presença das disfunções (D14) e (D15) na empresa "A". Contudo, eles não obtiveram consenso quanto aos benefícios (B8) e (B13), ou seja, não afirmaram se esses benefícios estão presentes ou não, o que implica em uma contradição das respostas assinaladas pelos entrevistados.

Na empresa "B", os entrevistados não obtiveram consenso sobre a presença das seguintes disfunções (D2), (D3), (D10), (D11) e (D14). Entretanto, quanto aos benefícios correspondentes a essas disfunções, os entrevistados entraram em consenso e concordaram totalmente que esses benefícios estão presentes na empresa, o que implica em uma contradição das respostas assinaladas pelos entrevistados.

Essas inconsistências e contradições se deve ao fato de que algumas dessas disfunções estiveram presentes na implantação e continuam nos dias atuais, que é o caso da disfunção (D2) na empresa "A" e a disfunção (D10) na empresa "B".

\subsubsection{Disfunções e Benefícios com Índice de Concordância Negativo}

Para as disfunções e os benefícios que possuem o índice de concordância negativo, ou seja, que não obtiveram homogeneidade nas respostas dos entrevistados, o coeficiente de variação também foi calculado, apresentando valores com alta dispersão, com dados heterogêneos. A partir dessa constatação, pode-se 
apresentar algumas reflexões, a primeira delas consiste no fato de que na empresa "A", a entrevistada 1, recém contratada, não possuía a experiência e tempo de função em relação aos colegas da área, logo suas respostas foram ao extremo quando comparadas as demais respostas, como pode ser observado no Apêndice 6 deste trabalho.

Enquanto na empresa "B", apesar de todos os entrevistados possuírem tempo de função e acompanharem o processo de implantação do modelo de referência, em algumas disfunções eles não tiveram a mesma percepção. No entanto, em relação aos benefícios, houve homogeneidade nas respostas.

Assim, as disfunções e benefícios que possuem índice de concordância negativo em ambas as empresas, não são passíveis de serem analisadas devido à alta dispersão dos dados obtidos nas respostas dos entrevistados. 


\section{CONCLUSÕES}

Neste capítulo, são discutidas as conclusões do trabalho e são apresentadas as limitações e sugestões para trabalhos futuros a partir dos resultados atingidos nesta pesquisa.

\subsection{Aspectos Gerais}

O trabalho foi delineado pelo seguinte objetivo de pesquisa: identificar $e$ analisar as disfunções e os benefícios que ocorrem na implantação e uso de modelos de referência específicos no processo de desenvolvimento de produto.

Para identificar as disfunções e os benefícios, foram utilizados dois métodos: A Revisão Bibliográfica e o Estudo de Caso.

A revisão bibliográfica resultou em uma lista de 25 disfunções e 13 benefícios (APÊNDICE 4) e (APÊNDICE 5) respectivamente. Posteriormente, foi realizado o estudo de caso, com o auxílio do questionário de pesquisa (APÊNDICE 3) em duas empresas que possuem, em seu processo de desenvolvimento de produto, um modelo de referência específico com a finalidade de identificar novas disfunções e benefícios.

A análise das disfunções e dos benefícios foi realizada com base nos relatos dos entrevistados na entrevista focada, nas questões abertas, parte III do questionário.

O resultado do estudo de caso foi detalhado e analisado no capítulo 4 deste trabalho.

Diante dos dados obtidos das questões fechadas (questões 23 e 24) e os relatos dos entrevistados nas questões abertas (questões 1 a 22) do questionário de pesquisa, a maioria das disfunções levantadas da literatura foi classificada no grupo 1 como "discordo totalmente" com índices de concordância acima de 0,7 nas empresas A e B. Este fato pode ser explicado por alguns fatores: 
$\checkmark$ Anteriormente à implantação do modelo de referência específico, as empresas tiveram uma preparação preliminar. No caso da empresa "A", a matriz realizou um estudo do PDP na filial e no caso da empresa "B" foi realizado um diagnóstico do PDP em parceria com uma universidade;

$\checkmark \quad$ A alta direção teve um papel fundamental na implantação do modelo de referência em ambas as empresas. Ela esteve presente e comprometida durante toda a fase de implantação, até nos dias atuais, quando ainda é necessário realizar quaisquer alterações;

$\checkmark \quad$ Durante a implantação do modelo de referência específico em ambas as empresas, houve a disseminação dos objetivos que a empresa pretendia alcançar com a implantação do modelo de referência específico a todos os envolvidos no PDP;

$\checkmark \quad$ Foram realizados inicialmente workshops para esclarecer as dúvidas do modelo de referência nas empresas "A" e "B" e, posteriormente à implantação, as empresas realizavam reuniões quinzenais com os times de projetos, o que permanece atualmente para discutir os projetos, as aprovações e etc.;

$\checkmark \quad$ No caso da empresa "B", durante a implantação, foi criado um time global, composto por duas pessoas de cada país em que a empresa atua, com autonomia para discutir os problemas do modelo de referência implantado e realizar quaisquer alterações para melhorar o modelo;

$\checkmark$ Os gestores da empresa "B" ofereceram liberdade para os funcionários criticarem os documentos padrões propostos pelo modelo de referência específico, com a finalidade de deixá-los mais próximos dos documentos padrões que os funcionários da empresa já utilizavam no seu dia a dia, o que facilitou a adaptação do modelo de referência específico na rotina dos funcionários;

$\checkmark$ As empresas A e B possuem um importante suporte de tecnologia de informação ( $\mathrm{TI}$ ) para apoiar o uso do modelo de referência específico. Os projetos, os documentos padrões e os requisitos de entregas estão localizados em um portal na intranet em que a matriz e todas as filiais têm acesso, o que facilita o uso do modelo de referência no dia a dia das pessoas envolvidas no PDP;

Porém, vale ressaltar que algumas dessas disfunções classificadas como "discordo totalmente" estiveram presentes durante a fase implantação do modelo de referência e, atualmente, não existem mais em ambas as empresas. O que significa 
que as algumas disfunções não são permanentes nas empresas, ou seja, estão presentes somente na fase de implantação do modelo de referência específico.

Nas empresas, as disfunções que foram classificadas no grupo 2 como "discordo e concordo parcialmente" com IC acima de 0,7 estiveram presentes em algum momento.

Em ambas as empresas, não foram identificadas novas disfunções em relação à lista de disfunções levantadas na literatura.

Outros pontos a destacar é que muitas das disfunções levantadas na literatura não são relacionadas diretamente com o modelo de referência específico, como se pode observar na descrição das seguintes disfunções.

Disfunção (D1) - Falta de comprometimento da alta direção (Ex.: Stakeholders);

Disfunção (D3) - Os funcionários trabalham em um constante estado de dissonância com a prática;

Disfunção (D4) - Falta de recursos para a implantação do modelo de referência;

Disfunção (D8) - Cultura organizacional não apoia o modelo de referência; e

Disfunção (D14) - Há uma relutância em compartilhar conhecimento e colaborar.

Assim, as disfunções levantadas relacionadas ao modelo de referência específico não estão limitadas apenas a sua representação, documentos padrões, entregas em cada atividade e linguagem comum do processo. As disfunções podem envolver outros aspectos, como, por exemplo, o aspecto humano, cultural e financeiro, que pode surgir após a implantação do modelo de referência específico na empresa.

As disfunções que apresentaram índice de concordância baixo, classificadas no grupo 4, não puderam ser avaliadas profundamente, pois não existiu consenso entre as respostas dos entrevistados e houve alta dispersão, o que não permite conclusões no trabalho.

Os benefícios levantados na literatura, diferentemente das disfunções, foram classificados como "concordo totalmente" e "concordo parcialmente" com índice de 
concordância acima de 0,7 nas empresas analisadas. A empresa "A" apresentou resultados diferentes quando comparada com a empresa "B", pois em muitos benefícios os entrevistados não possuíram consenso nas respostas do questionário de pesquisa. No total de treze benefícios apresentados, a empresa "A" classificou quatro benefícios no grupo 3 - "concordo totalmente" - e dois benefícios no grupo 2 - "discordo e concordo parcialmente", enquanto a empresa B classificou os treze benefícios apresentados como "concordo totalmente" e os entrevistados possuíram consenso em todos os benefícios levantados da literatura. Os resultados diferentes dos benefícios de ambas as empresas se devem ao fato primeiramente do tempo de função dos entrevistados não ser homogêneos. Outro fato a destacar é que no caso da empresa "A", nenhum dos entrevistados participou da implantação do modelo de referência na empresa, enquanto todos entrevistados da empresa "B" participaram do momento de implantação.

Houveram alguns benefícios adicionais destacados pelas empresas quanto ao uso do modelo de referência. Na empresa "A" os principais benefícios citados foram:

- Uniformização da nomenclatura;

- Evitar o retrabalho;

- Organização dos processos;

- Visualização do andamento do projeto;

- $\quad$ Alinhamento global entre a matriz e as filiais;

- Execução sem falha; e

- Segurança nas atividades do dia-a-dia.

Enquanto na empresa "B" os entrevistados destacaram alguns benefícios adicionais, descritos a seguir:

- Melhoria na precisão das informações;

- $\quad$ Organização dos processos;

- Organização dos documentos padrões;

- $\quad$ Melhor disciplina no PDP;

- $\quad$ Atender o escopo do projeto;E

- Redução do tempo de entrega do produto no mercado. 
Esse último benefício citado na empresa "B" foi enfatizado por um dos entrevistados, em que relatou que anteriormente a implantação do modelo de referência, a empresa demorava aproximadamente de 3 à 5 anos para lançar um produto no mercado e que atualmente esse tempo diminuiu para apenas 2 anos.

A Tabela 29 a seguir sumariza as disfunções e benefícios confirmados e não confirmados em ambas as empresas analisadas com alto índice de concordância.

Tabela 29 - Total das disfunções e benefícios nas empresas A e B.

\begin{tabular}{lcc}
\hline & Disfunções & Benefícios \\
\hline Concordo Totalmente & 1 & 17 \\
Discordo Totalmente & 21 & 0 \\
\hline
\end{tabular}

Por fim, de acordo com os dados apresentados na Tabela 29, as disfunções levantadas na literatura, em sua maioria não ocorreram durante a implantação do modelo de referência específico e também não foram confirmadas no uso do modelo. Enquanto os benefícios, diferentemente das disfunções foram confirmados em sua maioria, o que revela que o modelo de referência específico é considerado uma melhor prática para conduzir o negócio de ambas às empresas. O modelo de referência específico é considerado uma melhor prática nessas empresas, pois nele podem ser representadas não somente atividades de um processo, como também métodos, ferramentas e todas essas informações podem ser consideradas como melhores práticas que são adotadas pelas empresas na melhoria do PDP.

\subsection{Limitações}

As limitações deste trabalho estão descritas a seguir:

1. Na literatura não há muitas pesquisas direcionadas a analisar as disfunções que ocorrem na implantação e uso do modelo de referência específico. Diante disso, 
a lista de disfunções levantadas não obteve uma grande abrangência dos mais variados tipos de disfunções;

2. O número de empresas analisadas e o número de entrevistados não são uma amostra significativa;

3. O tempo de função dos entrevistados não é homogêneo;

4. Como os casos analisados possuem suas particularidades e especificidades, não se podem generalizar os resultados e conclusões obtidas com este trabalho.

\subsection{Trabalhos Futuros}

Como sugestão para trabalhos futuros, recomenda-se:

- $\quad$ Aplicar o questionário de pesquisa em uma quantidade maior de empresas que possuem o modelo de referência em seu desenvolvimento de produto;

- $\quad$ Adaptar o questionário para ser aplicado em empresas durante a implantação do modelo de referência específico e acompanhar todo o processo de implantação; - Realizar o questionário em empresas que possuam o modelo de referência específico recém-implantado com o objetivo de levantar novas disfunções. 


\section{REFERÊNCIAS}

ASSOCIAÇÃO BRASILEIRA DE NORMAS TÉCNICAS. NBR ISO 9000: Sistemas de Gestão da Qualidade - Fundamentos e Vocabulários. Rio de Janeiro: ABNT, 2000.

ALLIPRANDINI, D.H. TOLEDO, J.C. DE. Modelo para gestão de processo de desenvolvimento de produtos: uma proposta baseada em dimensões críticas. $4^{\circ} \mathrm{CBGDP}, 2003$.

ALVARENGA-NETTO, C. Definindo gestão por processos: características, vantagens, desvantagens. In: LAURINDO, F. J. B. e ROTONDARO, R. G. Gestão Integrada de Processos e da Tecnologia da Informação. São Paulo: Atlas, 2006. cap. 2, p. 14-37.

AMARAL, D.C. Arquitetura para gerenciamento de conhecimentos explícitos sobre processo de desenvolvimento de produto. $229 \mathrm{f}$. Tese (Doutorado em Engenharia Mecânica) - Escola de Engenharia de São Carlos, Universidade de São Paulo, São Carlos, 2002a.

AMARAL, C.S.T.; ROZENFELD, H. Sistematização das melhores práticas de desenvolvimento de produtos para acesso livre e compartilhamento na internet. Revista \& Produção, v. 9, n. 2, p. 120-135, 2008b.

AHLEMANN, F; GASTL, H. Process Model for an empirically grounded reference model construction. In: Reference Modeling for Business Systems Analysis. Idea Group Publishing, Heshey, p. 389, 2007.

BALDAM, R., et al. Gerenciamento de Processos de Negócios - BPM - Business Process Management. Rio de Janeiro: Editora Érica, 2006, p.240.

BARBALHO, M. C.S; ROZENFELD, H. Modelo de referência para o processo de desenvolvimento de produtos mecatrônicos (MRM): validação e resultados de uso. Revista G\&P, São Carlos, v.20, n.1, p.179,2012.

BREMER, C.F.; LENZA, R. De P. Um Modelo de referência para gestão da produção em sistemas de produção Assembly to order- ATO e suas múltiplas aplicações. Gestão \& Produção, v. 7, n. 3, p. 269-282, 2000. 
BURLTON, R. Business Process Management: profiting from process. Indianapolis: Sams Publishing.2001, 416p.

BROWNING, et al. Key concepts in modeling product development processes. Systems Engineering, v. 9, n. 2, p. 104-128, 2006.

BROWNING, T. R. On the alignment of the purposes and views of process models in project management. Journal of Operations Management, v. 28, n. 4, p.316-332, 2010.

CARVALHO, M.M. et al. Gestão da qualidade: teoria e casos. São Paulo: Campus/Elsevier, 2006. 355 p.

CHENG, L.C. Caracterização da Gestão de desenvolvimento do produto: delineando o seu contorno e dimensões básicas. In: Congresso Brasileiro de Gestão de Desenvolvimento de Produto, II, 2000, São Carlos. Anais ... São Carlos: UFSCAR, 2000. p. 1-9.

CHANG, J.F. Business Process Management Systems: Strategy and Implementation. Boca Raton: Auerbach Publications, 2006. 304 p.

CLARK, K. B. e FUJIMOTO, T. Product development performance: strategy, organization and management in the world auto industry. Boston, Mass.: Harvard Business School, 1991. 350 p.

CLARK, K. B. e WHEELWRIGHT, S. C. Managing new product and process development. New York: The Free Press, 1993. 896 p.

CRUZ, T. BPM \& BPMS: Business Process Management \& Business Process Management Systems. Rio de Janeiro: Brasport, 2008. 294 p.

COOPER, R. G. Winning at new products. Persus Pub, 2001.

COOPER, R. G. - Perspective: The Stage-Gate ${ }^{\circledR}$ Idea-to-Launch Process - Update, What's New and NexGen Systems - The Journal of Product Innovation Management, 2008.

DAVENPORT, T. H. Process innovation: reengineering work through information technology. Boston: Harvard Business School Press, 1993. 337 p. 
DE SORDI, J, O. Gestão por processos: Uma abordagem da moderna administração. Editora Saraiva 2008.288p.

DE OLIVEIRA. Qualificando os processos de sua organização. In: VALLE, R.; BARBARÁ, S. Análise e Modelagem de Processos de Negócio: foco na notação BPMN (Business Process Modeling Notation). São Paulo: Atlas, 2009, cap.3, p. 2127.

ENGWALL, M.; KLING, R. e WERR, A. Models in action: how management models are interpreted in new product development. R\&D Management, v. 35, n. 4, p. 427439, 2005.

FASS, F. D. M. et al. Seleção de um modelo de processo de desenvolvimento de produto para indústria de base tecnológica do ramo eletroeletrônico. In: $X X I X$ ENCONTRO NACIONAL DE ENGENHARIA DE PRODUÇÃO, Salvador, BH, Brasil. Anais... Salvador, 2009.

FETTKE, P.; LOOS, P. Using Reference Models for Business Engineering - State-ofthe-Art and Future Developments. Information Systems, 2006a.

FETTKE, P.; LOOS, P.; ZWICKER, J. Business Process Reference Models: Survey and Classification. 3rd International Conference on Business Process Management. Anais... p.469 - 483, 2006b. Nancy, FRANCE.: Springer-Verlag Berlin. FETTKE, P. e LOOS, P. Perspectives on Reference Modeling. In: Reference Modeling for Business Systems Analysis. Hershey: Idea Group Publishing, 2007.

FORMOSO, C.T.; TZORTZOPOULOS, P; LIEDTKE, R.A model for managing the product development process in house bulding. Engineering, construction and architectural management, v.9, n.5, p.419-432, 2002.

GRAHAM, M. e LeBARON, M. The horizontal revolution. San Francisco: JosseyBass. 1994.

GEORGES, M.R.R. Modelagem dos processos de negócio e especificação de um sistema de controle da produção na indústria de autoadesivos. Journal of Information Systems and Technology Management, 2010. 
GIL, Antônio C. Como elaborar projetos de pesquisa. 3. ed. São Paulo: Atlas, 1996.

GONÇALVES, J. E. L. As empresas são grandes coleções de processos. RAE Revista de Administração de Empresas, v. 40, n. 1, p. 6-19, 2000 a.

GONÇALVES, J. E. L. Processo, que processo? RAE - Revista de Administração de Empresas, v. 40, n.4, p. 8-19, 2000b.

GRÖNLUND, J.; SJÖDIN, D.R. e FRISHAMMAR, J. Open Innovation and the Stagegate Process: A Revised Model for New Product Development. California Management Review, v. 5, n. 3, p.106-131, 2010.

HAMMERS, C.; SCHMITT, R. Governing the process chain of product development with an enhanced Quality Gate approach. CIRP Journal of Manufacturing Science and Technology, v. 1, n. 3, 2009.

HAMMER, M. The process audit. Harvard Business Review, 85(4), 111-142, 2007.

HAMMER, M. e CHAMPY, J. Reengenharia: revolucionando a empresa. Rio de Janeiro: Campus, 1994. 190 p.

HARRINGTON, H.J. Aperfeiçoando processos empresariais. São Paulo: Makron Books. 1993. 343 p.

HARRISON, M. I. e SHIROM, A. Organizational Diagnosis and Assessment: Bridging Theory and Pratice. California: Sage Publications, 1999. 496 p.

JAMES, L.R.; DEMAREE, R.G.; WOLF G. Estimating within-group interrater reliability with and without response bias, Journal of Applied Psychology, V.69, n.1, p.85-98. 1984.

JAMES, L.R.; DEMAREE, R.G.; WOLF G. rwg: An Assessment of Within-Group Interrater Agreement. Journal of Applied Psychology, V.78, n.2, p.306-309. 1993.

JESTON, J., NELIS, J. Business Process Management Practical Guidelines to Succesful Implementations (2o edition.). Oxford: Elsevier.2006.p.504.

JUN, B.H; SUH, W.H. A modeling framework for product development process considering it characteristics. 2008.p.119. 
KARLSSON, C. Researching Operations Management. Taylor and Francis, 2008. KALPIC, B.P, B. Business process modelling in industry - the powerful tool in enterprise management. 2002. p.20.

KELLER, G. e TEUFEL, T. SAP R/3 process-oriented implementation. Londres: Addison Weley Longman. 1998. $880 \mathrm{p}$.

LAKATOS, E.M; MARCONI, M.A.de. Fundamentos de metodologia científica. São Paulo: Atlas, 1991. 270 p.

MAHAJAN, V. e WIND, Y. New Product Models: Practice, Shortcomings and Desired Improvements. Journal of Product Innovation Management, v. 9, n. 2, p.128-139, 1992.

MARTIN, J. Cybercorp: The New Business Revolution. New York: Amacom, 1996. $336 \mathrm{p}$.

MUNDIM, A.P. $F$ et al. Aplicando o cenário de desenvolvimento de produtos em um caso prático de capacitação profissional. Gestão \& Produção, v.9, n.1, 2002. p16.

MÜCKENBERGER, E.et al. Gestão de processos aplicada à realização de convênios internacionais bilaterais em uma instituição de ensino superior pública brasileira. Gestão \& Produção, 2011, p15.

McCARTHY, I. P., et al. New product development as a complex adaptive system of decisions. Journal of Product and Innovation Management, v. 23, n. 5, p. 437456, 2006.

MORETTI, I. C. et al. Modelo de referência para desenvolvimento de produtos:análise da contribuição acadêmica.XXXII Encontro Nacional de Engenharia de Produção,p.14, 2012a.

MORETTI, I.C; et al. Diagnóstico da gestão do processo de desenvolvimento de produto: um estudo de caso na indústria de confecção do vestuário. Revista Produto \& Produção, v.13, n.3, p.37-48,2012b. 
NEUBAUER, T. An empirical study about the status of business process management. Business Process Management Journal, v.15, n. 2, p. 166-183, 2009.

ONOYAMA, M.M.TOLEDO, J.C. A gestão do processo de desenvolvimento de produtos em empresas fornecedoras de bens de capital para o Setor Sucroalcooleiro. $8^{\circ}$ Congresso Brasileiro de Gestão de desenvolvimento de produto (CBGDP), 2011, p12.

PAHL, G.; BEITZ, W. Engineering design: systematic approach - 2 Ver. Ed, Berlim : Springer - Verlag London Limited, 1996.

PAHL, G.; BEITZ, W.; FELDHUSEN, J., GROTE, K. 2005. Projeto na engenharia: fundamentos do desenvolvimento eficaz de produtos, métodos e aplicações. Trad. Werner, H. A., 6ª ed. São Paulo: Editora Edgar Blücher.

PIDD, M. Modelagem empresarial: ferramentas para a tomada de decisão. Trad. Gustavo Severo de Borba. Porto Alegre: Bookman, 1998. 316 p.

PUGH, S. Total design: integrated methods for successful product engineering. Londres: Addison Weley Longman, 1990. 312 p.

RECKER, J. et al. Configurble Reference Modeling Languages. In: FETTKE, P. e LOOS, P., Reference Modeling for Business Systems Analysis. Heshey: Idea Group Publishing, 2007. p. 22-46.

ROZENFELD, H., et al. Gestão de Desenvolvimento de Produtos. São Paulo: Editora Saraiva 2006. 542 p.

ROZENFELD, H., Reflexões sobre a Manufatura Integrada por Computador (CIM). Escola de Engenharia de São Carlos (EESC-USP), 1996.16p.

RUMMLER, G. e BRACHE, A. Improving performance: How to Manage the White Space in the Organization Chart. San Francisco: Jossey-Bass, 1995. 256 p.

THOMAS, O. Understanding the Term Reference Model in Information Systems Research: History, Literature Analysis and Explanation. BPM 2005 Workshops, p. 484-496, 2006. 
SALGADO, G. E. et al. Modelos de Referência para Desenvolvimento de Produto:Classificação,Análise e Sugestões para Pesquisas Futuras. Revista Produção Online. v. 10, n. 4, p. 1-26, 2010.

SAMPIERI, R.H. Metodologia de Pesquisa. McGraw Hill. 2006.608 p.

SOUZA, C.A. ZWICKER, R. Ciclo de Vida de Sistemas ERP. Caderno de Pesquisa em administração, v.1, n.11, 2000.

SUAREZ, M.T et al. Adaptação e aplicação de um método de desenvolvimento de produtos em uma microempresa de manufatura de produtos decorativos. Revista P\&D em Engenharia de Produção v.07 N.01,2009.

SMITH, H. e FINGAR, P. Business Process Management the third wave. Tampa: Meghan-Kiffer Press., 2003. 311 p.

VALLE, R.; COSTA, M.M. Gerenciar os processos, para agregar valor à organização. In: VALLE, R.; BARBARÁ, S. Análise e Modelagem de Processos de Negócio: foco na notação BPMN (Business Process Modeling Notation). São Paulo: Atlas, 2009. Cap.1, p.1-13.

VON BROKE, J.Design Principles for Reference Modeling, In: Fettke, P., Loos, P. (ed) Reference Modeling for Business Systems Analysis. Capítulo 3, Idea Group Publishing. Hershey.2007.

VERNADAT, F. Enterprise Modeling and Integration: Principles and Applications. Londres: Springer, 1996. 528 p.

YIN, R. K. Estudo de Caso: Planejamento e Métodos. Porto Alegre: Bookman, 2005. $248 \mathrm{p}$.

ZAIRI, M. Business process management: a boundaryless approach to modern competitiveness. Business Process Management Journal, Vol. 3 No. 1, 1997, p.17.

ZANCUL, E. S. DE. Análise da Aplicabilidade de um sistema ERP no processo de desenvolvimento de produto. $242 \mathrm{f}$. Dissertação (Mestrado em Engenharia de Produção Mecânica) - Escola de Engenharia de São Carlos, Universidade de São Paulo, São Carlos, 2000. 


\section{APÊNDICE 1- TERMO DE CONSENTIMENTO LIVRE E ESCLARECIDO}

O Sr(a). está sendo convidado(a) para participar da pesquisa intitulada: Análise das disfunções que ocorrem na implantação e uso de modelos de referência no PDP. Sua colaboração é importante e necessária para o desenvolvimento da pesquisa, porém sua participação é voluntária. Sendo assim, a qualquer momento você pode desistir de participar e retirar seu consentimento. O Sr(a). não terá nenhum custo ou quaisquer compensações financeiras. Suas respostas serão tratadas de forma anônima e confidencial, isto é, em nenhum momento será divulgado o seu nome em qualquer fase do estudo. Quando for necessário exemplificar determinada situação, sua privacidade será assegurada uma vez que seu nome será substituído de forma aleatória. Você poderá solicitar informações ou esclarecimentos sobre o andamento da pesquisa em qualquer momento com o pesquisador responsável. Desde já agradecemos!

Pesquisador:

\section{(Assinatura)}

São Carlos de de 2013.

Declaro participar como voluntário(a) da pesquisa, afirmo que fui devidamente informado(a) e esclarecido(a) sobre os objetivos desta pesquisa, bem como sobre a utilização das informações exclusivamente para fins científicos. Meu nome não será divulgado de forma nenhuma e terei a opção de retirar meu consentimento a qualquer momento.

Sujeito da pesquisa:

(Assinatura) 


\section{APÊNDICE 2 - ESTRUTURA PARA A ELABORAÇÃO DO QUESTIONÁRIO}

\begin{tabular}{|c|c|c|c|c|c|}
\hline $\begin{array}{c}\text { Objetivo Principal } \\
\text { da Pesquisa }\end{array}$ & $\begin{array}{l}\text { Objetivos } \\
\text { Específicos }\end{array}$ & $\begin{array}{l}\text { Desdobramento } \\
\text { dos Objetivos }\end{array}$ & $\begin{array}{c}\text { O que vai avaliar/medir } \\
\text { (Características) }\end{array}$ & Variáveis - Como medir a característica & Questões \\
\hline \multirow{8}{*}{$\begin{array}{c}\text { Analisar as } \\
\text { disfunções que } \\
\text { ocorrem na } \\
\text { implantação e uso } \\
\text { do modelos de } \\
\text { referência } \\
\text { específico no PDP }\end{array}$} & \multirow{3}{*}{ 1. Dados Gerais } & \multirow{2}{*}{$\begin{array}{l}\text { Função e tempo de } \\
\text { função do } \\
\text { Funcionário }\end{array}$} & Função do funcionário & $\begin{array}{l}\text { Gerente de projetos } \\
\text { Gerente de Produto } \\
\text { Gerente de P\&D } \\
\text { Diretor de Engenharia }\end{array}$ & Qual é a sua função na empresa? \\
\hline & & & Tempo de função & $\begin{array}{l}\text { Até } 1 \text { ano } \\
\text { Acima de } 5 \text { anos } \\
\text { Acima } 10 \text { anos }\end{array}$ & Quanto tempo você está nessa função? \\
\hline & & $\begin{array}{l}\text { Definir o setor da } \\
\text { empresa }\end{array}$ & Setor & $\begin{array}{l}\text { 1. Aeroespacial e defesa; } \\
\text { 2. Equipamentos elétricos e eletrônicos; } \\
\text { 3. Engenharia industrial e transportes; } \\
\text { 4. Automotiva e parte; } \\
\text { 5. Alimentos e bebidas; } \\
\text { 6. Bens pessoais e domésticos; } \\
\text { 7. Cuidados com a saúde; } \\
\text { 8. Telecomunicações; } \\
\text { 9. Software e serviços computacionais; } \\
\text { 10. Tecnologia de hardware e equipamentos; } \\
\text { 11. Outra... }\end{array}$ & Qual setor da indústria a empresa está inserida? \\
\hline & \multirow{5}{*}{$\begin{array}{l}\text { 2. Analisar a } \\
\text { experiência das } \\
\text { empresas em } \\
\text { relação a } \\
\text { implantação e } \\
\text { uso do modelo } \\
\text { de referência } \\
\text { específico no } \\
\quad \text { PDP }\end{array}$} & \multirow{5}{*}{ Implantação } & MR específico & Tipo de modelo implantado & $\begin{array}{l}\text { O modelo de referência implantado na empresa decorreu do: } \\
\text { A. [ ] Modelo de referência da matriz; } \\
\text { B. [ ] Modelo de referência desenvolvido especificamente para a unidade, a partir de um } \\
\text { modelo padrão do seu segmento; } \\
\text { C. [ ] Modelo de referência desenvolvido especificamente para a unidade, a partir de um } \\
\text { modelo genérico encontrado em livros e/ou sites; } \\
\text { D. [ ] Modelo de referência desenvolvido especificamente para a unidade, a partir de um } \\
\text { serviço de consultoria; } \\
\text { E. [ ] Modelo de referência desenvolvido especificamente para a unidade, a partir da análise da } \\
\text { situação atual, definição de melhoria, com apoio único do pessoal interno. }\end{array}$ \\
\hline & & & $\begin{array}{l}\text { Envolvimento } \\
\text { da equipe }\end{array}$ & $\begin{array}{l}\text { Sim/Não } \\
\text { Variável qualitativa (atributo) }\end{array}$ & $\begin{array}{l}\text { Durante o desenvolvimento do modelo de referência houve uma interação com seus usuários } \\
\text { visando sua adaptação às necessidades específicas da empresa? Em caso afirmativo. Quais } \\
\text { foram às alterações necessárias? }\end{array}$ \\
\hline & & & Consulta do MR & Variável qualitativa (atributo) & Qual o meio utilizado para consultar o modelo? (Ex: quadro visual, gráfico, rede, intranet). \\
\hline & & & Auxílio na Implantação & $\begin{array}{c}\text { Sim/Não } \\
\text { Variável qualitativa (atributo) }\end{array}$ & $\begin{array}{l}\text { A empresa utilizou consultoria para auxiliar na implantação do modelo de referência na } \\
\text { empresa? } \\
\text { Qual o principal motivo da contratação? }\end{array}$ \\
\hline & & & Duração de implantação & Variável quantitativa & Quanto tempo durou a implantação do modelo de referência na empresa? \\
\hline
\end{tabular}




\begin{tabular}{|c|c|c|c|c|c|}
\hline $\begin{array}{l}\text { Objetivo Principal } \\
\text { da Pesquisa }\end{array}$ & $\begin{array}{l}\text { Objetivos } \\
\text { Específicos }\end{array}$ & $\begin{array}{l}\text { Desdobramento } \\
\text { dos Objetivos }\end{array}$ & $\begin{array}{l}\text { O que vai avaliar/medir } \\
\text { (Características) }\end{array}$ & Variáveis - Como medir a característica & Questões \\
\hline & & & $\begin{array}{l}\text { Modelo de apoio } \\
\text { à implantação }\end{array}$ & $\begin{array}{l}\text { Sim/Não } \\
\text { Variável qualitativa (atributo) }\end{array}$ & $\begin{array}{l}\text { Foi utilizado algum modelo de apoio durante a implantação do modelo de referência? } \\
\text { Quais foram as principais etapas desse modelo de implantação ? }\end{array}$ \\
\hline & & & $\begin{array}{c}\text { Envolvimento das áreas } \\
\text { durante a implantação } \\
\text { do MR } \\
\end{array}$ & Variável qualitativa (atributo) & Quais as áreas que se envolveram durante a implantação do modelo de referência na empresa? \\
\hline & & & $\begin{array}{l}\text { Áreas que } \\
\text { participam do PDP }\end{array}$ & Variável qualitativa (atributo) & Quais áreas que participam do processo de desenvolvimento de produto da empresa? \\
\hline & & & $\begin{array}{l}\text { Participação das } \\
\text { pessoas } \\
\text { na implantação }\end{array}$ & Sim/Não & $\begin{array}{l}\text { Durante a implantação do modelo de referência na empresa houve a participação de todas as } \\
\text { pessoas envolvidas no processo de desenvolvimento de produtos? }\end{array}$ \\
\hline & & & $\begin{array}{c}\text { Dificuldade } \\
\text { na implantação do MR }\end{array}$ & $\begin{array}{c}\text { Sim/Não } \\
\text { Variável quantitativa } \\
\text { Variável qualitativa (atributo) }\end{array}$ & $\begin{array}{l}\text { Houve problemas na implantação do modelo de referência? } \\
\text { Quais foram os principais problemas? Como foram solucionados? }\end{array}$ \\
\hline & & & $\begin{array}{l}\text { Tempo de implantação } \\
\text { do MR }\end{array}$ & Variável quantitativa & Há quanto tempo o modelo de referência está implantado na empresa? \\
\hline & & & Treinamento sobre MR & Variável quantitativa & 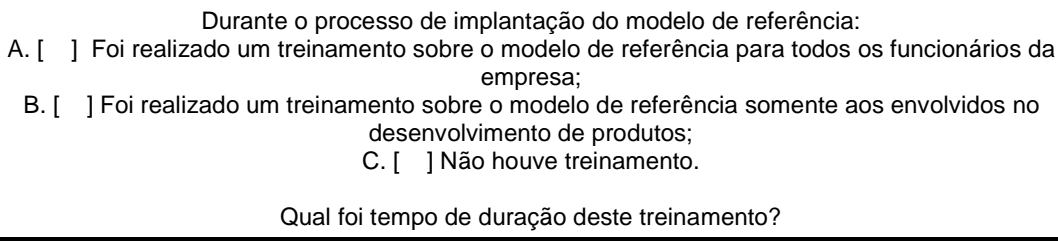 \\
\hline & & & $\begin{array}{l}\text { Utilidade do } \\
\text { treinamento do MR }\end{array}$ & Variável qualitativa ordinal & $\begin{array}{l}\text { Quão útil foi o treinamento para a compreensão do modelo de referência: } \\
\text { ( ) Muito útil } \\
\text { ( ) Util } \\
\text { ( ) Pouco útil } \\
\text { ( ) Indiferente }\end{array}$ \\
\hline & & \multirow{4}{*}{ Uso } & $\begin{array}{l}\text { Treinamento } \\
\text { sobre MR }\end{array}$ & Sim/Não & $\begin{array}{l}\text { O treinamento sobre modelo de referência faz parte da política de admissão dos funcionários } \\
\text { envolvidos no desenvolvimento de produtos? }\end{array}$ \\
\hline & & & Alterações no MR & $\begin{array}{c}\text { Sim/Não } \\
\text { Variável qualitativa (atributo) }\end{array}$ & $\begin{array}{l}\text { Depois de algum tempo implantado foram realizadas alterações no modelo de referência da } \\
\text { empresa? Em caso afirmativo. Quais? }\end{array}$ \\
\hline & & & $\begin{array}{l}\text { Responsáveis pela } \\
\text { alteração }\end{array}$ & Variável qualitativa (atributo) & Quem foram os responsáveis pelas alterações? \\
\hline & & & $\begin{array}{l}\text { Objetivo do Modelo de } \\
\text { referência }\end{array}$ & Variável qualitativa (atributo) & $\begin{array}{l}\text { Quais objetivos que a empresa pretendia alcançar com a implantação do modelo de referência } \\
\text { no processo de desenvolvimento de produto (PDP)? } \\
\text { Quais objetivos não foram alcançados? } \\
\text { Quais as razões de não terem sido alcançados? }\end{array}$ \\
\hline
\end{tabular}




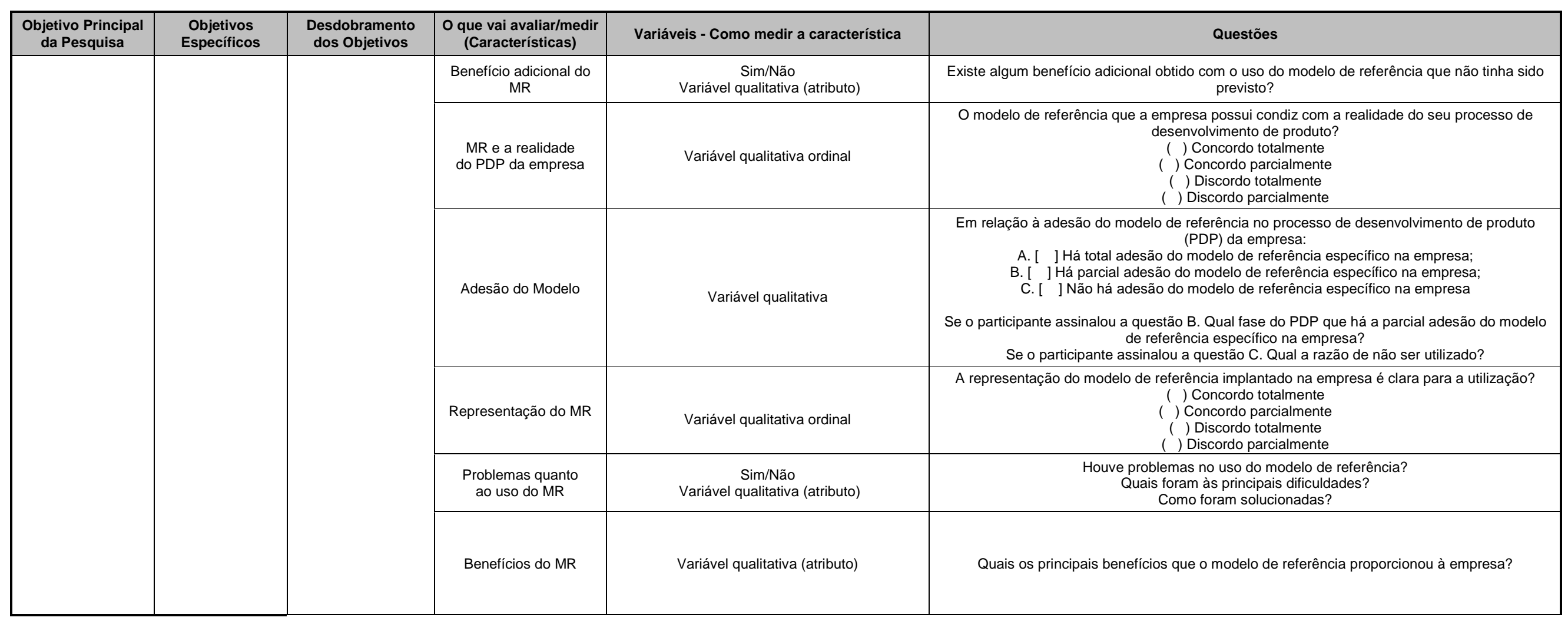




\section{APÊNDICE 3 - QUESTIONÁRIO DE PESQUISA}

\section{Proposta da Pesquisa}

Este questionário tem como objetivo analisar a experiência das empresas durante a implantação e uso de um modelo de referência específico no processo do desenvolvimento de produtos (PDP).

Todas as informações levantadas nesta pesquisa serão estritamente confidenciais. Os dados coletados serão neutralizados para análise, de forma que os leitores não possam identificar informações específicas da empresa.

\section{Parte I - Dados Gerais}

Empresa:

Setor de atuação:

Nome do entrevistado:

Função:

Tempo na função:

E-mail:

Data: 1

\section{Parte II - Questões de Pesquisa}

1. O modelo de referência implantado na empresa decorreu do:

A. [ ]Modelo de referência da matriz;

B. [ ]Modelo de referência desenvolvido especificamente para a unidade, a partir de um modelo padrão do seu segmento;

C. [ ]Modelo de referência desenvolvido especificamente para a unidade, a partir de um modelo genérico encontrado em livros e/ou sites; 
D. [ ]Modelo de referência desenvolvido especificamente para a unidade, a partir de um serviço de consultoria;

E. [ ]Modelo de referência desenvolvido especificamente para a unidade, a partir da análise da situação atual, definição de melhoria, com apoio único do pessoal interno.

Durante o desenvolvimento do modelo de referência houve uma interação com seus usuários visando sua adaptação às necessidades específicas da empresa?

$\operatorname{Sim}($ )

Não ( )

Em caso afirmativo. Quais foram às alterações necessárias?

2. Qual o meio utilizado para consultar o modelo? (Ex: quadro visual, gráfico, rede, intranet).

3. A empresa utilizou consultoria para auxiliar na implantação do modelo de referência na empresa?

$\operatorname{sim}($ )

Não ( )

Em caso afirmativo. Qual o principal motivo da contratação?

4. Quanto tempo durou a implantação do modelo de referência na empresa? 
5. Foi utilizado algum modelo de apoio durante a implantação do modelo de referência?

$\operatorname{Sim}()$

Não ( )

Em caso afirmativo. Quais as principais etapas do modelo de apoio durante a implantação do modelo de referência?

6. Quais as áreas que se envolveram durante a implantação do modelo de referência na empresa?
A. [ ]Pesquisa \& Desenvolvimento
B. [ ]Engenharia
C. [ ]Suprimentos
D. [ ]Marketing
E. [ ]Manufatura e Distribuição
F. [ ]Vendas

Outros:

7. Quais áreas que participam do processo de desenvolvimento de produto da empresa?
A. [ ]Pesquisa \& Desenvolvimento
B. [ ]Engenharia
C. [ ]Suprimentos 
D. [ ]Marketing

E. [ ]Manufatura e Distribuição

F. [ ]Vendas

\section{Outros:}

8. Durante a implantação do modelo de referência na empresa houve a participação de todas as pessoas envolvidas no processo de desenvolvimento de produtos?

$\operatorname{Sim}()$

Não ( )

9. Houve problemas na implantação do modelo de referência?

$\operatorname{Sim}()$

Não ( )

Quais foram os principais problemas? Como foram solucionados?

10. Há quanto tempo o modelo de referência está implantado na empresa?

11. Durante o processo de implantação do modelo de referência:

A. [ ] Foi realizado um treinamento sobre o modelo de referência para todos os funcionários da empresa;

B. [ ]Foi realizado um treinamento sobre o modelo de referência somente aos envolvidos no desenvolvimento de produtos;

C. [ ]Não houve treinamento. 
Se o participante assinalou as questões A ou B. Qual foi tempo de duração deste treinamento?

12. Quão útil foi o treinamento para a compreensão do modelo de referência:

( ) Muito útil

( ) Útil

( ) Pouco útil

( ) Indiferente

13. O treinamento sobre modelo de referência faz parte da política de admissão dos funcionários envolvidos no desenvolvimento de produtos?

$\operatorname{Sim}()$

Não ( )

14. Depois de algum tempo implantado foram realizadas alterações no modelo de referência da empresa? Em caso afirmativo. Quais?

15. Quem foram os responsáveis pelas alterações?

16. Quais objetivos que a empresa pretendia alcançar com a implantação do modelo de referência no processo de desenvolvimento de produto (PDP)? 
Quais objetivos não foram alcançados?

Quais as razões de não terem sido alcançados?

17. Existe algum benefício adicional obtido com o uso do modelo de referência que não tinha sido previsto?

18. O modelo de referência que a empresa possui condiz com a realidade do seu processo de desenvolvimento de produto?
( ) Concordo totalmente
( ) Concordo parcialmente
( ) Discordo totalmente
( ) Discordo parcialmente

19. Em relação à adesão do modelo de referência no processo de desenvolvimento de produto (PDP) da empresa:
A. [ ] ] Há total adesão do modelo de referência específico na empresa;
B. [ ]Há parcial adesão do modelo de referência específico na empresa; 
C. [ ] Não há adesão do modelo de referência específico na empresa.

Se o participante assinalou a questão B. Qual fase do PDP que há a parcial adesão do modelo de referência específico na empresa?

Se o participante assinalou a questão C. Qual a razão de não ser utilizado?

20. A representação do modelo de referência implantado na empresa é clara para a utilização?

( ) Concordo totalmente

( ) Concordo parcialmente

( ) Discordo totalmente

( ) Discordo parcialmente

21. Houve problemas no uso do modelo de referência?

$\operatorname{Sim}()$

Não ( )

Quais foram às principais dificuldades? Como foram solucionadas?

22. Quais os principais benefícios que o modelo de referência proporcionou à empresa? 


\section{Parte III - Disfunções e Benefícios}

23. O quadro a seguir representa um conjunto de disfunções relacionadas à aplicação do modelo de referência encontrada na literatura acadêmica por meio de relatos de estudos de casos. Assinale a seguinte escala de avaliação:

\begin{tabular}{|c|c|c|c|c|}
\hline Não sei & $\begin{array}{c}\text { Discordo } \\
\text { Totalmente }\end{array}$ & $\begin{array}{c}\text { Discordo } \\
\text { Parcialmente }\end{array}$ & $\begin{array}{c}\text { Concordo } \\
\text { Parcialmente }\end{array}$ & $\begin{array}{c}\text { Concordo } \\
\text { Totalmente }\end{array}$ \\
\hline 0 & 1 & 2 & 3 & 4 \\
\hline
\end{tabular}

\begin{tabular}{|l|l|}
\hline \multicolumn{1}{|c|}{ Disfunções } & $\begin{array}{c}\text { Escala de } \\
\text { Avaliação }\end{array}$ \\
\hline Falta de comprometimento da alta direção (Ex: Stakeholders). & \\
\hline $\begin{array}{l}\text { Modelo de referência interpretado de maneiras diferentes pelos } \\
\text { funcionários. }\end{array}$ & \\
\hline $\begin{array}{l}\text { Os funcionários trabalham em um constante estado de dissonância com a } \\
\text { prática. }\end{array}$ & \\
\hline Falta de recursos para implantação do modelo de referência. & \\
\hline Implantação demorada do modelo de referência. & \\
\hline Modelo de referência é considerado dispendioso. & \\
\hline $\begin{array}{l}\text { Imprecisão do modelo de referência. } \\
\text { Cultura organizacional não apoia os modelos de referência. }\end{array}$ & \\
\hline $\begin{array}{l}\text { Modelo de referência considerado abstrato e ambíguo. } \\
\text { próximas do usuário. }\end{array}$ & \\
\hline $\begin{array}{l}\text { Modelo de referência não ajudam os funcionários na autogestão. } \\
\text { ou em que estado devem estar. }\end{array}$ & \\
\hline As informações do modelo de referência que são documentadas não são & \\
\hline
\end{tabular}




\begin{tabular}{|c|c|}
\hline Disfunções & $\begin{array}{l}\text { Escala de } \\
\text { Avaliação }\end{array}$ \\
\hline Funcionários não entendem os benefícios do modelo de referência. & \\
\hline Há uma relutância em compartilhar conhecimento e colaborar. & \\
\hline $\begin{array}{l}\text { Modelo de referência é considerado uma restrição à oportunidade de } \\
\text { aprendizado. }\end{array}$ & \\
\hline Modelo de referência considerado burocrático. & \\
\hline Modelo de referência não oferece autonomia aos gestores. & \\
\hline Não há documentos formais que descrevem o modelo de referência. & \\
\hline $\begin{array}{l}\text { Não há distinção entre modelo de referência e diretrizes administrativas da } \\
\text { empresa. }\end{array}$ & \\
\hline Modelo de referência não atende aos desafios específicos da realidade. & \\
\hline $\begin{array}{l}\text { Modelo de referência limitado na questão de apoiar à gestão dos aspectos } \\
\text { humanos. }\end{array}$ & \\
\hline Modelo de referência visto como carga administrativa ao invés de suporte. & \\
\hline $\begin{array}{l}\text { Modelo de referência está distante da realidade do desenvolvimento de } \\
\text { produtos. }\end{array}$ & \\
\hline Modelos de referência não são importantes no sentido de guiar as ações. & \\
\hline O modelo de referência oferece uma grande liberdade de interpretação. & \\
\hline
\end{tabular}


24. O quadro a seguir representa um conjunto de benefícios dos modelos de referência encontrada na literatura acadêmica. Assinale a seguinte escala de avaliação:

\begin{tabular}{|c|c|c|c|c|}
\hline Não sei & $\begin{array}{c}\text { Discordo } \\
\text { Totalmente }\end{array}$ & $\begin{array}{c}\text { Discordo } \\
\text { Parcialmente }\end{array}$ & $\begin{array}{c}\text { Concordo } \\
\text { Parcialmente }\end{array}$ & $\begin{array}{c}\text { Concordo } \\
\text { Totalmente }\end{array}$ \\
\hline 0 & 1 & 2 & 3 & 4 \\
\hline
\end{tabular}

\begin{tabular}{|c|c|}
\hline Benefícios & $\begin{array}{l}\text { Escala de } \\
\text { Avaliação }\end{array}$ \\
\hline $\begin{array}{l}\text { Modelo de referência oferece uma linguagem comum a todos os envolvidos no } \\
\text { processo de desenvolvimento de produto (PDP). }\end{array}$ & \\
\hline $\begin{array}{l}\text { Modelo de referência oferece uma maneira padronizada de medir o progresso do } \\
\text { projeto. }\end{array}$ & \\
\hline Modelo de referência assegura que todos trabalham da mesma maneira. & \\
\hline $\begin{array}{l}\text { Modelos de referência foram vistos como apoio à cooperação e comunicação eficazes } \\
\text { entre os projetos. }\end{array}$ & \\
\hline $\begin{array}{l}\text { Modelo de referência permitiu maior comunicação dentro da equipe do projeto bem } \\
\text { como as partes interessadas externas e outros projetos. }\end{array}$ & \\
\hline Modelo de referência oferece agilidade na tomada de decisão. & \\
\hline Modelo de referência oferece maior agilidade no diagnóstico de projetos. & \\
\hline $\begin{array}{l}\text { Modelo de referência reforça a cultura do projeto como empreendimento de toda a } \\
\text { empresa e não somente da área funcional da engenharia de produto. }\end{array}$ & \\
\hline Modelo de referência oferece uma redução de tempo do projeto. & \\
\hline $\begin{array}{l}\text { Modelo de referência oferece resultados finais mais eficazes na melhoria da gestão } \\
\text { das organizações. }\end{array}$ & \\
\hline Modelo de referência oferece uma redução no custo do projeto. & \\
\hline Modelo de referência oferece disseminação de boas práticas. & \\
\hline $\begin{array}{l}\text { Modelo de referência possibilita a construção de soluções organizadas e integradas, } \\
\text { capazes de serem entendidas e internalizadas. }\end{array}$ & \\
\hline
\end{tabular}


APÊNDICE 4- LISTA DAS DISFUNÇÕES

\begin{tabular}{|c|c|c|c|c|c|c|}
\hline ID & Disfunções & 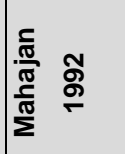 & 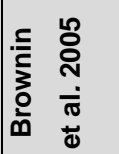 & 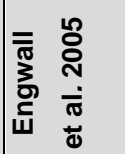 & 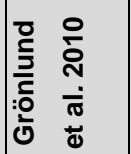 & 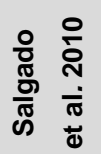 \\
\hline D1 & $\begin{array}{l}\text { Falta de comprometimento da alta direção (Ex: } \\
\text { Stakeholders). }\end{array}$ & $\checkmark$ & $\checkmark$ & & & \\
\hline D2 & $\begin{array}{l}\text { Modelo de referência interpretado de maneiras diferentes } \\
\text { pelos funcionários. }\end{array}$ & & $\checkmark$ & & & \\
\hline D3 & $\begin{array}{l}\text { Os funcionários trabalham em um constante estado de } \\
\text { dissonância com a prática. }\end{array}$ & & $\checkmark$ & & & \\
\hline D4 & Falta de recursos para implantação do modelo de referência. & & $\checkmark$ & & & $\checkmark$ \\
\hline D5 & Implantação demorada do modelo de referência. & $\checkmark$ & & & $\checkmark$ & $\checkmark$ \\
\hline D6 & Modelo de referência é considerado dispendioso. & $\checkmark$ & & & & \\
\hline D7 & Imprecisão do modelo de referência. & $\checkmark$ & & & & \\
\hline D8 & Cultura organizacional não apoia os modelos de referência. & $\checkmark$ & $\checkmark$ & & & \\
\hline D9 & Modelo de referência considerado abstrato e ambíguo. & & $\checkmark$ & & & \\
\hline D10 & $\begin{array}{l}\text { Modelo de referência não ajudam os funcionários na } \\
\text { autogestão. }\end{array}$ & & $\checkmark$ & & & \\
\hline D11 & $\begin{array}{l}\text { Modelo de referência não define exatamente quais } \\
\text { informações devem fluir ou em que estado devem estar. }\end{array}$ & & $\checkmark$ & & & $\checkmark$ \\
\hline D12 & $\begin{array}{l}\text { As informações do modelo de referência que são } \\
\text { documentadas não são próximas do usuário. }\end{array}$ & & $\checkmark$ & & & \\
\hline D13 & $\begin{array}{l}\text { Funcionários não entendem os benefícios do modelo de } \\
\text { referência. }\end{array}$ & $\checkmark$ & $\checkmark$ & & & $\checkmark$ \\
\hline D14 & $\begin{array}{l}\text { Há uma relutância em compartilhar conhecimento e } \\
\text { colaborar. }\end{array}$ & $\checkmark$ & $\checkmark$ & & & \\
\hline D15 & $\begin{array}{l}\text { Modelo de referência é considerado uma restrição à } \\
\text { oportunidade de aprendizado. }\end{array}$ & & & & $\checkmark$ & \\
\hline D16 & Modelo de referência considerado burocrático. & & $\checkmark$ & $\checkmark$ & $\checkmark$ & \\
\hline D17 & Modelo de referência não oferece autonomia aos gestores. & & & $\checkmark$ & & \\
\hline D18 & $\begin{array}{l}\text { Não há documentos formais que descrevem o modelo de } \\
\text { referência. }\end{array}$ & & & $\checkmark$ & & \\
\hline D19 & $\begin{array}{l}\text { Não há distinção entre modelo de referência e diretrizes } \\
\text { administrativas da empresa. }\end{array}$ & & & $\checkmark$ & & \\
\hline D20 & $\begin{array}{l}\text { Modelo de referência não atende aos desafios específicos da } \\
\text { realidade. }\end{array}$ & & & $\checkmark$ & & \\
\hline
\end{tabular}




\begin{tabular}{|c|c|c|c|c|c|c|}
\hline ID & Disfunções & 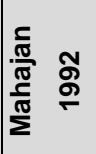 & 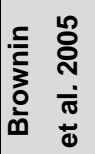 & 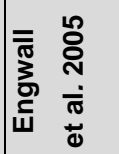 & 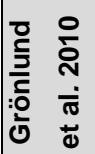 & 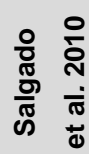 \\
\hline D21 & $\begin{array}{l}\text { Modelo de referência limitado na questão de apoiar à gestão } \\
\text { dos aspectos humanos. }\end{array}$ & & & $\checkmark$ & & \\
\hline D22 & $\begin{array}{l}\text { Modelo de referência visto como carga administrativa ao } \\
\text { invés de suporte. }\end{array}$ & & & $\checkmark$ & & \\
\hline D23 & $\begin{array}{l}\text { Modelo de referência está distante da realidade do } \\
\text { desenvolvimento de produtos. }\end{array}$ & & & $\checkmark$ & & \\
\hline D24 & $\begin{array}{l}\text { Modelos de referência não são importantes no sentido de } \\
\text { guiar as ações. }\end{array}$ & & & $\checkmark$ & & \\
\hline D25 & $\begin{array}{l}\text { O modelo de referência oferece uma grande liberdade de } \\
\text { interpretação. }\end{array}$ & & & $\checkmark$ & & \\
\hline
\end{tabular}




\section{APÊNDICE 5 - LISTA DOS BENEFÍCIOS}

\begin{tabular}{|c|c|c|c|c|}
\hline ID & Benefícios & 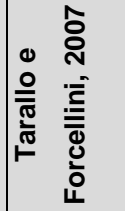 & 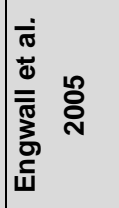 & 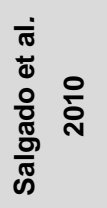 \\
\hline B1 & $\begin{array}{l}\text { Modelo de referência oferece uma linguagem comum } \\
\text { a todos os envolvidos no processo de } \\
\text { desenvolvimento de produto (PDP). }\end{array}$ & $\checkmark$ & $\checkmark$ & $\checkmark$ \\
\hline B2 & $\begin{array}{l}\text { Modelo de referência oferece uma maneira } \\
\text { padronizada de medir o progresso do projeto. }\end{array}$ & & $\checkmark$ & \\
\hline B3 & $\begin{array}{l}\text { Modelo de referência assegura que todos trabalham } \\
\text { da mesma maneira. }\end{array}$ & & $\checkmark$ & \\
\hline B4 & $\begin{array}{l}\text { Modelos de referência foram vistos como apoio à } \\
\text { cooperação e comunicação eficazes entre os projetos. }\end{array}$ & & $\checkmark$ & \\
\hline B5 & $\begin{array}{l}\text { Modelo de referência permitiu maior comunicação } \\
\text { dentro da equipe do projeto bem como as partes } \\
\text { interessadas externas e outros projetos. }\end{array}$ & $\checkmark$ & & $\checkmark$ \\
\hline B6 & $\begin{array}{l}\text { Modelo de referência oferece agilidade na tomada de } \\
\text { decisão. }\end{array}$ & $\checkmark$ & & \\
\hline B7 & $\begin{array}{l}\text { Modelo de referência oferece maior agilidade no } \\
\text { diagnóstico de projetos. }\end{array}$ & $\checkmark$ & & \\
\hline B8 & $\begin{array}{l}\text { Modelo de referência reforça a cultura do projeto } \\
\text { como empreendimento de toda a empresa e não } \\
\text { somente da área funcional da engenharia de produto. }\end{array}$ & $\checkmark$ & & \\
\hline B9 & $\begin{array}{l}\text { Modelo de referência oferece uma redução de tempo } \\
\text { do projeto. }\end{array}$ & & & $\checkmark$ \\
\hline B10 & $\begin{array}{l}\text { Modelo de referência oferece resultados finais mais } \\
\text { eficazes na melhoria da gestão das organizações. }\end{array}$ & & $\checkmark$ & \\
\hline B11 & $\begin{array}{l}\text { Modelo de referência oferece uma redução no custo } \\
\text { do projeto. }\end{array}$ & & & $\checkmark$ \\
\hline B12 & $\begin{array}{l}\text { Modelo de referência oferece disseminação de boas } \\
\text { práticas. }\end{array}$ & $\checkmark$ & & $\checkmark$ \\
\hline B13 & $\begin{array}{l}\text { Modelo de referência possibilita a construção de } \\
\text { soluções organizadas e integradas, capazes de serem } \\
\text { entendidas e internalizadas. }\end{array}$ & & $\checkmark$ & \\
\hline
\end{tabular}




\section{APÊNDICE 6 - AVALIAÇÃO DOS ENTREVISTADOS REFERENTE AS DISFUNÇÕES}

\begin{tabular}{|c|c|c|c|c|c|c|c|c|c|}
\hline \multirow{2}{*}{ ID } & \multirow{2}{*}{ Disfunções } & \multicolumn{4}{|c|}{ Empresa A } & \multicolumn{4}{|c|}{ Empresa B } \\
\hline & & E1 & E2 & E3 & E4 & E1 & E2 & E3 & E4 \\
\hline D1 & $\begin{array}{l}\text { Falta de comprometimento da alta } \\
\text { direção (Ex: Stakeholders). }\end{array}$ & 1 & 1 & 1 & 2 & 1 & 1 & 1 & 1 \\
\hline D2 & $\begin{array}{l}\text { Modelo de referência interpretado de } \\
\text { maneiras diferentes pelos funcionários. }\end{array}$ & 3 & 1 & 3 & 2 & 3 & 1 & 1 & 3 \\
\hline D3 & $\begin{array}{l}\text { Os funcionários trabalham em um } \\
\text { constante estado de dissonância com a } \\
\text { prática. }\end{array}$ & 1 & 3 & 3 & 2 & 2 & 2 & 1 & 3 \\
\hline D4 & $\begin{array}{l}\text { Falta de recursos para implantação do } \\
\text { modelo de referência. }\end{array}$ & 1 & 3 & 1 & 2 & 1 & 1 & 1 & 2 \\
\hline D5 & $\begin{array}{l}\text { Implantação demorada do modelo de } \\
\text { referência. }\end{array}$ & 4 & 3 & 1 & 2 & 1 & 1 & 3 & 1 \\
\hline D6 & $\begin{array}{l}\text { Modelo de referência é considerado } \\
\text { dispendioso. }\end{array}$ & 3 & 2 & 1 & 2 & 1 & 1 & 1 & 1 \\
\hline D7 & Imprecisão do modelo de referência. & 1 & 1 & 1 & 2 & 2 & 1 & 3 & 1 \\
\hline D8 & $\begin{array}{l}\text { Cultura organizacional não apoia os } \\
\text { modelos de referência. }\end{array}$ & 1 & 1 & 1 & 1 & 1 & 2 & 2 & 4 \\
\hline D9 & $\begin{array}{l}\text { Modelo de referência considerado } \\
\text { abstrato e ambíguo. }\end{array}$ & 1 & 1 & 1 & 2 & 1 & 2 & 3 & 3 \\
\hline D10 & $\begin{array}{l}\text { Modelo de referência não ajudam os } \\
\text { funcionários na autogestão. }\end{array}$ & 1 & 2 & 2 & 2 & 1 & 2 & 3 & 1 \\
\hline D11 & $\begin{array}{l}\text { Modelo de referência não define } \\
\text { exatamente quais informações devem } \\
\text { fluir ou em que estado devem estar. }\end{array}$ & 1 & 1 & 2 & 1 & 1 & 1 & 3 & 1 \\
\hline D12 & $\begin{array}{l}\text { As informações do modelo de referência } \\
\text { que são documentadas não são } \\
\text { próximas do usuário. }\end{array}$ & 2 & 1 & 2 & 1 & 2 & 1 & 3 & 2 \\
\hline D13 & $\begin{array}{l}\text { Funcionários não entendem os } \\
\text { benefícios do modelo de referência. }\end{array}$ & 2 & 3 & 2 & 2 & 4 & 2 & 1 & 3 \\
\hline D14 & $\begin{array}{l}\text { Há uma relutância em compartilhar } \\
\text { conhecimento e colaborar. }\end{array}$ & 1 & 2 & 1 & 2 & 4 & 2 & 1 & 3 \\
\hline D15 & $\begin{array}{l}\text { Modelo de referência é considerado uma } \\
\text { restrição à oportunidade de aprendizado. }\end{array}$ & 1 & 1 & 1 & 2 & 1 & 1 & 1 & 1 \\
\hline
\end{tabular}




\begin{tabular}{|c|c|c|c|c|c|c|c|c|c|}
\hline \multirow{2}{*}{ ID } & \multirow{2}{*}{ Disfunções } & \multicolumn{4}{|c|}{ Empresa A } & \multicolumn{4}{|c|}{ Empresa B } \\
\hline & & E1 & E2 & E3 & E4 & E1 & E2 & E3 & E4 \\
\hline D16 & $\begin{array}{l}\text { Modelo de referência considerado } \\
\text { burocrático. }\end{array}$ & 3 & 4 & 2 & 4 & 3 & 3 & 4 & 3 \\
\hline D17 & $\begin{array}{l}\text { Modelo de referência não oferece } \\
\text { autonomia aos gestores. }\end{array}$ & 1 & 2 & 1 & 3 & 1 & 1 & 4 & 2 \\
\hline D18 & $\begin{array}{l}\text { Não há documentos formais que } \\
\text { descrevem o modelo de referência. }\end{array}$ & 4 & 1 & 1 & 1 & 1 & 1 & 0 & 1 \\
\hline D19 & $\begin{array}{l}\text { Não há distinção entre modelo de } \\
\text { referência e diretrizes administrativas da } \\
\text { empresa. }\end{array}$ & 4 & 1 & 1 & 1 & 1 & 2 & 2 & 1 \\
\hline D20 & $\begin{array}{l}\text { Modelo de referência não atende aos } \\
\text { desafios específicos da realidade. }\end{array}$ & 4 & 3 & 1 & 3 & 1 & 1 & 1 & 1 \\
\hline D21 & $\begin{array}{l}\text { Modelo de referência limitado na } \\
\text { questão de apoiar à gestão dos aspectos } \\
\text { humanos. }\end{array}$ & 4 & 3 & 1 & 2 & 4 & 2 & 1 & 1 \\
\hline D22 & $\begin{array}{l}\text { Modelo de referência visto como carga } \\
\text { administrativa ao invés de suporte. }\end{array}$ & 1 & 1 & 2 & 2 & 2 & 1 & 3 & 1 \\
\hline D23 & $\begin{array}{l}\text { Modelo de referência está distante da } \\
\text { realidade do desenvolvimento de } \\
\text { produtos. }\end{array}$ & 1 & 3 & 1 & 2 & 1 & 1 & 1 & 1 \\
\hline D24 & $\begin{array}{l}\text { Modelos de referência não são } \\
\text { importantes no sentido de guiar as } \\
\text { ações. }\end{array}$ & 1 & 1 & 2 & 1 & 1 & 1 & 1 & 1 \\
\hline D25 & $\begin{array}{l}\text { O modelo de referência oferece uma } \\
\text { grande liberdade de interpretação. }\end{array}$ & 2 & 2 & 3 & 2 & 2 & 2 & 1 & 2 \\
\hline
\end{tabular}




\section{APÊNDICE 7 - AVALIAÇÃO DOS ENTREVISTADOS REFERENTE AOS BENEFÍCIOS}

\begin{tabular}{|c|c|c|c|c|c|c|c|c|c|}
\hline \multirow{2}{*}{ ID } & \multirow{2}{*}{ Benefícios } & \multicolumn{4}{|c|}{ Empresa A } & \multicolumn{4}{|c|}{ Empresa B } \\
\hline & & E1 & E2 & E3 & E4 & E1 & E2 & E3 & E4 \\
\hline B1 & $\begin{array}{l}\text { Modelo de referência oferece uma } \\
\text { linguagem comum a todos os envolvidos } \\
\text { no processo de desenvolvimento de } \\
\text { produto (PDP). }\end{array}$ & 3 & 3 & 3 & 3 & 4 & 4 & 4 & 4 \\
\hline B2 & $\begin{array}{l}\text { Modelo de referência oferece uma } \\
\text { maneira padronizada de medir o } \\
\text { progresso do projeto. }\end{array}$ & 4 & 3 & 4 & 4 & 4 & 4 & 4 & 4 \\
\hline B3 & $\begin{array}{l}\text { Modelo de referência assegura que } \\
\text { todos trabalham da mesma maneira. }\end{array}$ & 3 & 3 & 3 & 3 & 3 & 3 & 3 & 4 \\
\hline B4 & $\begin{array}{l}\text { Modelos de referência foram vistos como } \\
\text { apoio à cooperação e comunicação } \\
\text { eficazes entre os projetos. }\end{array}$ & 3 & 3 & 3 & 4 & 4 & 4 & 4 & 4 \\
\hline B5 & $\begin{array}{l}\text { Modelo de referência permitiu maior } \\
\text { comunicação dentro da equipe do } \\
\text { projeto bem como as partes interessadas } \\
\text { externas e outros projetos. }\end{array}$ & 3 & 4 & 3 & 4 & 4 & 3 & 4 & 4 \\
\hline B6 & $\begin{array}{l}\text { Modelo de referência oferece agilidade } \\
\text { na tomada de decisão. }\end{array}$ & 3 & 2 & 3 & 4 & 4 & 4 & 3 & 4 \\
\hline B7 & $\begin{array}{l}\text { Modelo de referência oferece maior } \\
\text { agilidade no diagnóstico de projetos. }\end{array}$ & 3 & 2 & 3 & 4 & 4 & 4 & 3 & 4 \\
\hline B8 & $\begin{array}{l}\text { Modelo de referência reforça a cultura do } \\
\text { projeto como empreendimento de toda a } \\
\text { empresa e não somente da área } \\
\text { funcional da engenharia de produto. }\end{array}$ & 4 & 4 & 4 & 1 & 4 & 4 & 4 & 4 \\
\hline B9 & $\begin{array}{l}\text { Modelo de referência oferece uma } \\
\text { redução de tempo do projeto. }\end{array}$ & 0 & 2 & 2 & 4 & 4 & 4 & 4 & 4 \\
\hline B10 & $\begin{array}{l}\text { Modelo de referência oferece resultados } \\
\text { finais mais eficazes na melhoria da } \\
\text { gestão das organizações. }\end{array}$ & 4 & 3 & 3 & 1 & 4 & 4 & 4 & 4 \\
\hline B11 & $\begin{array}{l}\text { Modelo de referência oferece uma } \\
\text { redução no custo do projeto. }\end{array}$ & 1 & 3 & 0 & 4 & 3 & 3 & 4 & 4 \\
\hline B12 & $\begin{array}{l}\text { Modelo de referência oferece } \\
\text { disseminação de boas práticas. }\end{array}$ & 4 & 4 & 3 & 4 & 4 & 4 & 4 & 4 \\
\hline B13 & Modelo de referência possibilita a & 4 & 3 & 4 & 2 & 3 & 3 & 4 & 4 \\
\hline
\end{tabular}




\begin{tabular}{|l|l|c|c|c|c|c|c|c|c|}
\hline \multirow{2}{*}{ ID } & \multicolumn{2}{|c|}{ Benefícios } & \multicolumn{3}{c|}{ Empresa A } & \multicolumn{3}{c|}{ Empresa B } \\
\cline { 3 - 9 } & & E1 & E2 & E3 & E4 & E1 & E2 & E3 & E4 \\
\hline \multirow{2}{*}{$\begin{array}{l}\text { construção de soluções organizadas e } \\
\text { integradas, capazes de serem } \\
\text { entendidas e internalizadas. }\end{array}$} & & & & & & & & & \\
\hline
\end{tabular}

